\title{
OTIMIZAÇÃO ECONÔMICA DE SEQUÊNCIAS DE COLUNAS DE DESTILAÇÃO CONVENCIONAIS E COLUNA COM PAREDE DIVIDIDA PARA A MISTURA BENZENO, TOLUENO E P-XILENO
}

Dissertação apresentada à Escola Politécnica da Universidade de São Paulo para obtenção do Título de Mestre em Ciências

Área de Concentração:

Engenharia Química

Orientador: Prof. Dr.

Galo Antonio Carrillo LeRoux

São Paulo 
RICARDO ANDRÉS TUSSO PINZÓN

OTIMIZAÇÃO ECONÔMICA DE SEQUÊNCIAS DE COLUNAS DE DESTILAÇÃO CONVENCIONAIS E COLUNA COM PAREDE DIVIDIDA PARA A MISTURA BENZENO, TOLUENO E P-XILENO

Dissertação apresentada à Escola

Politécnica da Universidade de São Paulo para obtenção do Título de Mestre em Ciências

São Paulo

2014 
Este exemplar foi revisado e alterado em relação à versão original sob responsabilidade única do autor e com anuência de seu orientador

São Paulo, 25 de março de 2014

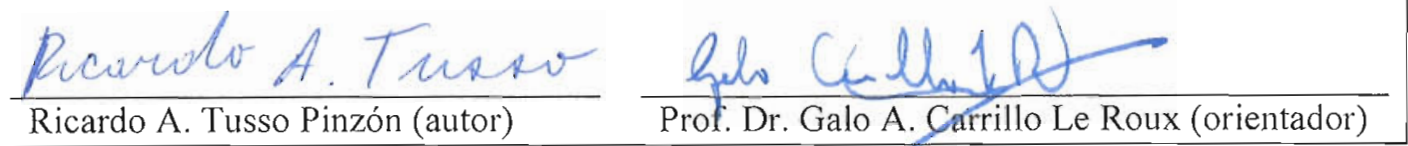

FICHA CATALOGRÁFICA- EDIÇÃO REVISADA

Tusso Pinzón, Ricardo Andrés

Otimização econômica de sequências de colunas de destilação convencionais e coluna com parede dividida para a mistura benzeno, tolueno e p-xileno / R.A. Tusso Pinzón. -- São Paulo, 2014.

$121 \mathrm{p}$.

Dissertação (Mestrado) - Escola Politécnica da Universidade de São Paulo. Departamento de Engenharia Química.

1.Colunas de destilação 2.Matrizes esparsas 3.Sequência direta 4.Sequência indireta 5.Método de ponto de bolha 6.Custo total anualizado I.Universidade de São Paulo. Escola Politécnica. Departamento de Engenharia Química Il.t. 


\section{DEDICATORIA}

A mi estrella que nunca desfalleció y siempre mantuvo la fé em lós momentos dificiles. Eres todo para mi 


\section{AGRADECIMENTO}

Agradeço ao Prof. Dr. Galo Antonio Carrillo Le Roux, pela oportunidade de orientar, apoiar o desenvolvimento do trabalho, pelos seus conhecimentos transmitidos. Ao Dr. Diego Mendoza, pela valiosa colaboração e continua ajuda através das sugestões e acompanhamento.

Ao Conselho Nacional de Desenvolvimento Científico e tecnológico (CNPq) pela ajuda financeira para a realização deste trabalho.

Aos colegas do LSCP, pela amizade, apoio, e bons desejos, Aldo; Bruno; Lina; Mayra; David; Alvaro; José Eduardo, José Otávio, Misagh; Marcio. Também ao Prof. Dr. Carlos Arturo Martinez, com os comentários e apoio.

Aos bons amigos no Brasil que me acolheram e compartilharam boas lembranças e bons momentos, Alex; Ruben; Lina; Erica; Arlet; Luis; Lenin; Carolina.

A minha família na Colômbia que me apoiu neste desafio e em especial à Diana, minha irmã, que me acompanhou nos momentos mais difíceis e foi uma grande inspiração para ser uma melhor pessoa cada dia. 
A única maneira de fazer um bom trabalho é amando o que você faz. Se você ainda não encontrou, continue procurando. Não se desespere. Assim como no amor, você saberá quando tiver encontrado.

Steve Jobs 


\section{RESUMO}

A destilação é um processo de separação com uma alta demanda de energia, razão pela qual, através de diferentes épocas tem sido estudadas diferentes configurações. O problema da separação de misturas multicomponente pode envolver sequências de colunas de destilação convencionais. Neste caso, surge um problema combinatório a fim de projetar a sequência mais econômica de separação. Por outro lado, em anos recentes têm sido proposto o uso de equipamentos alternativos, sendo as colunas com paredes divididas uma opção bastante estudada que se caracterizam pela integração de 2 seções de colunas compartilhando um único condensador e um único refervedor. Estes equipamentos propõem diminuir o custo total de processo de separação de misturas multicomponentes. Neste trabalho apresenta-se um estudo econômico da separação de três misturas ternárias de Benzeno, Tolueno, P-xileno, comparando os projetos ótimos de sequências convencionais e de colunas de paredes divididas. Inicialmente, são definidas as variáveis de projeto para cada configuração por meio de uma análise de graus de liberdade. $\mathrm{O}$ dimensionamento é realizado inicialmente com o método não rigoroso de valor de fronteira. Finalmente, as sequências diretas e indiretas e as colunas de parede divididas são projetadas usando modelos rigorosos, baseados no método de ponto de bolha, programação matemática para resolver os problemas de otimização do Custo Total Anualizado TAC com variáveis contínuas e enumeração exaustiva para tratar o problema combinatório. São obtidos projetos ótimos para uma alimentação com três composições diferentes. A sequência indireta forneceu o melhor resultado para a alimentação rica no componente mais pesado $(-58,35 \%)$ e no componente intermediário $(-45,98 \%)$. Já a sequência direta foi a melhor quando a alimentação é rica em componente leve (-33,36\%). A coluna com parede dividida teve o pior desempenho em todos os três casos estudados.

Palavras-chave: Coluna com parede dividida. Custo total anualizado. Sequência direta. Sequência indireta. 


\begin{abstract}
Distillation is a high-energy demand separation process, for that reason, alternative configurations have been studied through the ages. The separation problem of multicomponent mixtures may involve a sequence of conventional distillation columns. In this case, a combinatorial problem arises in order to design the most economical separation sequence. On the other hand, in recent years the use of alternative devices has been proposed. One of those options is the divided wall column, which is extensively studied, and is characterized by the integration of two column sections sharing a single condenser and a single reboiler. This equipment is sought to decrease the total cost of the separation process for multicomponent mixtures. This work presents an economic study for the separation of three ternary mixtures of benzene, toluene and p-xylene, comparing the optimum design of conventional sequences and divided wall columns. Initially, the design variables are defined for each configuration through a degrees of freedom analysis,. The sizing is initially performed with the boundary value shortcut method. Then, the direct and indirect sequences, and divided wall columns are designed using rigorous models based on the bubble point method. Mathematical programming is used for solving the optimization problems of minimization of the total annualized cost (TAC) with continuous variables and exhaustive enumeration to handle the combinatorial issue. Optimal designs for three feeds with different compositions are obtained. The indirect sequence provided the best result for the feed rich in the heaviest component $(-58.35$ $\%)$ and in the intermediate component (-45.98\%). The direct sequence result was the best when the feed composition is rich in lighter component $(-33.36 \%)$. The divided wall column had the worst performance in all three cases studied.
\end{abstract}

Keywords: Divided wall column distillation. Total annualized cost. Indirect sequence. Direct sequence. 


\section{LISTA ILUSTRAÇÕES}

Figura 3.1- Sequências de separação para 3 componentes na alimentação. .......... 26

Figura 3.2- Configurações de colunas complexas para destilação ternária

Figura 4.1- Secções de coluna de destilação apresentada como uma configuração de estágios no equilíbrio.

Figura 4.2- Configuração para cálculo de ponto de bolha, usando multiplas entradas e saídas

Figura 4.3- Condensador total, método ponto de bolha 40

Figura 4.4- Balanço estágios internos da coluna 40

Figura 4.5- Balanço no refervedor 41

Figura 4.6- Algoritmo para o método ponto de bolha

Figura 4.7- Estrutura de uma coluna termicamente acoplada.

Figura 4.8- Estágio interno sem conexões de fluxos laterais 45

Figura 4.9- Conexão superior da coluna principal..... 45

Figura 4.10- Conexão inferior da coluna principal..... 45

Figura 4.11- Conexão superior da fracionadora 45

Figura 4.12- Conexão inferior da fracionadora 45

Figura 4.13- Matriz esparsa para uma configuração de colunas termicamente acopladas

Figura 4-14 Geração de uma combinatoria entre as variaveis inteiras de uma sequência convencional 51

Figura 4.15- Configuração de 3 colunas convencionais. Método de Amminudim..... 53

Figura 4.16- Configuração coluna Petlyuk, método Cerda-Westerberg 54

Figura 5.1- Análise de graus de liberdade em uma sequência convencional 58

Figura 5.2- Análise dos graus de liberdade em uma coluna termicamente acoplada60

Figura 5.3- Aplicação das variáveis especificadas para os métodos de destilação usados 
Figura 5.4- Factibilidade de separação

Figura 5.5- Refluxo mínimo método valor de fronteira

Figura 5.6- Cargas de calor no condensador em uma sequência de separação convencional indireta

Figura 5.7- Custo total anualizado em uma sequência de separação convencional indireta avaliada a diferentes razões de refluxo.

Figura 5.8- Custo total anualizado em uma sequência de separação convencional indireta com diferentes números de estágios

Figura 5.9- Perfis de concentações da fase de vapor para mistura ternária Benzeno, Tolueno, $P$-xileno.

Figura 5.10- Vazões internas de vapor na coluna. 68

Figura 5.11- Vazões internas de liquido na coluna 68

Figura 5.12- Perfis de composição da fase de vapor para uma sequncia indireta resolvida simultaneamente validadas no ASPEN PLUS $®$. 69

Figura 5.13 Comportamnetos dos perfis dentro de uma coluna termicamente acoplada validad no ASPEN Hysys.

Figura 5.14- Resultados da otimização efetuada com valores de razão de refluxo y vazão de destilado diferentes à valor de fronteira.

Figura 5.15- Representação do custo total anualizada em função das cargas de calor 76

Figura 5.16- Resultados do TAC com variação do número de estágios sequência indireta com abundância em P-xileno (80\%) na alimentação . 78

Figura 5.17- Perfis de concentração da fase liquida a diferentes pontos iniciais de otimização 


\section{LISTA DE TABELAS}

Tabela 3.1- Número de possíveis sequências de separação por destilação

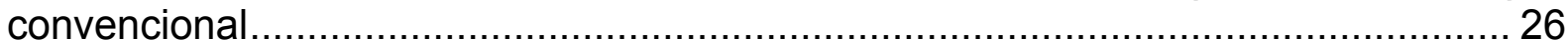

Tabela 4.1- Valores dos elementos fora da diagonal ......................................... 47

Tabela 5.1- Características das condições da alimentação ..................................... 57

Tabela 5.2- Variáveis obtidas para coluna com uma alimentação ............................58

Tabela 5.3- Graus de liberdade obtidas para sequência convencional com uma

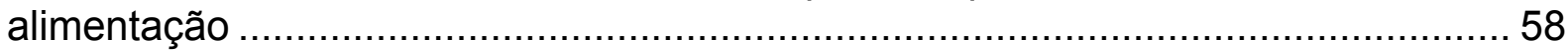

Tabela 5.4- Especificações das variáveis para uma sequência convencional.......... 59

Tabela 5.5- Especificação de variaveis em sequências convencionais usando

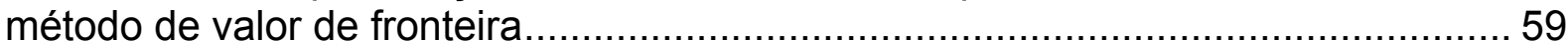

Tabela 5.6- Especificação de variaveis em sequências convencionais usando

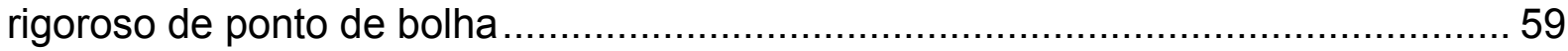

Tabela 5.7- Graus de liberdade para a coluna principal..........................................6 60

Tabela 5.8- Graus de liberdade para a coluna fracionadora ....................................60

Tabela 5.9- Graus de liberdade para uma sequência termicamente acoplada......... 61

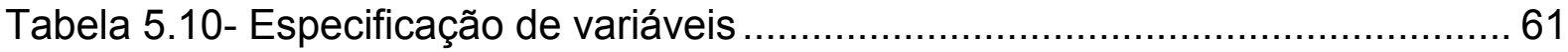

Tabela 5.11- Especificação de variáveis de projeto para uma coluna termicamente

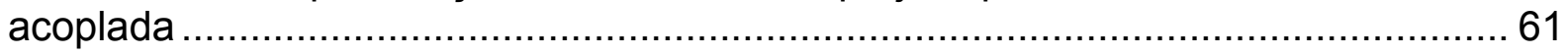

Tabela 5.12- Resultados preliminares para sequência direta na análise de

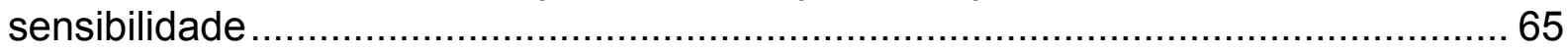

Tabela 5.13- Resultados preliminares para sequência indireta na análise de

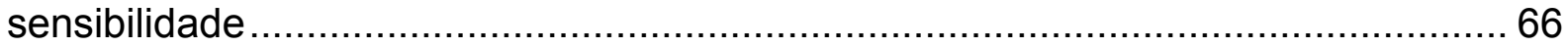

Tabela 5.14- Tempo computacional para uma solução sequencial e simultanea para

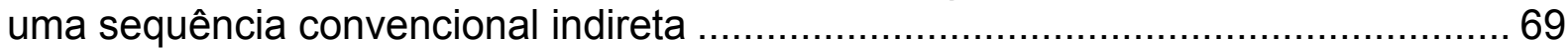

Tabela 5.15- Informação para validação de uma coluna termicamente acoplada ....70

Tabela 5.16 Resultados das cargas de calor para uma configuração termicamente acoplada 
Tabela 5.17- Resultados das otimizações usando a função objetivo com penalidade, e sem penalidade

Tabela 5.18- Comparação dos valores ótimos com os valores obtidos com o método de valor de fronteira para a sequência indireta

Tabela 5.19- Comparação dos valores ótimos com os valores obtidos com o método de valor de fronteira para a sequência direta.....

Tabela 5.20- Cargas de calor geradas para os resultados das diferentes sequências.

Tabela 5.21- Parâmetros de projeto para sequência indireta com custo mínimo ..... 78

Tabela 5.22- Resultados otimização combintaroria DWC

Tabela 5.23- Custo total anualizado para os estágios estabelecidos iniciais para uma alimentação com frações molares de 0,1 mol de Benzeno 0,1 mol de Tolueno e 0,8 mol de P-Xileno

Tabela 5.24- Cargas de calor para diferentes condições de alimentação em uma configuração termicamente acoplada.

Tabela 5.25- Custos de capital e de operação para diferentes condições de alimentação em uma configuração termicamente acoplada .....

Tabela 5.26- Comparação econômica dos resultados obtidos nas configurações convencionais e termicamente acoplada para uma alimentação 0,1 mol benzeno/0,1 mol Tolueno /0,8 mol p-xileno

Tabela 5.27- Comparação econômica dos resultados obtidos nas configurações convencionais e termicamente acoplada para uma alimentação 0,8 mol benzeno/0,1 mol Tolueno /0,1 mol p-xileno

Tabela 5.28- Comparação econômica dos resultados obtidos nas configurações convencionais e termicamente acoplada para uma alimentação 0,1 mol benzeno/0,8 mol Tolueno /0,1 mol p-xileno

Tabela A.1- Materiais de construção de colunas de destilacao ………………….... 93

Tabela A.2- Parâmetro das dimensões dos estágios ............................................... 93

Tabela A.3- Parâmetro das características dos estágios ........................................ 94

Tabela A.4- Material de trocador de carcaça e tubo ................................................ 94 


\section{LISTA DE ABREVIATURAS E SIGLAS}

M\&S Marshall and swift index (Índice de custos Marshall \& Swift)

NHE Number of heat exchanger (Número de trocadores de calor)

TAC Total annual cost (Custo total anualizado)

PCS Poder calorífico superior do combustível de aquecimento do vapor

DWC Coluna parede dividida 


\section{LISTA DE SÍMBOLOS}

$A_{j} \quad$ Coeficiente matriz tridiagoanal, método de ponto de bolha.

$A_{C} \quad$ Área da coluna $\left(m^{2}\right)$

$A_{H, c} \quad$ Área do condensador. $\left(\mathrm{m}^{2}\right)$

$A_{H, r} \quad$ Área do refervedor. $\left(\mathrm{m}^{2}\right)$

$B_{j} \quad$ Coeficiente no balanço de matéria modificado

$B \quad$ Vazão de saída de fundo. $\left(\mathrm{kmol} \mathrm{h}^{-1}\right)$

C Número de componentes da mistura.

$C_{\text {Cap }} \quad$ Custo de capital. (USD\$)

$C_{\text {Comb }} \quad$ Custo do combustível (USD\$)

$C_{f} \quad$ Correlação de Fair

$C_{j} \quad$ Coeficiente matriz tridiagoanal, método de ponto de bolha.

$C_{S} \quad$ Custos da carcaça cilíndrica. (USD\$)

$C_{\text {vap }} \quad$ Custo do vapor

$D_{j} \quad$ Coeficiente matriz tridiagoanal, método de ponto de bolha.

$d \quad$ Diâmetro da coluna. $(m)$

D Vazão de saída de destilado. $\left(\mathrm{kmol} \mathrm{h}^{-1}\right)$

$E_{j}^{0} \quad$ Eficiência dos estágios j. (\%)

$F l \quad$ Coeficiente de inundação

$F_{j} \quad$ Vazão de alimentação no estágio j. $\left(\mathrm{kmol} \mathrm{h}^{-1}\right)$

$F_{S} \quad$ Parâmetro de correlação ao espaço entre os estágios, determinação de custos

$F_{m} \quad$ Parâmetro de correlação para o material, trocadores de calor de carcaça e tubo

$g(X)^{2} \quad$ Termo de penalidade da função objetivo

$H \quad$ Altura da coluna $(m)$

$h_{j}^{L} \quad$ Entalpia do liquido do componente i no estágio j. $\quad\left(\mathrm{kJ} \mathrm{kmol}^{-1}\right)$

$h_{j}^{V} \quad$ Entalpia do vapor do componente i no estágio j. $\left(\mathrm{kJ} \mathrm{kmol}^{-1}\right)$

$K_{i, j} \quad$ Constante de equilíbrio líquido-vapor do componente i no estágio j

$L_{j} \quad$ Vazão de liquido no estágio j. $\quad\left(\mathrm{kmol} \mathrm{h}^{-1}\right)$

$M_{V} \quad$ Peso molecular da mistura na fase de vapor

$N \quad$ Número de estágios reais na coluna.

$N^{T} \quad$ Número de estágios teóricos na coluna.

$P_{i}^{\text {sat }} \quad$ Pressão de saturação do componente i. (bar) 


\begin{tabular}{|c|c|}
\hline$\dot{Q}_{B}$ & Calor adicionado pelo refervedor. $\left(k J h^{-1}\right)$ \\
\hline$\dot{Q}_{C}$ & Calor removido pelo condensador. $\left(k J h^{-1}\right)$ \\
\hline$r$ & Razão de refluxo do condensador. \\
\hline$S$ & Razão de refluxo do refervedor. \\
\hline$T_{D}$ & Temperatura do destilado $(K)$ \\
\hline$T_{i n}^{c w}$ & Temperatura de entrada do liquido de esfriamento no condensador $(K)$ \\
\hline$T_{j}$ & Temperatura no estágio j. $(K)$ \\
\hline$T_{\text {out }}^{c w}$ & Temperatura de saída do liquido de esfriamento no condensador $(K)$ \\
\hline$T_{s t m}$ & Temperatura de entrada do vapor com refervedor. $(K)$ \\
\hline$U_{\text {cond }}$ & Coeficiente de troca de calor no condensador. $\left(W m^{-2} K^{-1}\right)$ \\
\hline$U_{j}$ & Vazão de saída lateral de líquido no estágio j $\left(\mathrm{kmol} \mathrm{h}^{-1}\right)$ \\
\hline$U_{\text {ref }}$ & Coeficiente de troca de calor no refervedor. $\left(W m^{-2} K^{-1}\right)$ \\
\hline$V_{j}$ & Vazão da fase de vapor no estágio j. $\left(\mathrm{kmol} \mathrm{h}^{-1}\right)$ \\
\hline$W_{j}$ & Vazão de saída de vapor no estágio j $\left(k m o l ~ h^{-1}\right)$ \\
\hline$W_{r}$ & Fluxo de fluido de aquecimento refervedor. $\left(\mathrm{kg} \mathrm{h}^{-1}\right)$ \\
\hline$x_{i, B}$ & Fração molar de liquido do componente i do fundo. \\
\hline$x_{i, D}$ & Fração molar de liquido do componente i do destilado da coluna j. \\
\hline$x_{i, j}$ & Fração molar de liquido do componente i no estágio j. \\
\hline$y_{i, j}$ & Fração molar de vapor do componente i no estágio j. \\
\hline$z_{i}^{F}$ & Fração molar de liquido do componente i na alimentação. \\
\hline
\end{tabular}

\section{SÍMBOLOS GREGOS}

$\alpha_{i j} \quad$ Volatilidade relativa entre os componentes ij da mistura

$\tau \quad$ Convergência método ponto de bolha (\%)

$\rho_{v} \quad$ Densidade da fase de vapor da mistura $\left(\mathrm{kg} \mathrm{m}^{-3}\right)$

$\rho_{l} \quad$ Densidade da fase liquida da mistura $\left(\mathrm{kg} \mathrm{m}^{-3}\right)$

$\Delta H_{s t m} \quad$ Entalpia de vaporização do médio de aquecimento no refervedor. $\mathrm{kJ} \mathrm{kmol}^{-1}$

$\sigma \quad$ Tensão superficial da mistura $\left(\operatorname{din~} \mathrm{cm}^{-1}\right)$

$\mu \quad$ Viscosidade da mistura $(c P)$

$\phi \quad$ Elementos fora da diagonal da matriz esparsa 


\section{SUMÁRIO}

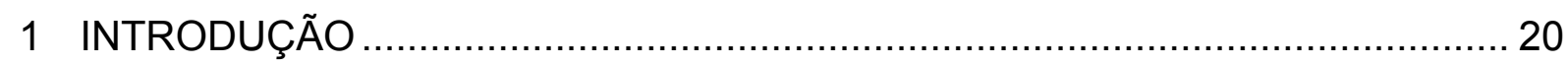

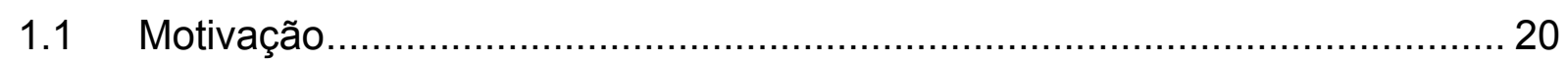

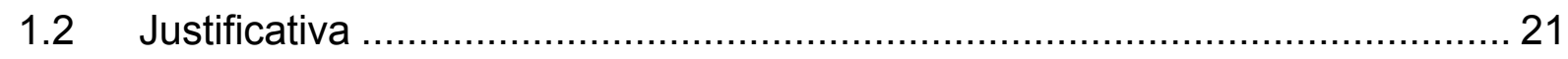

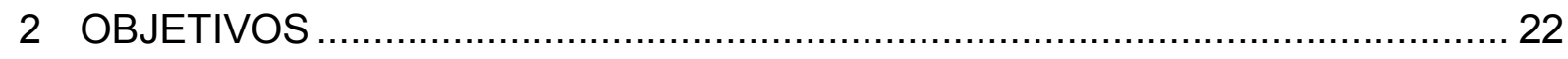

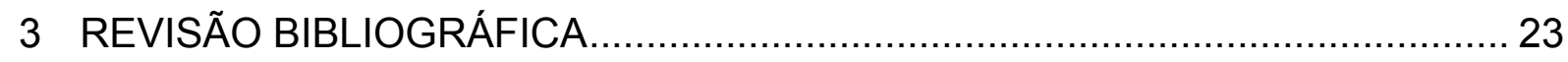

3.1 Estudo das sequências de separação …………………….................... 23

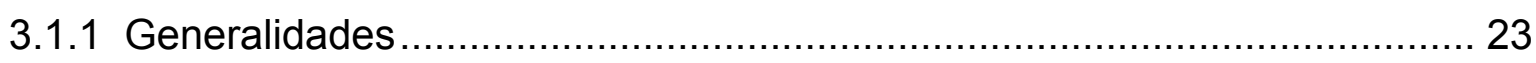

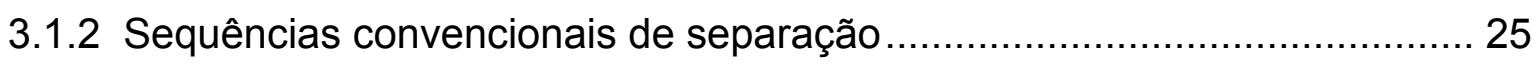

3.1.3 Colunas de destilação complexas ...................................................... 26

3.1.3.1.1 Coluna com saída de vapor lateral................................................. 27

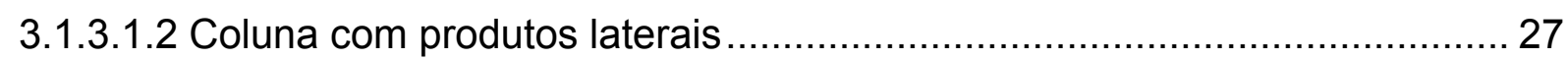

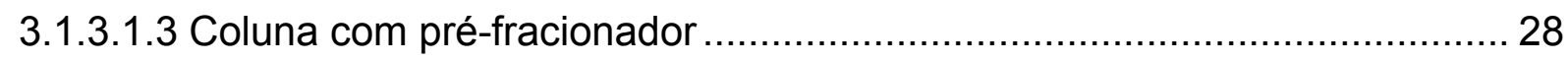

3.1.3.1.4 Coluna termicamente acoplada. Petlyuk .............................................. 28

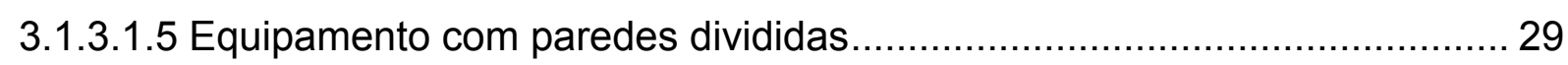

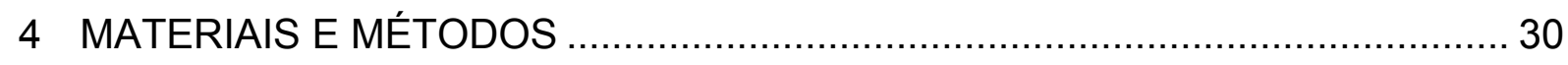

4.1 Caracterização das variáveis do modelo …………………...................... 30

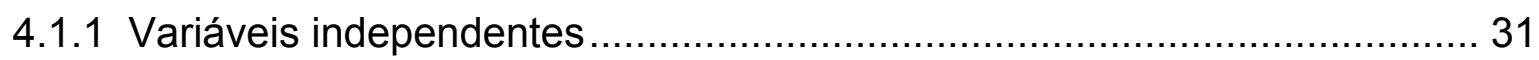

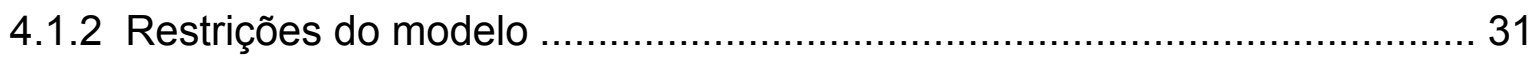

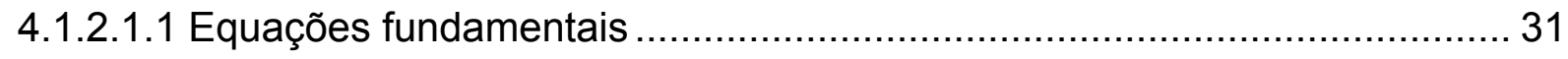

4.1.2.1.2 Restrições operacionais .................................................................. 31

4.2 Métodos aproximados de projeto de colunas de destilação únicas................ 31

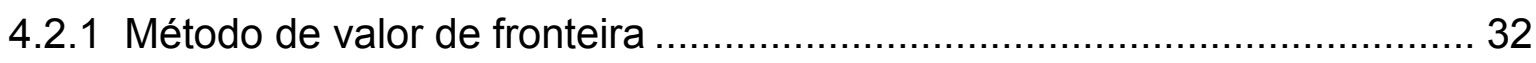

4.2.1.1.1 Balanço de matéria em um estágio de destilação genérico ...................... 32

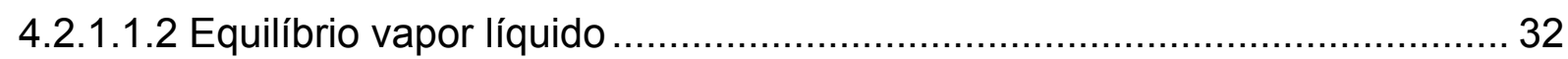

4.2.1.1.3 Divisão de uma coluna de destilação com uma alimentação..................... 33

4.2.1.1.4 Balanços efetuados na zona de retificação .............................................. 34

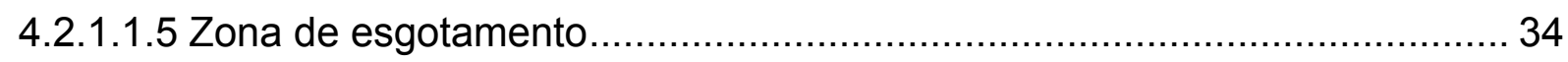

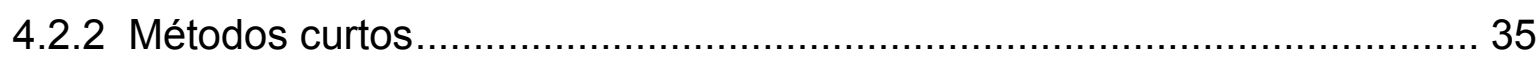

4.3 Métodos rigorosos de simulação para colunas de destilação ……................. 37

4.3.1 Método de ponto de bolha para uma coluna convencional....................... 37

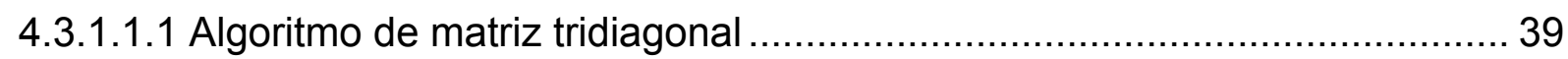


4.3.1.1.2 Balanço de energia.

4.3.2 Método de ponto de bolha para coluna termicamente acoplada 42

4.3.2.1.1 Balanço de matéria global na sequência termicamente acoplada 43

4.3.2.1.2 Balanço dos estágios internos por componente..................................... 44

4.3.2.1.3 Geração dos coeficientes da matriz esparsa ........................................ 45

4.3.2.1.4 Coeficientes dos elementos tridiagonais .............................................. 46

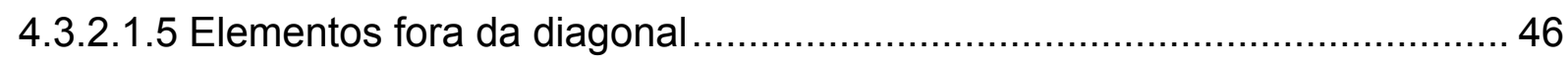

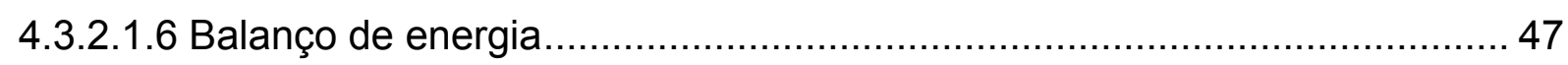

4.4 Métodos rigorosos de dimensionamento de uma coluna ............................ 48

4.4.1 Custo total anualizado, função objetivo. ............................................... 48

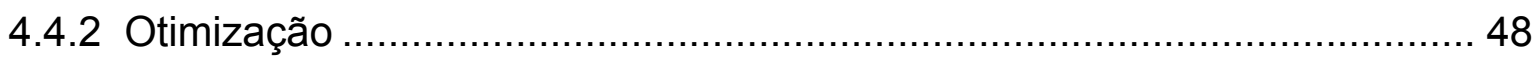

4.4.3 Propósito do uso de restrições com penalidade ....................................... 49

4.5 Método de projeto de sequências de colunas de destilação ou de projetos não convencionais. 49

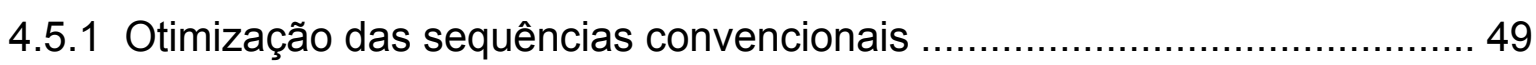

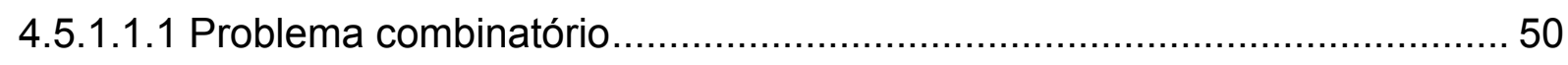

4.5.2 Otimização de uma sequências termicamente acopladas......................... 51

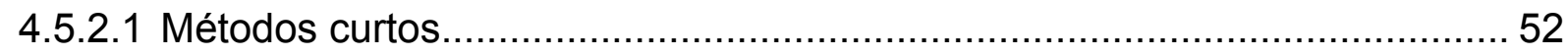

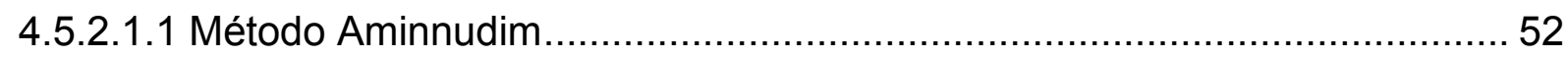

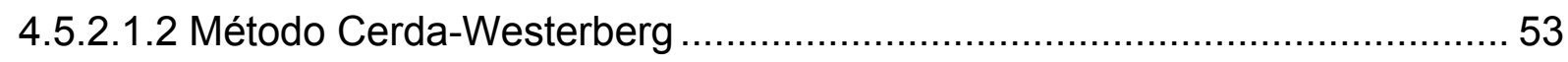

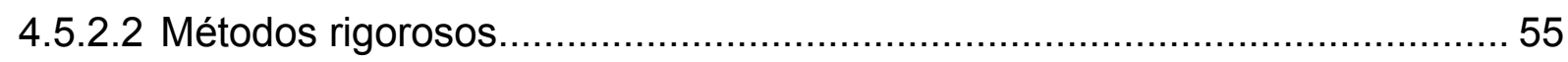

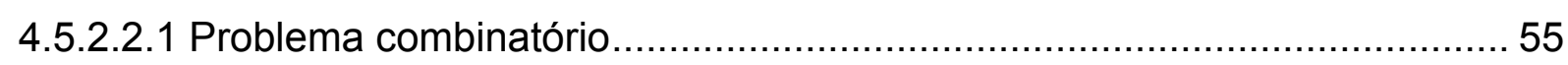

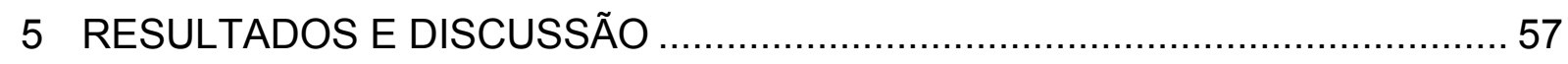

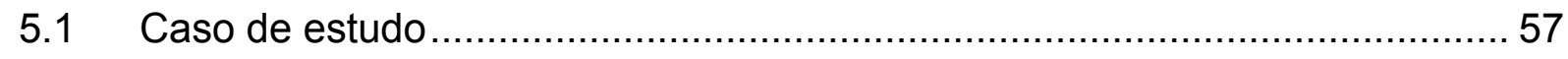

5.2 Graus de liberdade para sequências convencionais e configuração

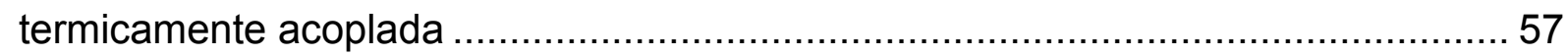

5.2.1 Graus de liberdade de sequências convencionais................................. 57

5.2.2 Graus de liberdade para uma coluna termicamente acoplada .................. 59

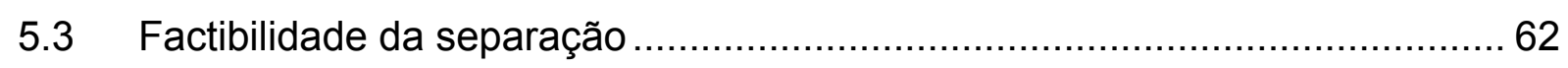

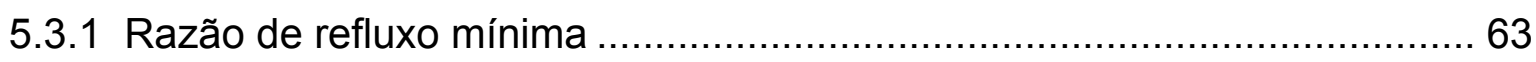

5.4 Análise de sensibilidade com método de valor de fronteira para as sequências

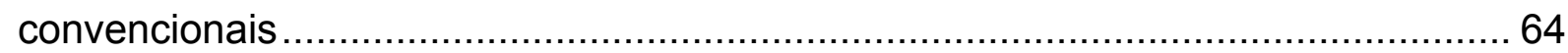

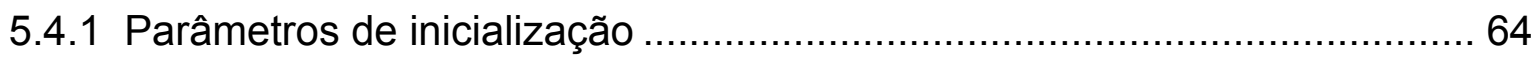


5.5 Validação dos métodos rigorosos para uma coluna convencional e para uma sequência termicamente acoplada, DWC 67

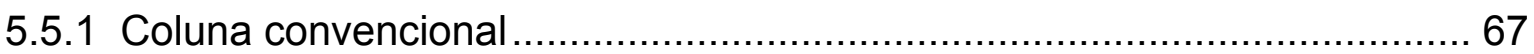

5.5.2 Solução simultânea de sequências de separação.................................... 68

5.5.3 Coluna termicamente acoplada ...................................................... 70

5.6 Otimização das sequências convencionais de separação ........................... 73

5.6.1 Influência das penalidades na convergência da função objetivo ................ 73

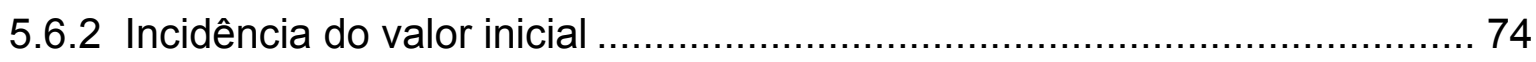

5.6.3 Determinação da sequência com mínimo custo total anualizado ............... 75

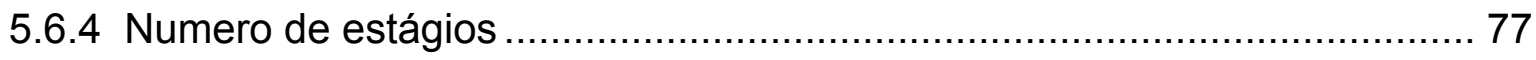

5.7 Otimização em sistemas termicamente acoplados...................................... 79

5.7.1 Incidência dos valores iniciais das vazões nas conexões, saídas de produto e

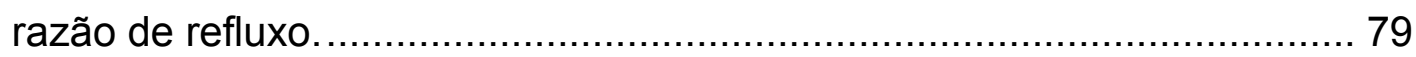

5.7.2 Custo de capital e custo de operação .................................................... 81

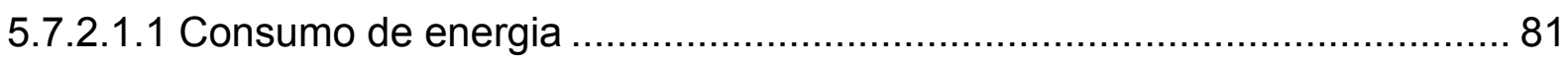

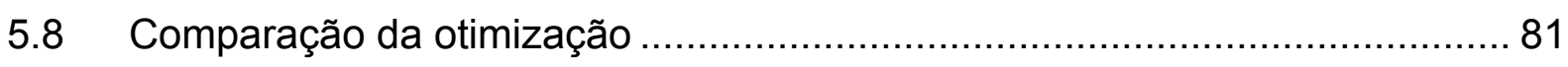

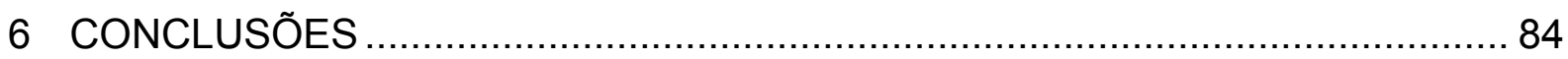

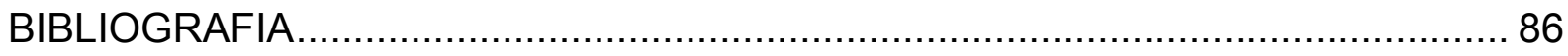

APÊNDICE A. MODELOS DE DIMENSIONAMENTO DE COLUNAS DE

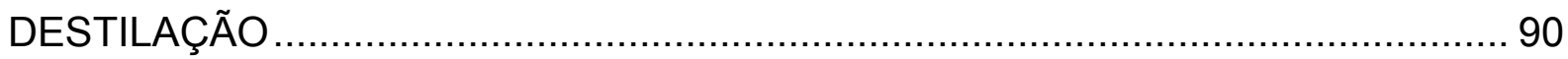

APÊNDICE B. PROGRAMAS PARA SEQUÊNCIAS CONVENCIONAIS E COLUNA

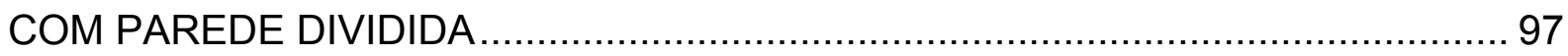

APÊNDICE C. RESULTADOS PARA UMA OTIMIZAÇÃO COMBINATÓRIA EM UMA

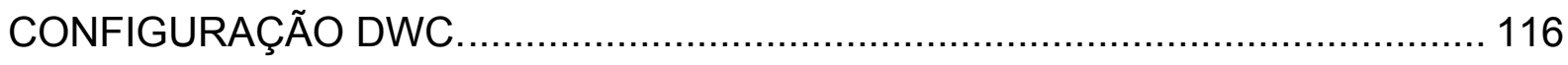




\section{INTRODUÇÃO}

\subsection{Motivação}

O processo de destilação é uma operação unitária usada amplamente para a separação de múltiplos componentes com um alto consumo de energia, e uma baixa eficiência termodinâmica (GUTIERREZ, SEGOVIA, \& HERNANDEZ, 2008). Pelo qual existe interesse em desenvolver novas configurações com a capacidade de diminuir e melhorar o uso da energia.

Um projeto efetivo de sistemas de separação é uma tarefa crítica de projeto de processos. Apesar de que nos últimos anos ter havido importantes avanços em novas tecnologias neste contexto, a destilação continua sendo a técnica de separação mais importante na indústria de processos químicos. A destilação com integração térmica tem sido proposta como uma alternativa promissora à destilação convencional devido à economia importante de energia e de capital de alguns destes projetos em comparação com os convencionais (KAIBEL,2010).

Dentro da destilação convencional, existem sequências diretas e sequências indiretas, para uma separação de uma mistura multicomponente. Estas sequências se caracterizam por colunas com pares de trocadores de calor, e tem apenas 2 saídas laterais, no topo e no fundo da coluna. No entanto, para diminuir os custos de operação e de capital, a proposta de uma coluna com parede dividida tem sido estudada. Ela consiste em uma coluna que tem uma lâmina metálica que divide os seus diferentes estágios, usando apenas um condensador e um refervedor para a troca de calor dentro da coluna, além de saídas laterais.

Há, atualmente, por volta de 30 processos industriais (CABALLERO, 2004), usam colunas com paredes divididas (DWC, divided wall columns). Mais ainda, existe uma grande variedade de possibilidades que podem produzir economias de capital e de energia, especialmente para misturas contendo mais do que três componentes.

Neste contexto, é preciso encontrar uma sequência de destilação que satisfaça um ou mais objetivos desejados, minimizando o consumo de energia e os custos de capital. Principalmente, em misturas com mais do que 3 componentes, deve-se encontrar a melhor configuração, entre varias, para satisfazer os requisitos de 
economia energética, sem aumentar a complexidade de operação nem o custo do processo.

No capítulo 3 é apresentada uma revisão do problema da separação de misturas multicomponentes, com uma descrição das tecnologias tradicionais baseadas em sequências de colunas e de sistemas de destilação não convencionais com integração de calor. Também são descritas as metodologias para projeto destas sequências.

No capítulo 4 é efetuada uma descrição dos métodos abordados neste trabalho. Primeiramente são descritos os métodos não rigorosos: o método de valor de fronteira e os métodos curtos. Posteriormente são descritos os métodos rigorosos de projeto de sequências de destilação através da otimização de um objetivo econômico que corresponde ao custo total anualizado.

No capítulo 5 são apresentados os resultados obtidos do trabalho, a factibilidade de separação da mistura ternária da mistura Benzeno, Tolueno, p-Xileno, são analisados os graus de liberdade, estabelecendo as variáveis de projeto, e são apresentados os resultados das otimizações combinatórias para as configurações convencionais e a coluna com parede dividida.

No capítulo 6, são apresentadas as conclusões do trabalho, quanto à aplicabilidade dos modelos nas sequências convencionas de separação e para as colunas de parede dividida.

\subsection{Justificativa}

Por outro lado, neste trabalho descreve-se e desenvolve-se uma alternativa para a determinação do processo de separação de uma mistura ternaria, ótimo em termos de custos, para diferentes condições de alimentação em sequências convencionais, direta e indireta, comparando-as com a coluna de destilação com parede dividida.

O problema de projeto é tratado como um problema de otimização não linear, com o custo total anualizado como função objetivo. 


\section{OBJETIVOS}

O objetivo geral deste trabalho é estabelecer uma comparação dos arranjos ótimos para a separação de uma mistura com 3 componentes através de um sistema de destilação sequenciado, e de um sistema de destilação com integração energética.

Para tal será estudada a separação de uma mistura ternária, Benzeno, Tolueno e pXileno com três composições diferentes. Inicialmente será realizada uma análise de graus de liberdade para as diferentes configurações estudadas.

O projeto conceitual do processo será realizado, para inicializar o método rigoroso, para ser submetido a uma otimização através de programação matemática do problema de projeto, para no fim estudar a influência das composições da alimentação no custo ótimo de separação das diferentes sequências analisadas. 


\section{REVISÃO BIBLIOGRÁFICA}

\subsection{Estudo das sequências de separação}

\subsubsection{Generalidades}

O primeiro sistema conhecido que se refere à integração energética de maneira explícita foi proposto por Wright em 1949, agora conhecido como destilação com paredes divididas, e suas bases teóricas estabelecidas por Petlyuk, Platonov, Slavinskii em 1965, (PETLYUK, 2004). Durante as duas últimas décadas, foram desenvolvidos novos conceitos sobre a operação e controle destas colunas e a capacidade de desenvolver modelos de separação mais complexos.

Logo foram apresentadas alternativas factíveis para a configuração de um sistema de destilação termicamente acoplado, onde o calor é fornecido ao sistema por um só refervedor, e o calor removido através de um só condensador simples (AGRAWAL, 1996), cuja sistematização lógica foi proposta, através de equações lineares para seu uso em um ambiente de programação matemática. (CABALLAERO E GROSSMANN, 2001).

Também, tem sido incluídas modificações e melhoras aos sistemas termicamente acoplados, além de esquemas para integração de calor multiefeito e novas regras para a geração de configurações termodinamicamente equivalentes (AGRAWAL, 1999).

Por outro lado, existem estudos para sistemas estendidos a misturas multicomponentes, cujas consideram mostraram que em sistemas termicamente acoplados, sempre se produz uma vazão mais baixa de vapor, em condições de volatilidades relativas constantes e fluxo molar constante (HALVORSEN I., 2003).

Posteriormente, estabeleceu-se que provavelmente, uma das aproximações mais gerais e flexíveis, é o conceito de Super-tasks (SHAH, 2002), que foi desenvolvido e usado com uma grande quantidade de alternativas, múltiplas saídas laterais e múltiplas alimentações (SHAH, 2002).

Por outra parte, foi feita uma combinação da lógica e da programação matemática para gerar todas as configurações termodinamicamente equivalentes, para incluir todas as alternativas que estão nos sistemas convencionais para os sistemas termodinamicamente acoplados, expressões matemáticas para calcular o número de 
configurações para uma sequência de separações (CABALLERO, REYESLABARTA, \& GROSSMAN, 2003).

Atualmente, existem processos onde este tipo de destilação é aplicado, principalmente na recuperação de solventes. Além disso, é conhecida a obtenção de 1-octeno, a produção de butadieno, através da destilação extrativa (KAIBEL G. A., 2010).

Para uma separação multicomponente, inicialmente o aspecto mais importante é encontrar a sequência de separação ótima identificando diferentes alternativas para um número de componentes de uma mistura determinada, considerando integração energética entre as colunas e sistemas, que vão de sistemas convencionais a sistemas termicamente acoplados.

A melhor sequência ou configuração será aquela que tem menores custos. Do ponto de vista dos custos, os trocadores de calor representam uma quantidade significativa do conjunto completo dentro do equipamento de separação, portanto é desejável estabelecer um sistema, onde o uso destas unidades seja mínimo, que corresponde a 2 trocadores de calor; sendo um refervedor e um condensador, independentemente da quantidade de componentes da mistura (AGRAWAL, 1996).

Esta configuração oferece uma vantagem sobre o sistema convencional, cuja ineficiência produzida pela irreversibilidade termodinâmica durante a mistura das vazões de alimentação com as que vão dentro do equipamento, topo e fundo, é reduzida nestas configurações integradas (OLUJIC, GADALLA, RIJKE, \& JANSENS, 2008).

A possibilidade de uma integração energética depende da presença ou não de trocadores de calor ou aquecedores em estágios intermédios, neste caso, o condensador está associado com o componente mais volátil, e o refervedor com o componente menos volátil. O número mínimo de colunas $\mathrm{N}$ está diretamente relacionado com a quantidade de componentes da mistura que se deseja separar NHE, pela equação (1) (AGRAWAL, 1996):

$2 N-N H E_{f}-1 \leq$ No.de separações $\leq N(N-1)$ 
Para um sistema acoplado a energia mínima investida só é garantida para sistemas de $\mathrm{N}(\mathrm{N}-1)$ seções de coluna. Do ponto de vista das secções, nas colunas tipo Kaibel, elas são projetadas com um número menor do que a quantidade mínima de seções na expressão anterior, onde a vazão de liquido ou vapor é retirada com o componente de volatilidade intermédia, no caso de 3 componentes. (KAIBEL G. , 1987).

\subsubsection{Sequências convencionais de separação}

Em um sistema de separação convencional, o número de colunas mantém-se mínimo, e somente aumenta por motivos especiais: Equipamento com comprimento maior, ou colunas multi-efeito. Uma das formas sugeridas para encontrar uma sequência de separação, é através de State task network (SEM), que é muito intuitivo e útil para entender as diferentes relações entre os diferentes estágios, com o objetivo de produzir separações fatíveis. Sua maior desvantagem, é que aumenta consideravelmente a programação matemática do sistema na medida em que aumentam a quantidade de componentes. Assim, para uma mistura de 4 componentes, há 15 formas de separação, para 5,35 e para 6, 70. (YEOMANS, 2000).

Alternativamente para colunas convencionais, considera-se a síntese de todas as possíveis sequências de destilação ordinária uma mistura de alimentação multicomponente, a ser separada nos seus produtos finais, podendo ser puros ou misturas multicomponentes. Segundo o número de componentes existe uma relação de geração de número de sequências de colunas convencionais $\mathrm{N}$, que produz produtos $\mathrm{P}$, pelo qual, a determinação do número de sequências para $\mathrm{P}$ produtos é obtida através da equação (2).

$$
N_{S}=\sum_{j=1}^{P-1} N_{j} N_{P-1}=\frac{[2(\operatorname{Prod}-1)] !}{\text { Prod } ![\operatorname{Prod}-1] !}
$$

Observa-se do resultado desta relação, que o número de sequências aumenta rapidamente, na medida em que o número de produtos aumenta de acordo com o número de componentes na alimentação como se observa na Tabela 3.1. Para um número de 3 componentes na alimentação, existem 2 sequências de separação. $A$ primeira sequência, na qual o produto ligeiro é obtido na primeira coluna, dentre as 
configurações conhecidas, é a mais amplamente usado. Por outra parte, encontra-se a sequência indireta, menos desejada pela dificuldade de retirada das impurezas dos componentes mais pesados. Figura 3.1. (SEIDER, 1999).

Tabela 3.1- Número de possíveis sequências de separação por destilação convencional

\begin{tabular}{ccc}
\hline Número de produtos & $\begin{array}{c}\text { Número de separações na } \\
\text { sequência }\end{array}$ & $\begin{array}{c}\text { Número de diferentes } \\
\text { sequências Ns }\end{array}$ \\
\hline 2 & 1 & 1 \\
3 & 2 & 2 \\
4 & 3 & 5 \\
5 & 4 & 14 \\
6 & 5 & 42 \\
7 & 6 & 132 \\
8 & 7 & 429 \\
9 & 8 & 1430 \\
10 & 9 & 4862 \\
\hline
\end{tabular}

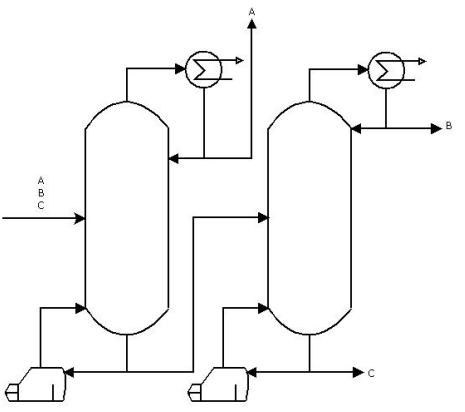

A. Sequência direta

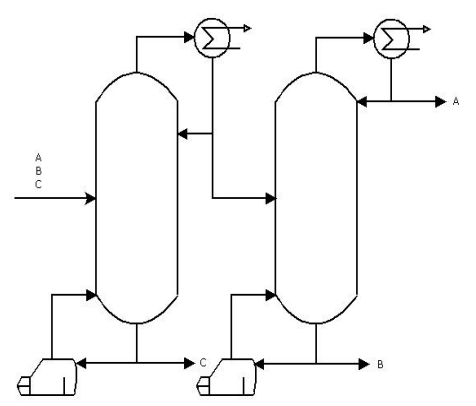

B. Sequência indireta Figura 3.1- Sequências de separação para 3 componentes na alimentação.

\subsubsection{Colunas de destilação complexas}

Além do amplo uso das colunas convencionais, também deve-se considerar as colunas que envolvem uma maior complexidade. Este tipo de colunas caracterizamse por ter 1 ou mais alimentações e produtos, visando efetuar uma separação eficiente, ale disso, são usadas quando a mistura tiver 3 ou mais componentes.

Na Figura 3.2, são apresentadas as configurações de colunas estabelecidas mais usadas.

\subsection{Coluna com saída de vapor lateral}

Nas figuras 3.2A e 3.2B são apresentadas as colunas ligadas termicamente, que se caracterizam pela eliminação de um dos trocadores de calor intermediários. As colunas de destilação com saída de vapor lateral na zona de retificação, também são conhecidas como sequência direta de separação ligada termicamente. Nesta sequência um refervedor fornece a carga térmica para atingir a separação dos 
componentes. Por outra parte, a sequência de destilação com saída de vapor lateral na zona de esgotamento, é conhecida como sequência indireta ligada termicamente. Nesta sequência, é requerido um só condensador para retirar a carga de calor. Estes tipos de sequências se diferenciam das sequências convencionais na redução dos custos em termos de energia e operação. No entanto, para estas configurações é necessário que a coluna principal mantenha uma pressão maior do que a coluna de esgotamento ou de retificação, para manter um fluxo natural entre as duas colunas.

\subsection{Coluna com produtos laterais}

Nesta configuração, Figura 3.2D, similar a uma coluna convencional, a saída lateral está localizada acima ou embaixo do estágio de alimentação, favorecendo a separação do componente intermédio. Se esta saída estiver acima do estágio de alimentação, há uma maior contaminação dos componentes mais ligeiros, favorecendo uma separação indireta. Caso contrário, se esta saída estiver embaixo do estágio de alimentação, existirá uma interação entre os componentes intermédios com os pesados, favorecendo uma separação direta. (DOHERTY, 2001).

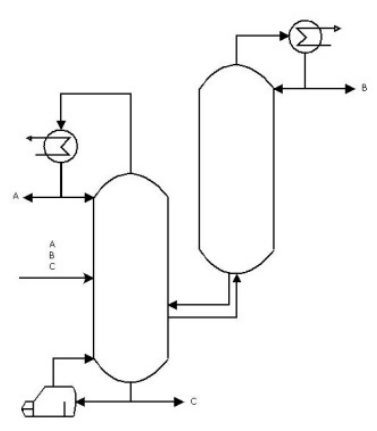

A. Destilação com saída de vapor lateral na zona de retificação

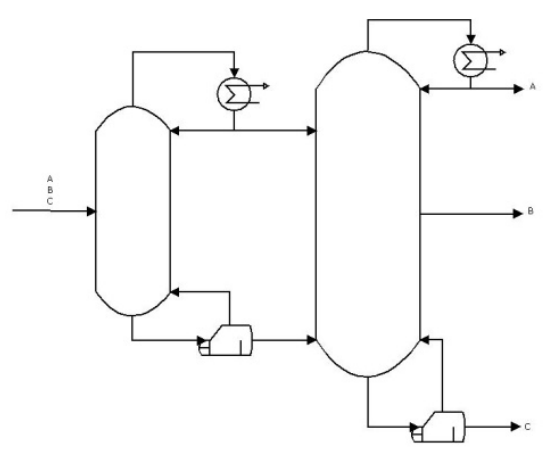

C. Destilação com pre-fracionador

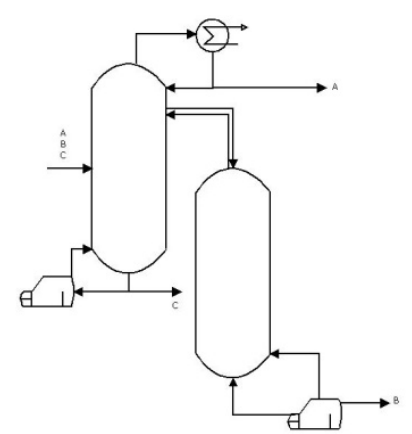

B. Destilação com saída de vapor lateral na zona de esgotamento

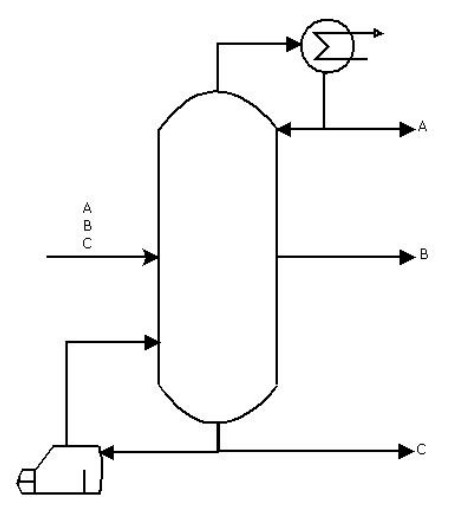

D. Destilação com saída lateral intermédia 


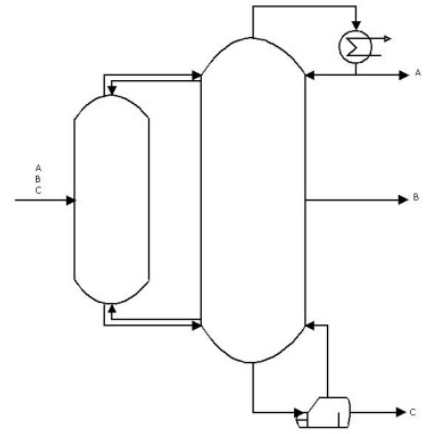

E. Sistema térmicamente acoplado. Coluna Petlyuk

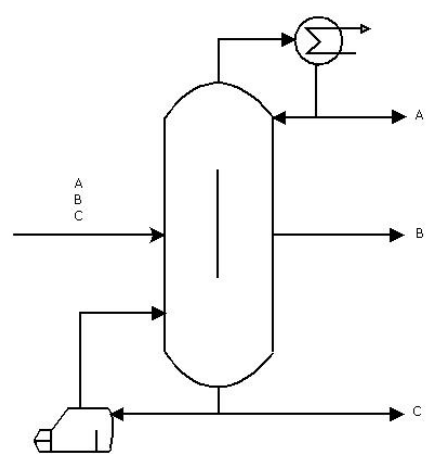

F. Coluna com parede dividida.

Figura 3.2- Configurações de colunas complexas para destilação ternária

\subsection{Coluna com pré-fracionador}

Esta configuração, figura 3.2C, tem um pré-fracionador e uma coluna principal. No pré-fracionador é realizada a separação dos componentes, leve e pesado, com o componente intermediário distribuído entre eles. Após ter sido efetuada esta separação, na coluna principal são obtidos os produtos, destilado; corrente lateral e fundo. A quantidade de energia utilizada nesta sequência é menor, causada pela distribuição prévia no pré-fracionador, contribuindo para uma maior facilidade de separação dos componentes.

\subsection{Coluna termicamente acoplada. Petlyuk}

Se forem eliminados os trocadores intermediários da coluna com pré-fracionador, e colocando refluxos no seu lugar, podem-se integrar termicamente, Figura 3.2E. Inicialmente, no pré-fracionador são separados, o produto de topo, que é enviado para a parte superior, enquanto o pesado ao fundo. Por outro lado, os demais componentes distribuam-se através das secções. Estes sub-produtos, gerados no pré-fracionador, são enviados à coluna principal, ingressando em estágios intermediários, cuja separação dos componentes puros, finalmente é efetuada (SEIDER, 1999).

Além do mais, existem avanços na operabilidade e controle destes equipamentos sob mínimo consumo de energia (WOLFF \& SKOGESTAD, 1995) 


\subsection{Equipamento com paredes divididas}

Este equipamento possui uma partição vertical com uma lâmina plana, Figura 3.2F, também, é possível isolar o equipamento termicamente, especialmente se forem requeridos produtos com alta qualidade, para evitar o fluxo de liquido indesejado na parede. Usualmente, a colocação da parede está no centro do equipamento, embora seja possível colocar a parede fora do centro deste, nos casos em que a concentração do produto intermediário entre os componentes de maior e menor volatilidade, seja menor (KAIBEL, 2010).

A vantagem das colunas termicamente acopladas, é que podem operar a diferentes pressões, se cada coluna estiver com um condensador e um refervedor.

$\mathrm{Na}$ destilação convencional, cada coluna tem um intervalo de pressões, às quais podem trabalhar. No entanto, as colunas de paredes divididas, somente podem trabalhar com uma única pressão de operação. Como consequência, resulta em uma maior diferença de temperatura entre o refervedor e o condensador.

Se não existir um comportamento quase ideal da mistura, é preciso utilizar outro tipo de considerações (STICHLMAIR, 1998). 


\section{MATERIAIS E MÉTODOS}

As equações do modelo, dependendo do grau de detalhe incluído nas considerações do modelo e a complexidade do processo, são em grande quantidade.

Inicialmente é efetuada a caracterização das variáveis do processo para uma separação por meio de colunas de destilação, visando a entender e resolver a especificação do sistema.

Posteriormente, são apresentados os diferentes métodos de resolução de colunas de destilação, uma descrição dos métodos curtos e dos métodos mais rigorosos, como o de ponto de bolha, são desenvolvidas as diferentes equações que descrevem os balanços de matéria e energia, e o equilíbrio, tanto para as sequências convencionais, quanto para a configuração termicamente acoplada e adaptação para esta configuração.

Posteriormente são descritos e estabelecidos os problemas de otimização para as sequências convencionais e a configuração termicamente acoplada, as restrições que estão envolvidas no projeto da separação, e a avaliação de diferentes combinações relacionadas com as variáveis inteiras, alcançando a minimização do custo total anualizado.

\subsection{Caracterização das variáveis do modelo}

O modelo matemático para desenvolver o processo de uma sequência convencional direta ou indireta, baseia-se nos balanços de energia, massa e de equilíbrio vaporlíquido. Inicialmente, será feito uma análise de graus de liberdade, estabelecendo as variáveis do projeto. Por outra parte, serão calculados os estágios da região da zona de retificação, considerando o estado do destilado, corrente $D$, bem como, para os estágios pertencentes ao fundo da torre, corrente B.

Para este caso, é necessário achar a distribuição das misturas ternárias dentro da coluna, levando em conta as variações que se apresentam de acordo com os balanços feitos, e consequentemente obter os perfis das duas seções assim como a intersecção delas através de diagramas ternários. (DOHERTY, 2001) 
Posteriormente, com estes perfis obtidos, serão calculados o número de estágios reais e o estágio ótima de alimentação e seguidamente, os equipamentos de transferência de calor que interagirão dentro deste sistema.

Depois que o dimensionamento de cada um dos equipamentos for realizado, podese estimar o custo deles, gerando o custo de instalação e de operação, que serão parte do custo total anualizado, TAC. Esta função será a função objetivo do problema da otimização, para um conjunto de sequências convencionais de separação, indiretas e diretas.

\subsubsection{Variáveis independentes}

Estas variáveis referem-se às especificações de operação:

- Frações molares da alimentação.

- Temperaturas e pressões

\subsubsection{Restrições do modelo}

No processo de separação, as restrições apresentadas no modelo, estão classificadas, como restrições matemáticas e operacionais.

\subsection{Equações fundamentais}

Estas são inerentes ao modelo, para processos de destilação:

- Balanços de equilíbrio.

- Balanços de massa

- Balanços de energia

\subsection{Restrições operacionais}

Estas restrições estão relacionadas com as características de produção e representam a pureza dos produtos, ou as suas recuperações.

\subsection{Métodos aproximados de projeto de colunas de destilação únicas}

Apesar de existirem métodos rigorosos de cálculo para problemas de separação por destilação, os métodos aproximados são usados de maneira considerável para vários propósitos, tais como estudos paramétricos para estabelecer condições de projeto, e estudos de processos para sequências ótimas de separação (HENLEY, SEADER, 1981). 
Aqui são apresentados os métodos aproximados que são utilizados para projetar a separação de sistemas ternários, o método de valor de fronteira (DOHERTHY, 2001), e o métodos curto de Underwood, Gilliland, Fenske que pode ser aplicados para uma quantidade maior do que 3 componentes..

\subsubsection{Método de valor de fronteira}

\subsection{Balanço de matéria em um estágio de destilação genérico}

Segundo o conceito de estagio de equilíbrio, a coluna de destilação é modelada como uma série de estágios em equilíbrio ligados entre si. Dentro de cada estágio assume-se mistura perfeita das fases. As frações molares da espécie i que sai com o fluxo $V$ do estágio n são $y_{i, n}$, e as frações de $L$ são $x_{i, n}$, comforme a Figura 4.1.

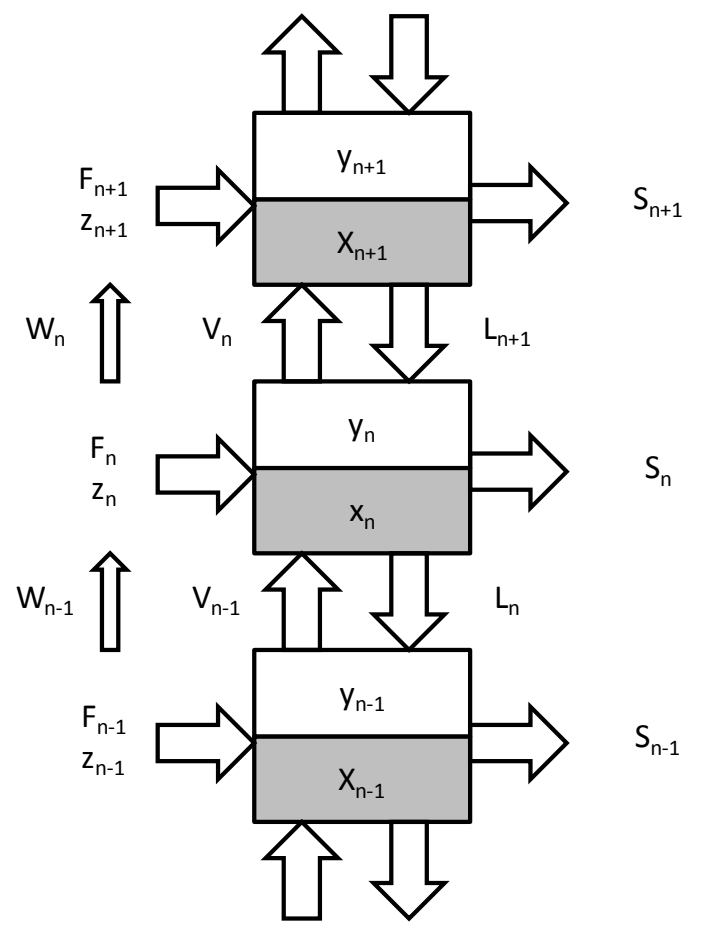

Figura 4.1- Secções de coluna de destilação apresentada como uma configuração de estágios no equilíbrio

\subsection{Equilíbrio vapor líquido}

Neste modelo a desenvolver aplica-se no modelo líquido-vapor, atribui o modelo de gás ideal à fase de vapor e o modelo de solução ideal à fase líquida, dado que para os gases o coeficiente de fugacidade é igual à unidade, mesmo assim como para o coeficiente de atividade do líquido. Por tanto a equação de Raoult fica:

$y_{i, j} P=x_{i, j} P_{i}^{s a t}$ 
Em que $y_{i, j}$, corresponde a fração molar de vapor do componente i no estágio $\mathrm{j}, x_{i, j}$ é a fração molar de liquido do componente i no estágio j, $P_{i}^{\text {sat }}$ é a pressão de saturação do componente i.

Com esta relação liquido-vapor, se supõe que as vazões que saem do estágio estão em equilíbrio termodinâmico, pelo qual,

$y_{i, j}=x_{i, j} K_{i, j}$

Esta relação de equilíbrio calcula-se usando a pressão no estágio $\mathrm{Pj}$, junto com as pressões de saturação do componente i, dadas às condições do estágio.

$K_{i, j}=\frac{P_{i}^{\text {sat }}}{P}$

A pressão de vapor pode ser determinar através de coeficientes dados para cada componente, usando-se a equação de Antoine (POLING, PRAUSNITZ, \& O'CONELL, 2001).

$P_{i}^{s a t}\left(T_{j}\right)=a+\frac{b}{c+T_{j}(K)}$

Inicialmente os modelos utilizados para este tipo de configuração baseiam-se nos balanços de massa, energia e equilíbrio.

No desenvolvimento do modelo, os balanços efetuados nos estágios que pertencem à zona de retificação, são feitos levando em conta as vazões parciais no destilado $D$, enquanto os balanços efetuados na zona de retificação, são efetuados levando em conta as vazões parciais no fundo, B.

\subsection{Divisão de uma coluna de destilação com uma alimentação}

Este tipo de coluna pode-se dividir em três secções ou zonas: o estágio de alimentação, a zona de retificação e a zona de esgotamento. A zona de alimentação é aquela onde ingressa a vazão da alimentação, a zona de retificação está localizada acima do estágio de alimentação, e a zona de esgotamento, localizada abaixo de ela.

\subsection{Balanços efetuados na zona de retificação}

Os balanços de matéria no estágio $\mathrm{n}$ efetuados dentro da zona de retificação da coluna estão estabelecidos da seguinte maneira:

Balanço global da seção:

$V_{j-1}=L_{j}+D$ 
Balanço por componente

$V_{j-1} y_{j-1}=L_{j} x_{j}+D x_{D}$

Como resultado

$y_{i, j-1}=\frac{r}{1+r} x_{i, j}+\frac{x_{i, D}}{1+r}$

Em que $y_{i, n-1}$ corresponde à fração molar do componente i dentro da vazão de vapor que entra ao estágio j, $x_{i, j}$ corresponde à fração molar de i que deixa o estágio $\mathrm{j}, x_{i, D}$, corresponde às frações molares do componente i no destilado, $r$ corresponde à razão de refluxo molar entre o líquido que sai do estágio $L_{n}$, e o fluxo de destilado $\mathrm{D}$.

$r=\frac{L_{j}}{D}$

$r+1=\frac{V_{j}}{D}$

As composições das frações de vapor que ingressam à etapa devem satisfazer o principio de fração molar

$\sum_{i=1}^{n} y_{i}=1$

As demanda de calor no condensador total é determinada a partir do balanço de energia em volta desta unidade, para estabelecer a demanda de energia do condensador em função da razão de refluxo, além da vazão do destilado.

$V_{n} h_{j}^{V}+\dot{Q}_{C}=L_{j+1} h_{j+1}^{L}+D h_{D}^{L}$

$V_{j} h_{j}^{V}+Q_{C}=h_{D}^{L}\left(L_{j+1}+D\right)$

$\hat{Q}_{C}=D\left[h_{D}^{L}(r+1)-h_{j}^{V}(r+1)\right]$

$\hat{Q}_{c}=D\left[(r+1)\left(h_{D}^{L}+h_{j}^{V}\right)\right]$

Em que $h_{D}$, é a entalpia molar do destilado, $h_{j}^{V}$, entalpia molar que entra ao condensador, $Q_{c}$ representa a energia removida no condensador.

\subsection{Zona de esgotamento}

O balanço por componente no estágio é efetuado a um balanço similar à zona de retificação

Balanço global da seção:

$L_{j+1}=V_{j}+B$

Balanço por componente 
$L_{j+1} x_{j+1}=V_{j} y_{j}+B x_{B}$

Como resultado

$x_{i, j+1}=\frac{L_{j+1}}{V_{j}} y_{i, j}+\frac{B}{V_{j}} x_{B}$

Analogamente como na seção de retificação, as composições das frações de líquido que ingressam ao estágio $\mathrm{n}$ devem satisfazer o principio de fração molar.

$\sum_{i=1}^{n} x_{i, j+1}=1$

Existe uma relação entre o refluxo no condensador e no refervedor através do balanço de energia, pela condição da alimentação, e a separação desejada.

$\dot{Q}_{B}=D h_{D}^{L}+B h_{B}^{L}-F h_{F}-\dot{Q}_{C}$

O refervedor fornece um fluxo de vapor no fundo da coluna. O produto é muitas vezes removido como líquido. Este fluxo de vapor gerado está relacionado ao fundo e os fluxos internos estão relacionados à razão externa de refluxo $s$, gerado neste equipamento.

$s+1=\frac{V}{B}$

Efetuando um balanço de energia no refervedor, é possível determinar $s_{m}$, fixando-a como uma função objetivo.

$\frac{Q_{B}}{B}+\frac{s}{1+s}+h_{j+1}^{L}-s \quad h_{j}^{V}-h_{B}=0$

Posteriormente mudando o balanço por componente de entrada do líquido em cado estágio, em função da razão de refluxo no refervedor, fica:

$x_{i, j+1}=\frac{s}{1+s} y_{i, j}+\frac{x_{i, B}}{1+s}$

\subsubsection{Métodos curtos}

Os métodos curtos são usados principalmente para uma aproximação do projeto de colunas de destilação (SEADER, 1981). Estes métodos ajudam significativamente na simplificação do cálculo dos diferentes parâmetros da torre. Estes métodos tem o problema de precisão, embora seus resultados sejam bastante adequados. Sua aplicação é uma boa alternativa se não se tiver um método rigoroso disponível ou tempo suficiente para programá-lo.

A equação de Fenske determina o número de estágios necessárias na coluna para alcançar uma determinada separação. Este número de estágios corresponde a uma 
razão de refluxo total na coluna. Para usar esta equação, são indicados os componentes chave, leve i e pesado j, além da sua distribuição no primeiro e ultimo estágio da coluna, também a volatilidade relativa entre ambos componentes, constante ao longo da coluna, de acordo com a equação (25).

$N_{\text {min }}=\frac{\log \left[\left(\frac{x_{i, 1}}{x_{i, N+1}}\right)\left(\frac{x_{j, 1}}{x_{j, N+1}}\right)\right]}{\log \propto_{i, j}}$

Em que a volatilidade relativa média na coluna entre os componentes chave leve e chave pesado $\propto_{i, j}$ é calculada como a média geométrica das volatilidades relativas entre os componentes i e j no primeiro e último estágio da coluna:

$\propto_{i, j}=\left[\left(\propto_{i, j}\right)_{N}\left(\propto_{i, j}\right)_{1}\right]^{1 / 2}$

E equação (26), pode-se obter a distribuição dos componentes (i) não chaves no destilado (D) e no fundo (B), como é apresentado nas equações (27) e (28).

$b_{i}=\frac{f_{i}}{1+\frac{d_{H K}}{b_{H K}} \propto_{i, H K}^{N_{\min }}}$

$d_{i}=\frac{f_{i} \frac{d_{H K}}{b_{H K}} \propto_{i, H K}^{N_{\min }}}{1+\frac{d_{H K}}{b_{H K}} \propto_{i, H K}^{N_{\min }}}$

Na equação de Underwood, equação (29), é determinada a razão de refluxo mínima na coluna, e corresponde a um número de estágios de equilíbrio infinito, Esta condição impossível de realizar, sendo uma referência para determinar o refluxo com o qual é possível operar a coluna. Para obtê-lo, deve-se resolver de maneira simultânea as equações (29) e (30).

$$
\begin{aligned}
& 1-q=\sum \frac{\propto_{i, H K} x_{i, F}}{\propto_{i, H K}-\theta}=\sum f_{i} \\
& \frac{V_{\text {min }}}{D}=\sum \frac{\propto_{i, H K} x_{i, D}}{\propto_{i, H K}-\theta}=1+R_{\text {min }}
\end{aligned}
$$


A equação de Gilliland é usada para calcular os estágios da coluna obtendo-se uma vazão real, cujo valor é um múltiplo do refluxo mínimo obtido da equação de Underwood. Esta correlação é mostrada na equação (31)

$\frac{N-N_{\min }}{N+1}=1-\exp \left[\left(\frac{1+54,4 X}{11+117,2 X}\right)\left(\frac{X-1}{1 X^{0,5}}\right)\right]$

$X=\frac{R-R_{\min }}{R+1}$

Esta correlação é válida se existirem um número de componentes entre 2 e 11, a pressão for de até 40,82 atm, se a condição térmica q, estiver entre um valor de 0,28 e até 1,42, e a volatilidade relativa entre 1,11 e 4,05.

Da equação de Kirkbride, equação (33), é obtido o estágio de alimentação ótimo, supondo a distribuição ideal dos componentes através da coluna.

$\frac{N_{R e t}}{N_{E s g o}}=\left[\left(\frac{x_{F, H K}}{x_{F, L K}}\right)\left(\frac{x_{B, L K}}{x_{D, H K}}\right)\left(\frac{B}{D}\right)\right]^{0.206}$

Porém, se a zona inferior possuir mais estágios do que a zona superior, a solução perde precisão, por que a razão de refluxo no reboiler não é considerada importante no projeto da coluna.

\subsection{Métodos rigorosos de simulação para colunas de destilação}

Estes métodos se caracterizam pela complexidade, na predição de propriedades. São necessários para o projeto final do equipamento, obtendo dados com maior exatidão sobre o processo. Nestes métodos são aplicados os balanços de matéria, energia, e equilíbrio, nos estágios da coluna. Sua complexidade provém principalmente das não linearidades e da sua grande interação. Estes métodos estão incluídos dentro dos programas de simulação de processos.

\subsubsection{Método de ponto de bolha para uma coluna convencional}

No desenvolvimento do modelo, na vazão de alimentação, são levadas em conta as fases de vapor e liquido. Principalmente, o equacionamento é baseado em balanços de matéria e as restrições nas composições para as vazões de liquido e vapor que saem dos estágios, os balanços de energia, sem considerar queda de pressão nos estágios. 
O método de ponto de bolha permite cálculos rigorosos em uma coluna de destilação, tal como a ilustrada na Figura 4.2.

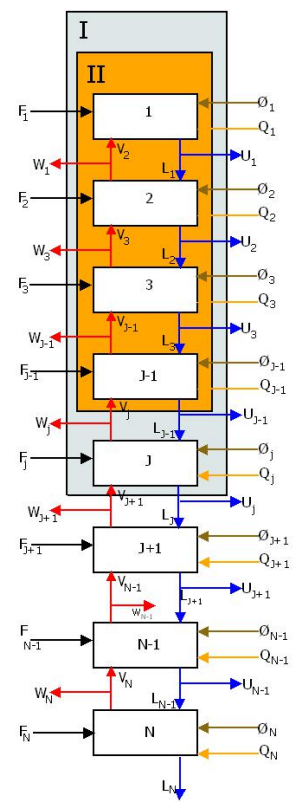

Figura 4.2- Configuração para cálculo de ponto de bolha, usando multiplas entradas e saídas Balanço global na coluna sem inclusão dos trocadores de calor

$$
\sum_{m=1}^{j}\left(F_{m}+W_{m}-U_{m}\right)+\left(V_{j+1}-W_{j+1}\right)=L_{j}
$$

Em que são levadas em conta as fases de liquido e vapor, correspondentes às qualidades da alimentação.

$$
F_{j}=L_{j}+V_{j}
$$

Balanço por componente no estágio j

$$
\left(L_{j-1}-U_{j-1}\right) x_{i, j-1}+\left(V_{j+1}-W_{j+1}\right) y_{i, j+1}+\left(L_{j}-V_{j}\right) z_{F j}=L_{j} x_{i j}+V_{j} y_{i j}
$$

Restrições às composições

$$
\sum_{i=1}^{j} y_{i j}=1
$$




$$
\sum_{i=1}^{j} x_{i j}=1
$$

Equilíbrio de fases

$$
y_{i j}=K_{i j} x_{i j}
$$

Onde $K_{i j}$ está relacionado através das pressões de vapor para cada componente equação (5).

Balanço de energia no estágio j

$$
\left(L_{j-1}-U_{j-1}\right) h_{i, j-1}^{L}+\left(V_{j+1}-W_{j+1}\right) h_{i, j+1}^{V}+\left(L_{j}-V_{j}\right) h_{F j}+\dot{Q}_{J}=L_{j} h_{i, j}^{L}+V_{j} h_{i, j}^{V}
$$

Queda de pressão no estágio

$$
\begin{aligned}
& P_{j}=P_{j-1}+\Delta P_{j} \\
& \Delta P_{j}=0
\end{aligned}
$$

Posteriormente, as equações de balanço de matéria são modificadas, mudando uma das somatórias de composições equações (7) e (8), e também, determinando as vazões de liquido em função das vazões de vapor e as temperaturas nos estágios, onde posteriormente. As diferentes equações de fração molar na fase liquida, serão linearizadas, usando o algoritmo de Thomas, os balanços no estágio j são estabelecidos da seguinte maneira:

$$
\begin{aligned}
& L_{J, K}=R^{*} D+\sum_{i=1}^{J}\left(F_{i}+W_{i}-U_{i}\right)+V_{11} \\
& L_{J-1, K}=R^{*} D+\sum_{i=1}^{J-1}\left(F_{i}+W_{i}-U_{i}\right)
\end{aligned}
$$

\subsection{Algoritmo de matriz tridiagonal}

No método de ponto de bolha é preciso linearizar as equações de balanço por componente, sendo que as frações molares liquidas são levadas em conta, resolvendo-as através do algoritmo de Thomas ou da matriz tridiagonal. 
$\mathrm{Na}$ metodologia proposta no desenvolvimento, foram obtidos separadamente, os diferentes balanços nos equipamentos, condensador, refervedor, e coluna. As diferentes equações são apresentadas para a construção da matriz tridiagonal.

Os cálculos dos termos $A_{j}, B_{j}, C_{j}, D_{j}$ nos equipamentos, estão demostrados a seguir.

Balanço no condensador total (Figura 4.3).

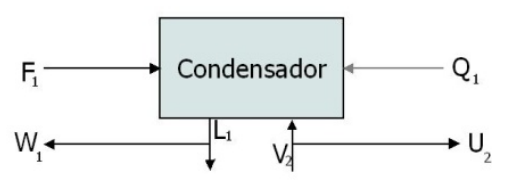

Figura 4.3- Condensador total, método ponto de bolha

$$
\begin{aligned}
& B_{J, K}=-\left[L_{0}+V_{M, I}+V_{12}+\sum_{i=1}^{J}\left(F_{i}+W_{i}-U_{i}\right)_{K}-V_{K} K_{K}\right] \\
& C_{J, K}=V_{J+1 K} K_{J+1 K} \\
& D_{J, K}=-F_{1 K} z_{i J K}
\end{aligned}
$$

Balanço nos estágios (Figura 4.4).

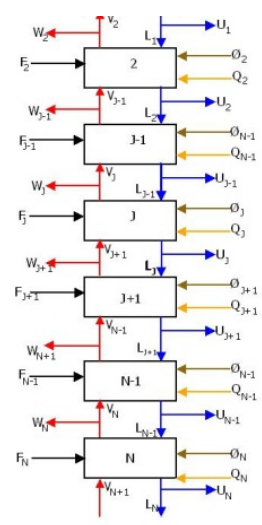

Figura 4.4- Balanço estágios internos da coluna

$$
\begin{aligned}
& A_{J, K}=L_{0}+V_{M, J-1}+V_{I J}+\sum_{i=1}^{J-1}\left(F_{i}+W_{i}-U_{i}\right)_{K} \\
& B_{J, K}=-\left[L_{0}+V_{M, I}+V_{12}+\sum_{i=1}^{J}\left(F_{i}+W_{i}-U_{i}\right)_{K}-V_{K} K_{K}\right]
\end{aligned}
$$


$C_{J, K}=V_{J+1 K} K_{J+1 K}$

$D_{J, K}=-F_{1 K} z_{i J K}$

Balanço no refervedor (Figura 4.5).

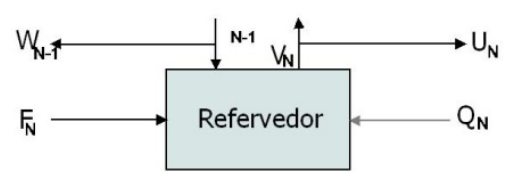

Figura 4.5- Balanço no refervedor

$$
\begin{aligned}
& A_{J, K}=L_{0}+V_{M, J-1}+V_{1 J}+\sum_{i=1}^{J-1}\left(F_{i}+W_{i}-U_{i}\right)_{K} \\
& B_{J, K}=-\left[L_{0}+V_{M, I}+V_{12}+\sum_{i=1}^{J}\left(F_{i}+W_{i}-U_{i}\right)_{K}-V_{K} K_{K}\right] \\
& D_{J, K}=-F_{1 K} z_{i J K}
\end{aligned}
$$

Geração da matriz tridiagonal para determinação de $x_{i, j-1}, x_{i, j}, x_{i, j+1}$

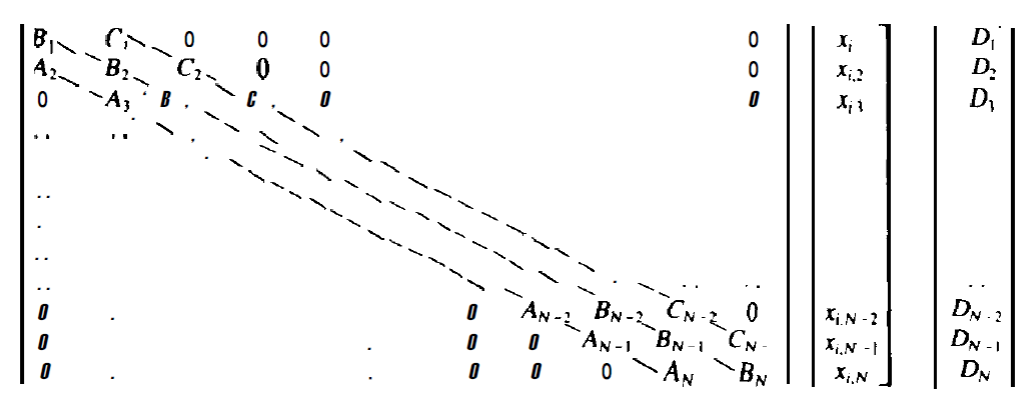

\subsection{Balanço de energia}

Posteriormente, os valores das frações de vapor, são determinados junto com as novas temperaturas dos estágios aplicando as equações de equilíbrio. As entalpias molares para cada vazão de liquido e vapor que saem o estágio são calculadas a partir de um conjunto consistente de valores $x_{i, j}$, T,e $y_{i, j}$. Especificando $F_{1}, U_{1}, V_{1}$, $W_{1}, L_{1}$, se determina $V_{2}$ de equação (56). O calor no condensador é determinado a partir de equação (54). A quantidade de calor necessária no refervedor, equação (55) é achada na somatória do balanço de energia nos estágios que são expressas a continuação. 


$$
\begin{aligned}
& \dot{Q_{1}}=\left[V_{j+1}-W_{j+1}+\sum_{j=1}^{N-1} F_{j}-\sum_{j=1}^{N-1} U_{j}-\sum_{j=2}^{N} W_{j}\right] h_{j}^{L}-F_{j} h_{f}-\left(V_{j+1}-W_{j+1}\right) h_{j}^{V} \\
& \dot{Q_{N}}=\sum_{j=1}^{N}\left[\left(L_{j}+V_{j}\right) h_{F j}-U_{j} h_{j}^{L}-W_{j} h_{j}^{V}\right]-\sum_{j=1}^{N-1} Q_{j}-V_{j+1} h_{j}^{V}-L_{j} h_{j}^{L}
\end{aligned}
$$

Onde as vazões de vapor internas da coluna são obtidas na equação (56)

$$
V_{j+1}=\left(\sum_{j=1}^{N-1} U_{j}\left(h_{j}^{L}-h_{j-1}^{L}\right)+\sum_{j=2}^{N} W_{j}\left(h_{j}^{V}+h_{j}^{L}\right)-\sum_{j=1}^{N} Q_{j}-\sum_{j=1}^{N} F_{j} h_{F j}\right){ }_{h_{j+1}^{V}}+h_{j}^{L}
$$

Critério de convergência equação (57)

$\tau=\left|T_{j}^{(K)}-T_{j}^{(K-1)}\right| \leq 1 E-6$

A Figura 4.6 apresenta o algoritmo de resolução do método de ponto de bolha para colunas de destilação.

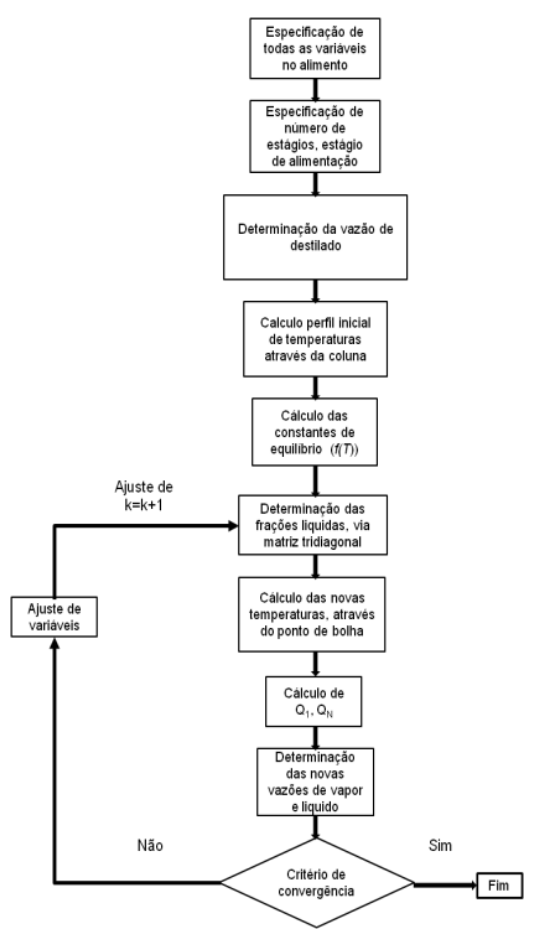

Figura 4.6- Algoritmo para o método ponto de bolha

\subsubsection{Método de ponto de bolha para coluna termicamente acoplada}

No desenvolvimento do projeto de uma coluna termicamente acoplada são determinados os diferentes balanços, energia, matéria e componente, sendo 
resolvidas as duas colunas de maneira simultânea. Posteriormente são apresentados os balanços efetuados dentro do sistema de separação termicamente integrado. Para estes balanços, é considerada a coluna principal e a fracionadora.

\subsection{Balanço de matéria global na sequência termicamente acoplada}

O número de estágios $\mathrm{N} 1$ corresponde ao número de estágios que estão dentro da coluna principal, e N2, aos estágios que estão dentro da fracionadora. Segundo os volumes de controle gerados para esta sequência, na Figura 4.7, as vazões de liquido são obtidas em função das vazões de vapor e das vazões de alimentação. No caso da coluna principal a vazão de liquido está em função das saídas e das entradas nas conexões, além da saída lateral do produto intermédio. Por outro lado, na fracionadora, as vazões internas de liquido são dadas em função das entradas e saídas das conexões com a coluna principal e a vazão de alimentação. No entanto, também é possível adicionar diferentes saídas e múltiplas entradas, no caso de mais do que três componentes. Segundo a configuração efetuada na Figura 4.7, as vazões internas de liquido dentro da coluna são obtidas levando em conta a entrada e a saída das diferentes correntes que estão interagindo em cada seção. Nas equações (58)-(65) estão representados estes balanços.

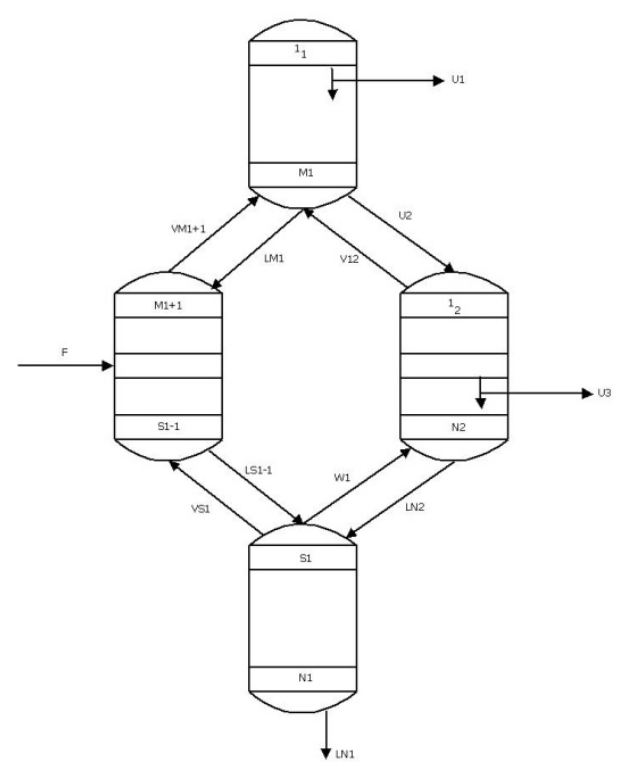

Figura 4.7- Estrutura de uma coluna termicamente acoplada 
- Balanço de matéria global entre o estágio $1_{1}$ e o estágio $M_{1-1}$

$$
\begin{aligned}
& L_{J-l, K}=R * D+\sum_{i=1}^{M_{l}-2}\left(F_{i}+W_{i}-U_{i}\right) \\
& L_{J, K}=R * D+\sum_{i=1}^{M_{J}-1}\left(F_{i}+W_{i}-U_{i}\right)
\end{aligned}
$$

- Balanço de matéria global entre o estágio $M_{1}$ e o estágio $S_{1-1}$

$$
\begin{aligned}
& L_{J-1, K}=R^{*} D+\sum_{i=1}^{S_{l}-2}\left(F_{i}+W_{i}-U_{i}\right)+V_{11} \\
& L_{J, K}=R^{*} D+\sum_{i=1}^{M_{J}}\left(F_{i}+W_{i}-U_{i}\right)+V_{11}
\end{aligned}
$$

- Balanço de matéria global entre o estágio $S_{1}$ e o estágio $N_{1}$

$$
\begin{aligned}
& L_{J-1, K}=R^{*} D+\sum_{i=1}^{S_{l}-2}\left(F_{i}+W_{i}-U_{i}\right)+V_{11}+L_{N 2} \\
& L_{J, K}=R^{*} D+\sum_{i=1}^{M_{J}}\left(F_{i}+W_{i}-U_{i}\right)+V_{11}+L_{N 2}
\end{aligned}
$$

- Balanço de matéria global entre o estágio $1_{2}$ e o estágio $N_{2}$

$$
\begin{gathered}
L_{J-1, K}=U_{M 1}+\sum_{i=1}^{N_{2}-1}\left(F_{i}+W_{i}-U_{i}\right)+W_{S 1}-V_{11}-L_{N 2} \\
L_{J, K}=U_{M 1}+\sum_{i=1}^{M_{J}}\left(F_{i}+W_{i}-U_{i}\right)+W_{S 1}-V_{11}-L_{N 2}
\end{gathered}
$$

\subsection{Balanço dos estágios internos por componente}

Na sequência de separação termicamente acoplada, são considerados 2 tipos de estágios, aqueles onde há uma interação apenas das vazões de liquido do estágio superior, e a vazão de vapor do estágio inferior, como é mostrado na Figura 4-8, e a outra, que consiste, além das interações dos estágios superior e inferior da coluna. Desse modo também de uma interação entre os estágios da coluna pela qual está acoplada, pelo qual há uma vazão a mais, correspondente a uma vazão de liquido ou de vapor segundo a localização na sequência. Se estiver na zona de 
esgotamento da coluna principal, então esta vazão encontra-se na fase liquida, caso contrario, se estiver localizada na zona de retificação, a vazão lateral extra, corresponde a uma vazão na fase de vapor. Estes estágios são apresentados na Figura 4.9 até a Figura 4.12. Analogamente à determinação dos balanços por componente na coluna convencional, na coluna termicamente acoplada são efetuados os balanços por componente, onde posteriormente são gerados os coeficientes da matriz esparsa.

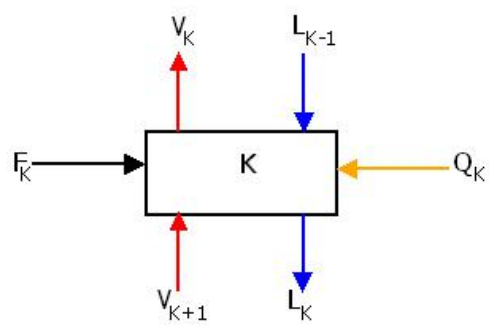

Figura 4.8- Estágio interno sem conexões de fluxos laterais

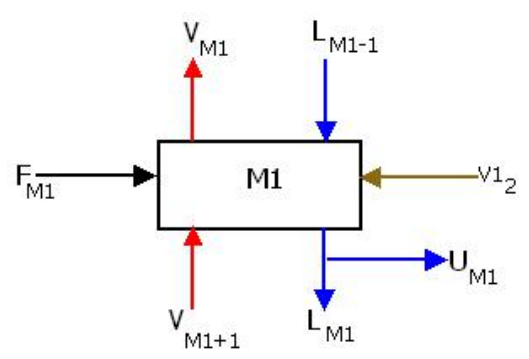

Figura 4.9- Conexão superior da coluna principal

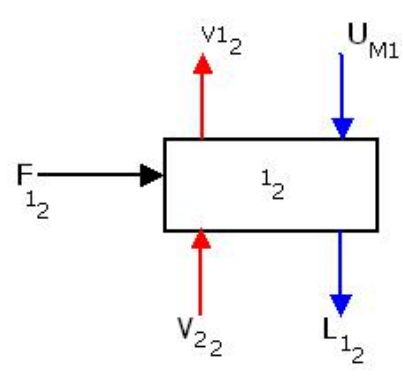

Figura 4.11- Conexão superior da fracionadora

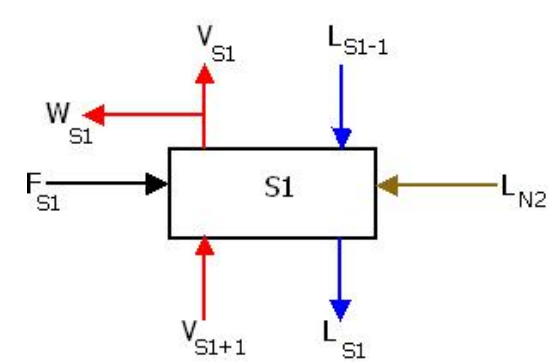

Figura 4.10- Conexão inferior da coluna principal

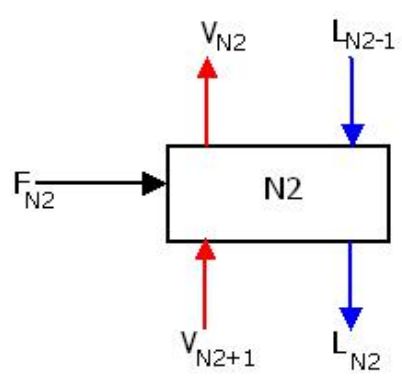

Figura 4.12- Conexão inferior da fracionadora

\subsection{Geração dos coeficientes da matriz esparsa}

Segundo os balanços globais efetuados em cada zona da sequência, junto com os balanços por componente nos estágios das colunas, são obtidos os coeficientes 
correspondentes aos balanços por componentes, obtendo-se uma relação linear similar à relação gerada nas sequências convencionais. A partir dessas relações linearizadas, serão resolvidos os perfis de composições na fase liquida como é mostrada na equação (66).

$$
A_{K} x_{i, J-1, K}+B_{K} x_{i, J, K}+C_{K} x_{i J+1, K}=D_{K}
$$

\subsection{Coeficientes dos elementos tridiagonais}

Do balanço por componente no estágio j, equação (67), é possível visualizar a não linearidade desta equação. Para levá-la ao formato da equação (66), são inseridos os balanços globais em cada zona da sequência, equações (58) até (65), como resultado em cada estágio das colunas. Estas transformações estão representadas nas equações (68) até (71). A distribuição destes coeficientes é exatamente igual à distribuição aplicada a uma coluna convencional, obtendo-se uma diagonal principal com o coeficiente $B_{K, J}$, com uma diagonal superior, representada pelo coeficiente $C_{K, J}$, e uma diagonal adjacente inferior, representada pelo coeficiente $A_{K, J}$

$$
\begin{aligned}
& F_{J, K} z_{I, J, K}+L_{K-l} x_{i, J-1, K}+V_{J+1, K} y_{i, J-1, K}-L_{K} x_{i, J, K}-V_{K} y_{i, J, K}=0 \\
& A_{K, J}=L_{0}+V_{M, J-1}+V_{1 J}+\sum_{i=1}^{J-1}\left(F_{i}+W_{i}-U_{i}\right)_{K} \\
& B_{K, J}=-\left[L_{0}+V_{M, I}+V_{12}+\sum_{i=1}^{J}\left(F_{i}+W_{i}-U_{i}\right)_{K}-V_{K} K_{K}\right] \\
& C_{K, J}=V_{J+l K} K_{J+l K} \\
& D_{K, J}=-F_{1 K} z_{i J K}
\end{aligned}
$$

\subsection{Elementos fora da diagonal}

Os coeficientes fora da diagonal estão relacionados com as conexões que entram tanto na pré-fracionadora quanto na coluna principal. Estes valores são os termos que não estão especificados na equação da matriz tridiagonal equação (72). Na 
Tabela 3.1 são apresentados estes coeficientes para o caso da fracionadora, no estágio $1_{2}$, no estágio $N_{2}$, e assim como para os estágios $M_{1}, S_{1}$ na coluna principal.

$$
A_{K} x_{i, J-1, K}+B_{K} x_{i, J, K}+C_{K} x_{i J+1, K}+\phi=D_{K}
$$

Tabela 4.1- Valores dos elementos fora da diagonal

\begin{tabular}{ccc}
\hline Estágio $\mathrm{J}$ & Valor de $\phi$ & Colocação na matriz esparsa \\
\hline $\mathrm{M}_{1}$ & $V_{12} K_{i, 1,2}$ & $\mathrm{C}\left(1_{2}, \mathrm{M}_{1}\right)$ \\
$1_{2}$ & $U_{M 1}$ & $\mathrm{~A}\left(\mathrm{M}_{1}, 1_{2}\right)$ \\
$\mathrm{N}_{2}$ & $W_{S 1}$ & $\mathrm{C}\left(\mathrm{N}_{2}, \mathrm{~S}_{1}\right)$ \\
$\mathrm{S}_{1}$ & $L_{N 2}$ & $\mathrm{~A}\left(\mathrm{~S}_{1}, \mathrm{~N}_{2}\right)$ \\
\hline
\end{tabular}

Observa-se que dentro da resolução dos balanços efetuados nestes estágios, são gerados os novos coeficientes, para vapor, no caso do estágio $S_{1}$ da coluna principal, com a coordenada correspondente ao estágio $\mathrm{N}_{2}$ da fracionadora, que é $W_{1}$, e a fase liquida corresponde a $L_{N 2}$. Na zona superior da sequência, encontra-se $U_{M 1}$ na fase liquida e $V_{11}$ da fase de vapor entre os estágios $M_{1}$ da coluna principal e o estágio $1_{1}$ na fracionadora. Finalmente, estas relações são apresentadas na Figura 4-13, correspondente a uma matriz esparsa para esta sequência. Nesta matriz, pode-se identificar que desde $I_{1}$ até $N_{1}$, estão localizados os estágios da coluna principal, posteriormente desde $I_{2}$ até $N_{2}$ estão localizados os estágios do fracionador.

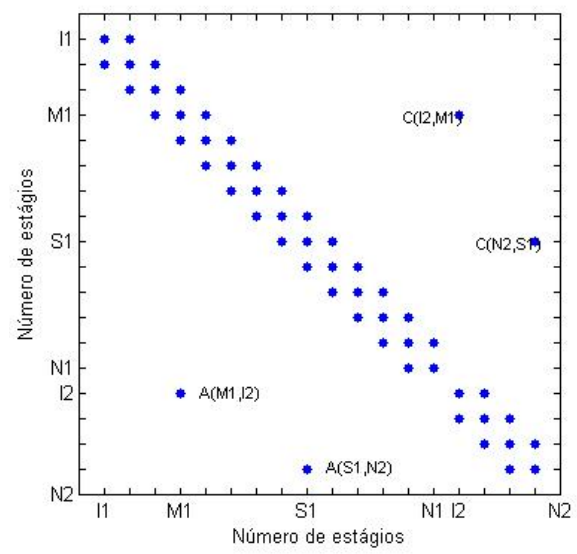

Figura 4.13- Matriz esparsa para uma configuração de colunas termicamente acopladas

\subsection{Balanço de energia}

Para o balanço de energia nesta configuração, a diferença em relação à coluna de separação convencional, está no balanço do refervedor, devido a que são levados 
em conta os balanços de entalpia tanto do fracionador quanto da coluna principal, por meio das conexões existentes entre eles, como é observado na equação (72). Já para o balanço no condensador e a obtenção das novas vazões da fase liquida e da fase de vapor, as equações são similares às equações (54) e (56), respectivamente, determinando os coeficientes $\alpha_{J}, \beta_{J}, \gamma_{J}$, que estão em função das entalpias em cada estágio.

Semelhantemente à equação (55), obtém-se a equação (73).

$Q_{N 1}=\sum_{i=1}^{J}\left(F_{i} h_{i}^{F}-U_{i} h_{i}^{L}-W_{i} h_{i}^{V}\right)-\sum_{i=1}^{N 1-1} Q_{i}-\sum_{i=1}^{N I+1+N 2} Q_{i}-V_{N 2} h_{N 2}^{V}-L_{N} h_{N}^{L}$

Para o critério de convergência para a solução da configuração, é aplicada a mesma tolerância estabelecida para uma coluna convencional, como apresentado na equação (57).

\subsection{Métodos rigorosos de dimensionamento de uma coluna}

\subsubsection{Custo total anualizado, função objetivo.}

O custo do processo de destilação está relacionado ao consumo de recursos, como água, vapor, o custo de instalação da coluna, componentes internos, instalação dos trocadores de calor, e equipamentos auxiliares.

Neste problema será usado o modelo do Total annual cost, TAC (DOUGLAS, 1988)

$$
\begin{aligned}
& T A C_{\text {Col } i}=\left[2.43 K_{\text {Cap }}+0.19\right] C_{\text {Cap }}+C_{O p} \\
& T A C_{\text {Total }}=\sum_{i=1}^{n} T A C_{\text {Col } i}
\end{aligned}
$$

Em que $C_{\text {Cap }}$, é o custo de capital, correspondente ao custo dos equipamentos, trocadores de calor e coluna, $C_{O p}$, é o custo de operação, correspondente ao aquecimento e esfriamento do sistema, $K_{C a p}$, é o fator de ajuste de valor monetário em valor presente, equivalente a $1 / 4 \mathrm{ano}^{-1}$.

Este modelo é propício para uma estimativa inicial, que relacionam ambas variáveis de custo. Por tanto, este modelo de custos, é a função objetivo a minimizar. 
O cálculo para cada um dos custos está no Apêndice $A$, onde são determinados o dimensionamento dos equipamentos e o custo de consumo energético.

\subsubsection{Otimização}

A ferramenta da otimização utilizada para esta avaliação, é a inclusão da função objetivo com penalidade, relacionado com as restrições de pureza nas saídas dos produtos.

Principalmente, o método de penalidade de uma função objetivo não linear é transformar um problema com restrições em uma sequência de problemas sem restrições.

$\min f(X)$

Sujeito a:

$g(X) \leq 0$

$h(X)=0$

Função de penalidade

$\min P(f, g, h, \mathrm{r})$

Em que $P(f, g, h, \mathrm{r})$ é a função de penalidade, $\mathrm{r}$ é um parâmetro de penalidade positivo. Depois da função de penalidade ser estabelecida, é minimizado para uma série de valores que aumentam os valores de $r$, levando a uma aproximação do valor ótimo do problema com restrições (EDGAR, 1988).

\subsubsection{Propósito do uso de restrições com penalidade}

Em contraste com outros métodos de otimização, os métodos que envolvem a função de penalidade, resolvem uma sequência de problemas de otimização sem restrições, cuja solução corresponde à solução do problema original de otimização com restrições (GRIVA Igor, 2009). As vantagens do método de penalidade são que ele não requer que as iterações na busca do mínimo local estejam dentro da região factível. Este método foi escolhido pelas características não lineares das restrições, forçando a região de busca na medida em que os pesos dos parâmetros associados às restrições estejam violando as restrições de pureza dos produtos.

\subsection{Método de projeto de sequências de colunas de destilação ou de projetos não convencionais}

\subsubsection{Otimização das sequências convencionais}

O objetivo é obter uma pureza de produto na saída de destilado, no caso de uma sequência direta de 99\% (molar) de Benzeno na primeira coluna, e de Tolueno na 
segunda. Seguidamente, o mesmo procedimento é efetuado para a sequência indireta, cujos produtos desejados, na primeira coluna, correspondem a Tolueno, e o p-Xileno na segunda. Igualmente, a otimização efetuada para cada sequência e características da alimentação é efetuada mudando o número de estágios e os estágios de alimentação de cada coluna, gerando diversas combinações e avaliando a influência delas para cada configuração.

Portanto, segundo esta definição e sob estas considerações a função objetivo, equação (75) fica:

$\min T A C_{\text {Total }}=\sum_{i=1}^{n} T A C_{\text {Col } i}+\mathrm{r} \sum_{i \in I} g(X)^{2}$

Sujeito a:

$x_{i, \text { Coluna } 1} \geq 0.99$

$x_{i \text { Coluna } 2} \geq 0.99$

O termo da penalização, $\mathrm{r} \sum_{i \in I} g(X)^{2}$, permite uma convergência atinge a factibilidade da separação.

As variáveis de otimização a serem avaliadas nesta análise são as vazões de destilado e as razões de refluxo das colunas das sequências direta e indireta.

A linguagem utilizada para estas otimizações é o MATLAB, com a função fmincon, sendo a função objetivo com as restrições expressas através de penalidade.

\subsection{Problema combinatório}

O problema de otimização para sequências convencionais, esta relacionado com 4 variáveis inteiras para as 2 colunas. Estas variáveis são o número de estágios e os estágios de alimentação para cada uma das colunas.

Cada variável é gerada como um vetor de 3 dimensões. Cada um deles é avaliado com os demais conjuntos de variáveis, obtendo-se um problema combinatório, como observado na Figura 4.14. A configuração será otimizada, calculando-se o custo anualizado mínimo. Levando em conta cada conjunto de dados em cada variável, é gerado um conjunto de 81 otimizações para cada situação onde as características da alimentação são especificadas. 


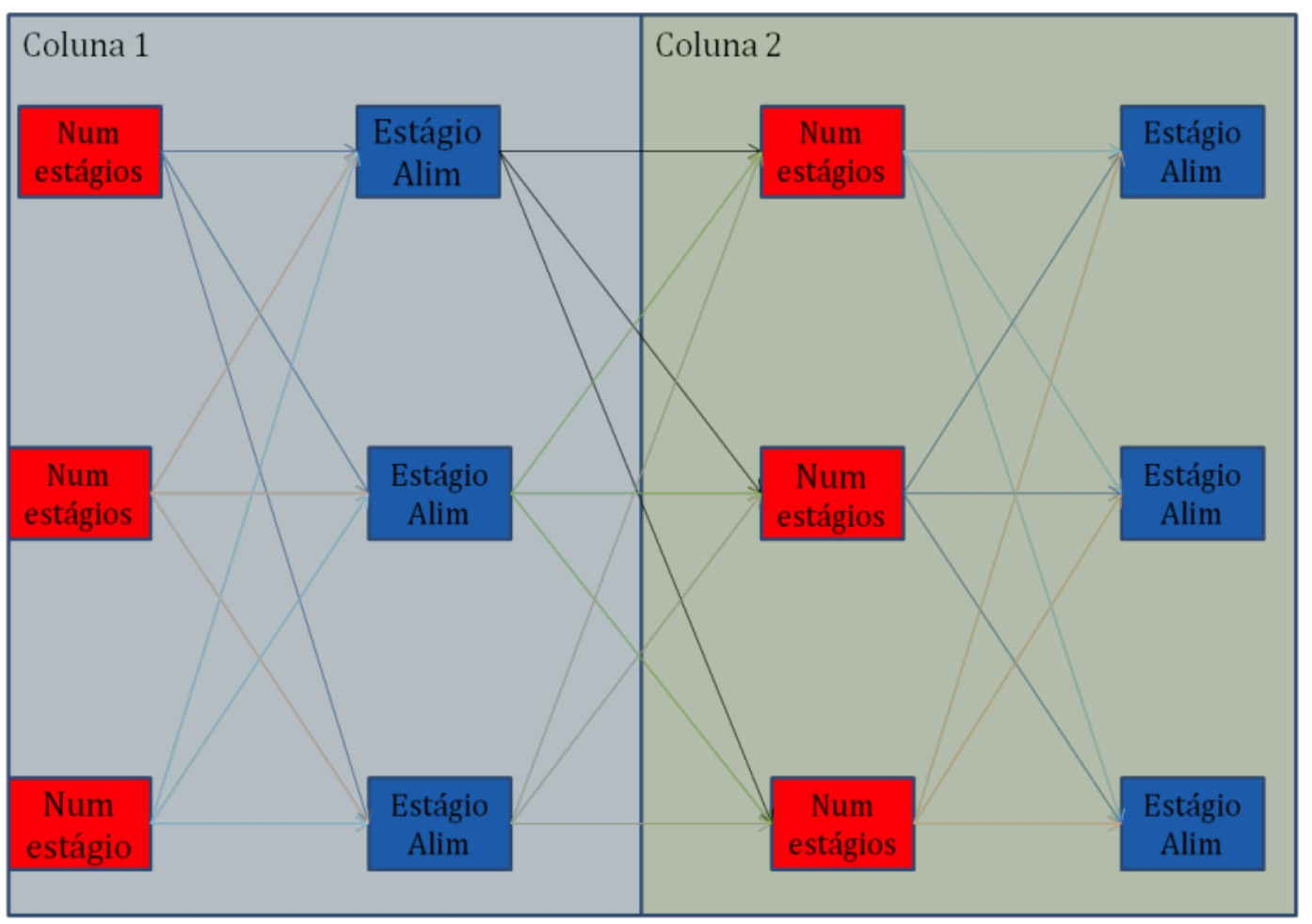

Figura 4-14 Geração de uma combinatoria entre as variaveis inteiras de uma sequência convencional

\subsubsection{Otimização de uma sequências termicamente acopladas}

Segundo os resultados da análise dos graus de liberdade, foram estabelecidas 5 vaiáveis de projeto a serem submetidos à rotina de otimização, cuja variação é limitada entre limites para a vazão de destilado, e a razão de refluxo. As outras 3 variáveis, conexões laterais, e saída lateral, estão submetidas a restrições relacionadas através dos balanços entre as colunas. Estas considerações permitirão minimizar o custo mínimo em uma coluna com parede dividida.

Seguindo estas hipóteses, o problema de otimização para este sistema é, equação (78).

$\min T A C_{\text {Total }}$

Com as seguintes restrições relacionadas com a fração molar do componente i nas saídas da coluna principal, equação (79), que correspondem à localização das saídas de benzeno, tolueno, $p$-Xileno.

$x_{i,} \geq 0.99$ 
Com relação às sequências convencionais, na sequência de uma coluna de destilação termicamente acoplada são geradas mais 3 restrições não lineares que relacionam-se com as vazões nas conexões, liquida e vapor, que saem da coluna principal e alimentam a fracionadora. Estas restrições estão diretamente relacionadas com a vazão de destilado e a razão de refluxo da coluna principal determinadas da seguinte maneira:

1. Para a conexão superior, que corresponde à vazão liquida no estágio $M_{1}$, $U_{M 1}$, a restrição é estabelecida na equação (80), com relação à razão de refluxo, $r$, e a vazão de destilado $D$.

$U_{M 1} \leq r * D$

2. A saída lateral, estágio SL, correspondente à vazão liquida do produto intermédio $U_{S L}$ esta sujeita à vazão que provem da conexão superior $U_{M 1}$ através da equação (81)

$U_{S L} \leq r * D-U_{M 1}$

3. Para a conexão inferior, estágio $S_{1}$ vazão de vapor $W_{S 1}$ que conecta a coluna principal com a fracionadora, se estabelece uma restrição que igualmente esta relacionada com a razão de refluxo $r$ e a vazão de destilado $D$, em função da vazão interna de vapor dentro da coluna principal pela equação (82)

$W_{S 1} \leq(r+1) * D$

\subsubsection{Métodos curtos}

\subsection{Método Aminnudim}

Inicialmente, é preciso determinar a viabilidade da separação, usando o método de valor na fronteira (DOHERTY, 2001), e aplicando estágios no equilíbrio, são estimados os parâmetros da torre.

Por outro lado, no desenvolvimento deste método, são assumidas duas simplificações; fluxo molar constante, volatilidades relativas constantes. Além disso, a coluna tipo Petlyuk, é calculada assumindo 3 colunas convencionais acopladas entre si, Figura 4.15. 


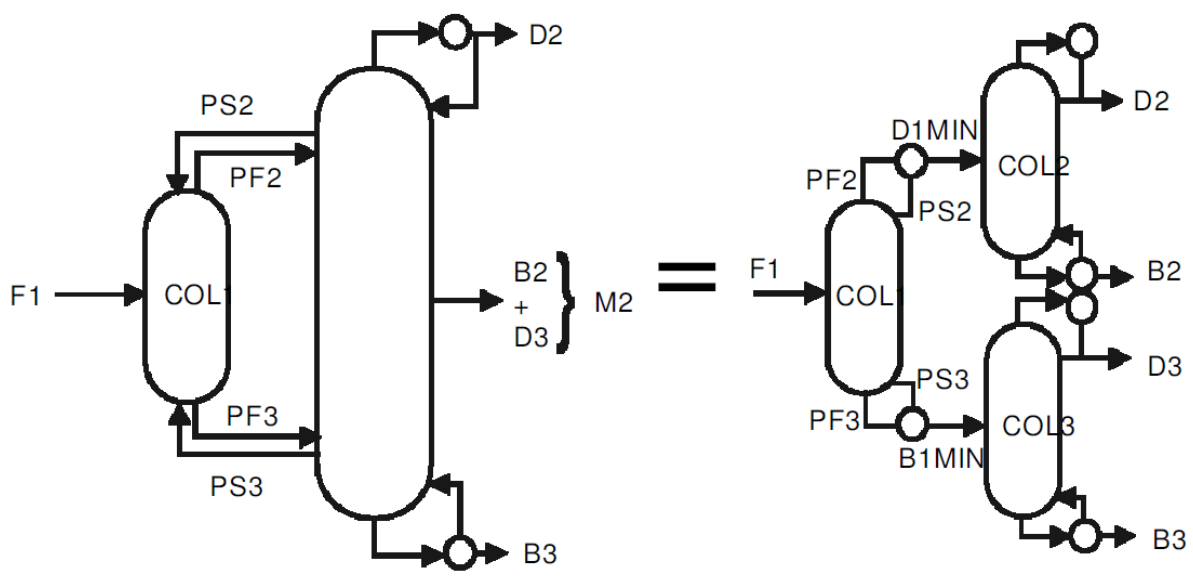

Figura 4.15- Configuração de 3 colunas convencionais. Método de Amminudim

$\mathrm{Na}$ coluna principal, as composições do produto intermediário devem satisfazer às condições de obtenção, levando a que o destilado da parte inferior da coluna seja igual ao fundo da coluna superior, além de satisfazer os balanços de matéria.

No desenvolvimento do método, são estabelecidas as restrições não lineares representadas através dos balanços de massa, energia e equilíbrio, e desenvolvido por meio de uma programação não linear, especificando as condições da alimentação, requerimentos de produto, representado como frações de recuperação, além da condição térmica da alimentação. (AMMINUDIN, SMITH, \& TOWLER, 2001).

\subsection{Método Cerda-Westerberg}

O objetivo deste método é encontrar valores aproximados para os diferentes parâmetros de operação na condição limite de refluxo.

As colunas podem ser consideradas como uma serie de separadores interligados que separam os componentes de volatilidades relativas, próximas, obtendo as diferentes relações de refluxo apropriadas para a dita separação, além disso, das outras fracionadoras em que estiverem ligados.

Nas sequências do tipo Petlyuk, o número de parâmetros independentes estão na mesma quantidade que o número de fracionadoras que interagem no sistema. Nesta sequência, o numero de fracionadoras é 3 , e 2 são as variáveis independentes neste sistema, Figura 4.16. 


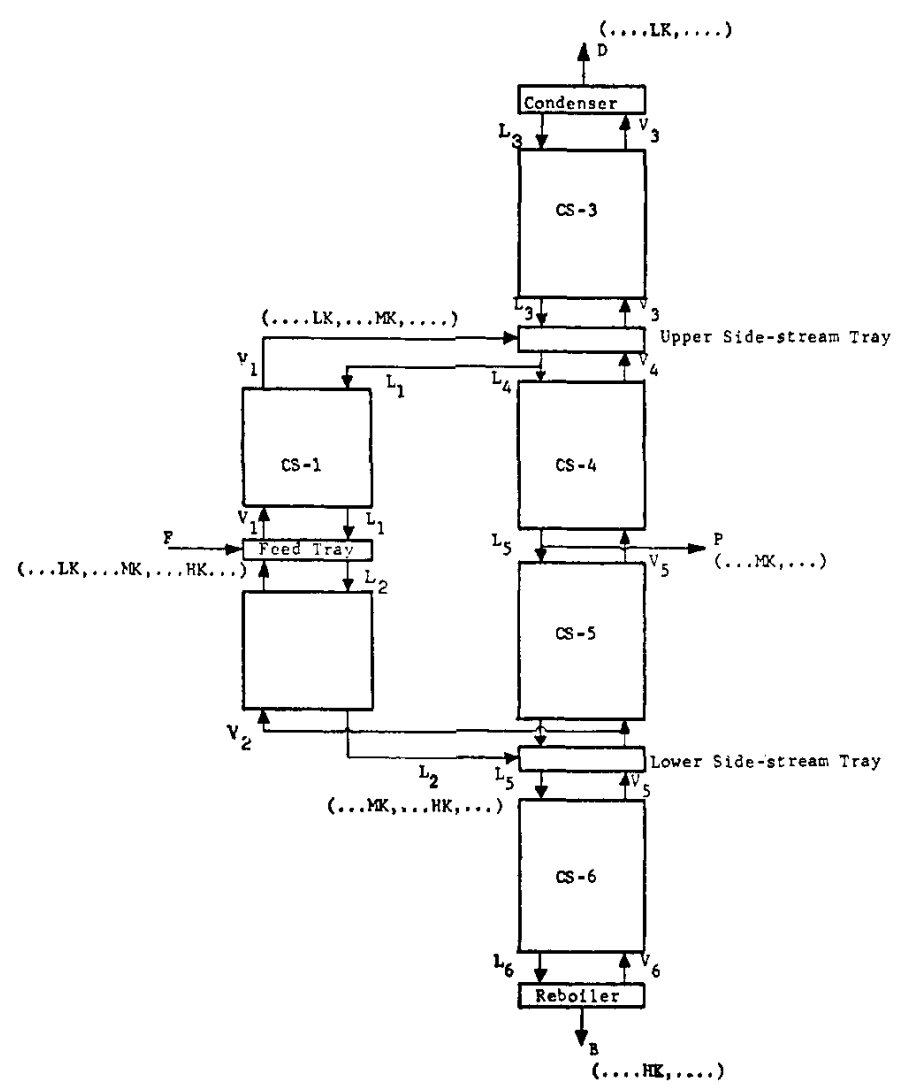

Figura 4.16- Configuração coluna Petlyuk, método Cerda-Westerberg Parâmetros de operação

Razão de refluxo da coluna principal

$$
R=\frac{L_{3}}{D}
$$

Fração de liquido de retorno à fracionadora

$$
x_{L}=\frac{L_{1}}{L_{3}}
$$

Fração de vapor que retorna à fracionadora

$$
x_{V}=\frac{V_{2}}{V_{6}}
$$

Razão do refervedor na coluna principal

$$
S=\frac{V_{6}}{B}
$$

Razão dos parâmetros com a $S=(r+1)\left(\frac{D}{B}\right)(1+q)\left(\frac{F}{B}\right)$
condição térmica na alimentação $q$

Além destes parâmetros, também são levados em conta o grau de separação dos componentes distribuídos na fracionadora, nas seções 1 e 2 das vazões de líquidos 
e vapor $\left(V_{1}-L_{1}\right)$ e $\left(V_{2}-L_{2}\right)$, chamado $X_{V, m}$. Se no sistema existirem as condições limite dos fluxos no pré-fracionador, reduzindo $R X_{L}$, são gerados zonas Pinch ao redor das alimentações dos outros 2 fracionadoras que compõem a coluna principal. Definindo a variável $X_{V, m}$

$$
\left(r^{\prime} X_{V}\right)_{m}=\left(r^{\prime} X_{L}\right)_{m}\left(\frac{D}{B}\right)+q\left(\frac{F}{B}\right) \frac{\left(L_{2}-V_{2}\right)_{m}}{B}
$$

Por causa disso, somente 2 parâmetros do sistema são independentes. (CERDA \& WESTERBERG, 1981)

\subsubsection{Métodos rigorosos}

\subsection{Problema combinatório}

O problema de otimização anteriormente estabelecido, é gerado apenas para um determinado número de estágios dentro de cada coluna, um determinado número de estágios de entradas e saídas para cada uma das vazões que estão interagindo entre elas. Porém nesta otimização, os estágios onde estão localizadas as vazões será alterada, visando encontrar uma configuração com o mínimo custo, mostrandose que a localização destas vazões influi consideravelmente na determinação deste custo mínimo.

Estas variáveis correspondem concretamente às seguintes condições:

- O estagio da conexão superior de liquido que sai da coluna principal até a fracionadora, estágio $\mathrm{M}_{1}$.

- O estágio onde está localizada a saída lateral do produto intermédio $S L$.

- O estagio da conexão inferior do vapor que sai da coluna principal até o prefracionador, estágio $\mathrm{S}_{1}$.

- O estágio de alimentação, localizado na fracionadora $N_{F}$.

- O número de estágios da coluna principal $\mathrm{N}_{2}$.

- O número de estágios da fracionadora $\mathrm{N}_{1}$.

- Na mesma maneira que no desenvolvimento das sequências convencionais, cada variável é gerada como um vetor de dimensão 3 em que cada um deles é avaliado com os demais conjuntos de variáveis, obtendo-se uma análise combinatória, cuja configuração será otimizada. Calcula-se o mínimo custo anualizado, levando em conta cada conjunto de dados em cada variável, 
sendo gerado um conjunto de 729 otimizações para cada situação em que as características da alimentação são especificadas. 


\section{RESULTADOS E DISCUSSÃO}

\subsection{Caso de estudo}

O sistema químico estudado é uma separação ternária (Benzeno, Tolueno, Pxileno), com uma fração de recuperação de $99,9 \%$ de cada um dos 3 componentes. São estudados três casos com as seguintes características de alimentação, apresentadas na Tabela 5.1:

Tabela 5.1- Características das condições da alimentação

\begin{tabular}{|c|c|c|c|}
\hline $\begin{array}{l}\text { Vazão de alimentação (kmol/h) } \\
\text { Pressão (bar) } \\
\text { Condicão da alimentação }\end{array}$ & $\begin{array}{l}200 \\
1,01325 \\
\text { Liquido sa }\end{array}$ & urado & \\
\hline $\begin{array}{l}\text { Composições na alimentação } \\
\text { (\%mol) }\end{array}$ & Benzeno & Tolueno & P-Xileno \\
\hline Caso 1 & 0,8 & 0,1 & 0,1 \\
\hline Caso 2 & 0,1 & 0,8 & 0,1 \\
\hline Caso 3 & 0,1 & 0,1 & 0,8 \\
\hline
\end{tabular}

\subsection{Graus de liberdade para sequências convencionais e configuração termicamente acoplada}

Para estes tipos de separações, com múltiplos estágios, em que existe equilíbrio de fases e componentes é preciso estabelecer o número de variáveis independentes para desenvolver um projeto ótimo.

\subsubsection{Graus de liberdade de sequências convencionais}

Foi efetuada uma análise de graus de liberdade em um sistema de destilação de sequência direta, que é estruturalmente análogo ao de uma sequência convencional indireta. Esta análise é efetuada inicialmente para cada um dos equipamentos que compõem o sistema de separação, condensador total; refervedor parcial; divisor; estágio de alimentação, seção de retificação e seção de esgotamento.

Para o desenvolvimento efetivo da análise dos graus de liberdade na coluna de destilação, são identificadas as correntes redundantes, onde estão as interconexões de cada parte do equipamento, vazões entre trocadores de calor e coluna, vazões de entrada e saída do estágio de alimentação, e também, as vazões de conexão entre o refervedor e a coluna, identificados na Figura 5.1. 


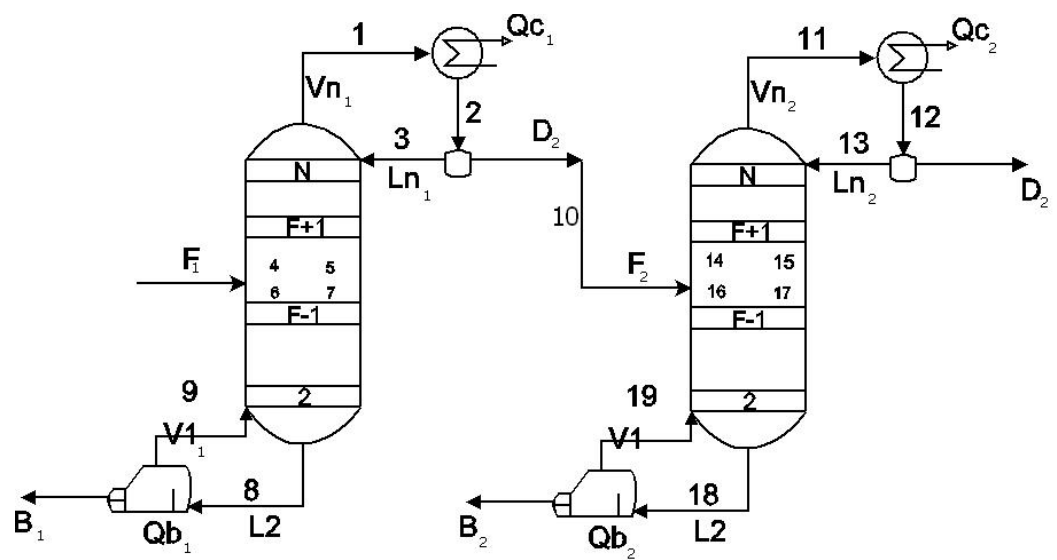

Figura 5.1- Análise de graus de liberdade em uma sequência convencional $\mathrm{Na}$ análise dos graus de liberdade, é determinado o número de variáveis que são levadas em conta para estabelecer o problema de projeto de separação. Isto é analisado para cada equipamento do sistema, condensador, divisor, coluna, refervedor, como mostrado na Tabela 5.2.

\begin{tabular}{lc}
\multicolumn{1}{c}{ Tabela 5.2- Variáveis obtidas para coluna com uma alimentação } \\
\hline \multicolumn{1}{c}{ Equipamento } & Graus de liberdade \\
\hline Condensador total & $\mathrm{C}+4$ \\
Divisor & $\mathrm{C}+5$ \\
Estágios internos acima da & $2 \mathrm{M}_{1}+2 \mathrm{C}+5$ \\
alimentação & $3 \mathrm{C}+8$ \\
Estágio de alimentação & $2 \mathrm{M}_{2}+2 \mathrm{C}+5$ \\
$\begin{array}{l}\text { Estágios intermédios } \\
\text { inferiores ao estágio alim. }\end{array}$ & $\mathrm{C}+4$ \\
$\begin{array}{l}\text { Refervedor parcial } \\
\mathrm{M}_{\mathrm{T}}=\mathrm{M}_{1}+\mathrm{M}_{2}+3\end{array}$ & $2\left(\mathrm{M}_{1}+\mathrm{M}_{2}-3\right)+10+31$ \\
Correntes redundantes & $9(\mathrm{C}+2)$ \\
\multicolumn{2}{c}{ Total } \\
\hline
\end{tabular}

Em que $M_{1}$, correspnde aos estágios da coluna que estão acima do estágio de alimentação, $\mathrm{M}_{2}$ são os estágios que estão abaixo do estágio de alimentação e $\mathrm{C}$ é o número de componentes da mistura. Por outra parte, na Tabela 5.3, apresenta-se o número de graus de liberdade da sequência completa, coluna 1 e 2, cujas especificações compõem restrições do modelo de otimização, e descritas no modelo matemático. Tais graus de liberdade permitem calcular as diferentes variáveis, após terem sido estabelecidas as especificações do projeto, Tabela 5.4 .

Tabela 5.3- Graus de liberdade obtidas para sequência convencional com uma alimentação

\section{Equipamento}

Coluna 1

Coluna 2

Correntes redundantes

\section{Graus de liberdade}

$2 \mathrm{M}_{\mathrm{T}}+\mathrm{C}+7$

$2 \mathrm{~N}_{\mathrm{T}}+\mathrm{C}+7$

$-(\mathrm{C}+3)$

Total $\quad 2 \mathrm{M}_{\mathrm{T}}+2 \mathrm{~N}_{\mathrm{T}}+\mathrm{C}+11$ 
Tabela 5.4- Especificações das variáveis para uma sequência convencional

\begin{tabular}{lc}
\multicolumn{1}{c}{ Variável } & Graus de liberdade \\
\hline Pressão nos estágios Coluna 1 & $\mathrm{N}_{\mathrm{T}}$ \\
Pressão nos estágios coluna 2 & $\mathrm{M}_{\mathrm{T}}$ \\
Estágios adiabáticos na coluna 1 e & $\mathrm{M}_{\mathrm{T}}+\mathrm{N}_{\mathrm{T}}-4$ \\
2, exceto nos trocadores de calor & $\mathrm{C}+2$ \\
Corrente de alimentação & 2 \\
$\begin{array}{l}\text { Pressão dos divisores } \\
\text { Divisores adiabáticos }\end{array}$ & 2 \\
Fase da corrente conexão entre as & 1 \\
colunas 1 e 2 & Total \\
\hline
\end{tabular}

Os graus de liberdade com especificações para 1 sequência convencional são 8 . Para o método de valor de fronteira estas variáveis de entrada estão especificadas da seguinte maneira, Tabela 5.5.

Tabela 5.5- Especificação de variaveis em sequências convencionais usando método de valor de fronteira

\begin{tabular}{lc}
\hline \multicolumn{1}{c}{ Variável } & $\begin{array}{c}\text { Número de variáveis } \\
\text { especificadas }\end{array}$ \\
\hline Razões de refluxo nas colunas da sequência & 2 \\
Frações de recuperação & 4 \\
Frações molares nos produtos & 2 \\
Total & $\mathbf{8}$ \\
\hline
\end{tabular}

Como variáveis de resposta, no desenvolvimento do método estão o número de estágios, estágio de alimentação, a vazão de destilado e fundo e razão de refluxo como variáveis de entrada para o método rigoroso. Tabela 5.6.

Tabela 5.6- Especificação de variaveis em sequências convencionais usando rigoroso de ponto de bolha

\begin{tabular}{lc}
\hline \multicolumn{1}{c}{ Variável } & $\begin{array}{c}\text { Número de variáveis } \\
\text { especificadas }\end{array}$ \\
\hline Número de estágios & 2 \\
Vazões de destilado & 2 \\
Razões de refluxo & 2 \\
Estágios & 2 \\
alimentação & de \\
Total & $\mathbf{8}$ \\
\hline
\end{tabular}

Por tanto, estes 2 métodos serão complementares, no sentido em que o método rigoroso e o método de valor de fronteira permitirá, através de um valor inicial, otimizar as colunas por meio do método rigoroso, simultaneamente.

\subsubsection{Graus de liberdade para uma coluna termicamente acoplada}

No projeto de colunas termicamente acopladas, foi realizada uma análise de graus de liberdade visando comprovar que o número de variáveis a serem especificadas seja consistente, observado na Figura 5.2. Aqui, são somados os graus de liberdade 
em cada seção da coluna, onde também são eliminadas as variáveis redundantes. $\mathrm{Na}$ Tabela 5.7 estão analisados os graus de liberdade para a coluna principal, que inclui os trocadores de calor, o divisor, e os estágios internos $\mathrm{Na}$ Tabela 5.8, estão determinados para a fracionadora, que contém somente estão os estágios que a compõem.

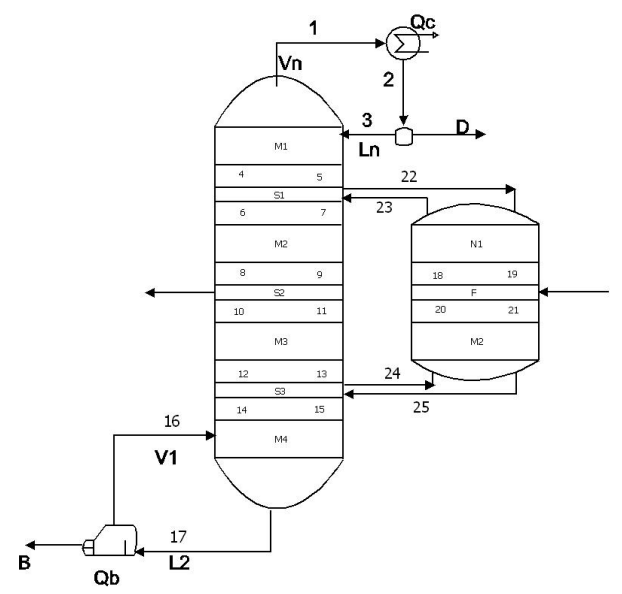

Figura 5.2- Análise dos graus de liberdade em uma coluna termicamente acoplada

Tabela 5.7- Graus de liberdade para a coluna principal

\begin{tabular}{|c|c|}
\hline Equipamento & Graus de liberdade \\
\hline Condensador total & $\mathrm{C}+4$ \\
\hline Divisor & $C+5$ \\
\hline Estágios internos M1 & $2\left(M_{1}\right)+2 C+5$ \\
\hline Estágio S1 (conexão) & $3 C+9$ \\
\hline Estágios internos M2 & $2\left(M_{2}\right)+2 C+5$ \\
\hline Estágio S2 (Saída lateral) & $2 \mathrm{C}+7$ \\
\hline Estágios internos M3 & $2\left(M_{3}\right)+2 C+5$ \\
\hline Estágio S3 (conexão) & $3 C+9$ \\
\hline Estágios internos M4 & $2\left(M_{4}\right)+2 C+5$ \\
\hline Refervedor parcial & $\mathrm{C}+4$ \\
\hline$M_{T}=M_{1}+M_{2}+M_{3}+M_{4}+5$ & $2\left(M_{T}-5\right)+19 C+58$ \\
\hline Correntes redundantes & $-17(C+2)$ \\
\hline & $\Sigma\left(N_{D}\right)=2 M_{T}+2 C+14$ \\
\hline
\end{tabular}

Tabela 5.8- Graus de liberdade para a coluna fracionadora

$$
\begin{aligned}
& \quad \text { Equipamento } \\
& \text { Estágios internos M1 } \\
& \text { Estágio } \mathrm{S} 1 \text { (Alimentação) } \\
& \text { Estágios internos M2 } \\
& \text { Correntes redundantes } \\
& \mathrm{N}_{\mathrm{T}}=\mathrm{N}_{1}+\mathrm{N}_{2}+1
\end{aligned}
$$$$
\text { Graus de liberdade }
$$$$
2\left(\mathrm{~N}_{1}\right)+2 \mathrm{C}+5
$$$$
3 \mathrm{C}+8
$$$$
2\left(\mathrm{~N}_{2}\right)+2 \mathrm{C}+5
$$$$
-4(\mathrm{C}+2)
$$$$
2\left(\mathrm{~N}_{\mathrm{T}}-1\right)+3 \mathrm{C}+10
$$$$
\text { Total } \quad \Sigma\left(\mathrm{N}_{\mathrm{D}}\right)=2 \mathrm{~N}_{\mathrm{T}}+3 \mathrm{C}+8
$$

$\mathrm{Na}$ análise, as correntes redundantes totais são 25, 17 que corresponde à coluna principal, 4 que estão internamente na fracionadora, e as restantes as conexões. 
Para obter uma especificação adequada do sistema, são especificadas as variáveis da Tabela 5.10.

Tabela 5.9- Graus de liberdade para uma sequência termicamente acoplada

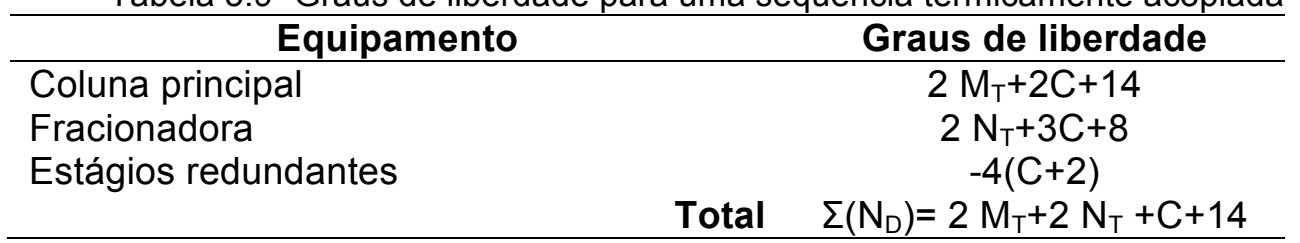

Tabela 5.10- Especificação de variáveis para uma sequência termicamente acoplada

\begin{tabular}{lc}
\multicolumn{1}{c}{ Especificação de variáveis } & Número de variáveis \\
\hline Pressão nos estágios coluna principal & $\mathrm{M}_{\mathrm{T}}$ \\
Pressão nos estágios fracionadora & $\mathrm{N}_{\mathrm{T}}$ \\
Estágios adiabáticos na coluna principal e & \\
fracionadora exceto o refervedor e o & $\mathrm{M}_{\mathrm{T}}+\mathrm{N}_{\mathrm{T}}-2$ \\
condensador & $\mathrm{C}+2$ \\
Corrente de alimentação & 1 \\
Pressão do divisor & 1 \\
Divisor adiabático & 1 \\
Fase líquida da saída lateral & 11 \\
Total graus de liberdade & \\
\hline
\end{tabular}

Ainda faltando 11 variáveis para completar os graus de liberdade, na Tabela 5.9, estão especificadas as variáveis de projeto, cujo propósito será minimizar o TAC dentro da rotina proposta de otimização, usando variáveis de processo, continuas, como no caso das vazões, razão de refluxo, e as variáveis inteiras, no caso do número de estágios nas colunas e a localização das vazões de entrada, conexões e saída lateral, como são apresentadas na Tabela 5.11.

Tabela 5.11- Especificação de variáveis de projeto para uma coluna termicamente acoplada

\begin{tabular}{|c|c|}
\hline Especificação de variáveis & Número de variáveis \\
\hline Vazão de destilado & 1 \\
\hline Razão de refluxo & 1 \\
\hline $\begin{array}{l}\text { Vazão de líquido na conexão superior da } \\
\text { coluna principal }\end{array}$ & 1 \\
\hline $\begin{array}{l}\text { Vazão de vapor na conexão inferior da } \\
\text { coluna principal }\end{array}$ & 1 \\
\hline $\begin{array}{l}\text { Vazão de produto intermédio na saída } \\
\text { lateral da coluna principal }\end{array}$ & 1 \\
\hline $\begin{array}{l}\text { Número de estágios (Coluna principal e } \\
\text { freacionadora) }\end{array}$ & 2 \\
\hline Estágio de alimentação & 1 \\
\hline $\begin{array}{l}\text { Estágios das conexões na coluna } \\
\text { principal }\end{array}$ & 2 \\
\hline Estágio de saída de produto intermédio & 1 \\
\hline
\end{tabular}

Na maioria das operações de separação, são conhecidas ou são estabelecidas as variáveis relacionadas com as condições da alimentação, transmissão e troca de calor dentro dos estágios, e também as pressões delas. As outras especificações 
podem ser substituídas por outras, porém devem ser matematicamente independentes. Por esse motivo as variáveis que estão especificadas na Tabela 5.11 serão conhecidas ou especificadas. Também existem outras variáveis que também podem ser especificadas, tais como a carga de calor no condensador, no refervedor e vazão máxima de vapor na coluna (SEADER \& HENLEY, 1981).

Para este problema, não foram especificadas as cargas de calor no refervedor nem no condensador, devido a que no método de ponto de bolha estas variáveis são dependentes do balanço de energia dentro do sistema. A vazão máxima de vapor não foi levada em conta por duas razões: a primeira, que este problema é um problema de projeto, e a coluna não é uma coluna existente, em funcionamento; além disso, esta variável é uma resposta do método iterativo.

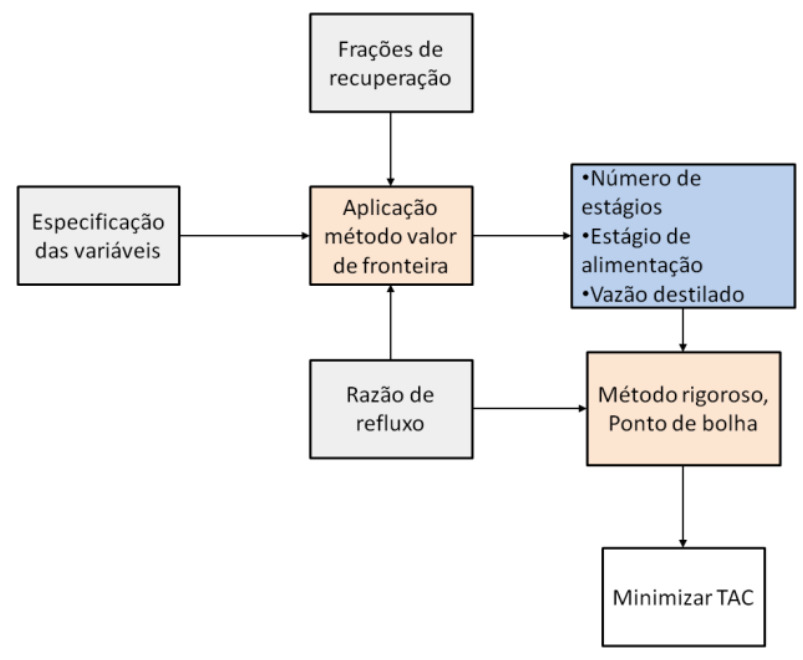

Figura 5.3- Aplicação das variáveis especificadas para os métodos de destilação usados

\subsection{Factibilidade da separação}

Um problema de separação, no caso de um problema de projeto, as condições da alimentação são fornecidas, e também a fração a ser recuperada em termos de fração de recuperação. Pelo qual, existintindo uma informação na distribuição dos produtos dentro da coluna. Uma produção factível refere-se a que sempre é possível atingir uma distribuição do produto, com um número de estágios, e uma razão de refluxo apropriado (AMMINUDIN, et. al, 2001). Esta distribuição dos produtos através da coluna é representada como os perfis de concentração dos componentes da mistura, usando os balanços em cada estágio. Se estes perfis de concentrações se interceptarem, Figura 5.4B, então a produção sob estas condições especificadas são 
possíveis de realizar, se não, seria uma separação impossível, como resultado apresentado na Figura 5.4A. (DOHERTY, 2001).

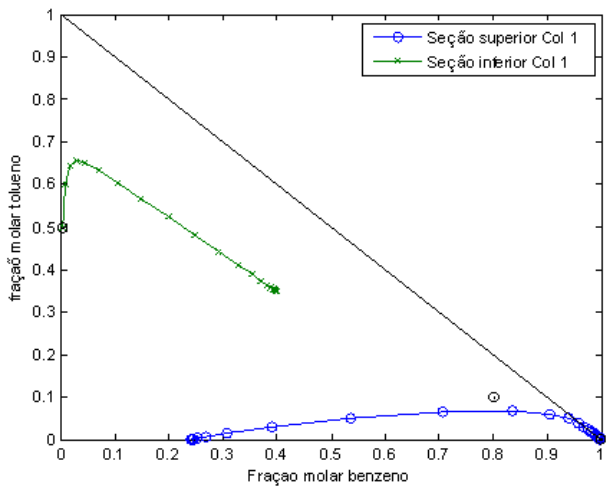

A. Separação naõ factível

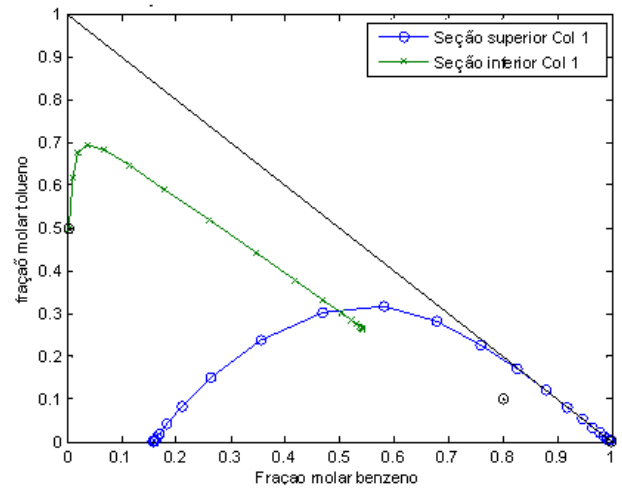

B. Separação factível

Figura 5.4- Resultados Factibilidade de separação

Obtiveram-se os diferentes perfis de concentrações da fase líquida, gerados a partir dos diferentes balanços de energia, matéria, e do equilíbrio líquido-vapor da seção de topo até o estágio de alimentação e da seção de fundo de igual maneira, sendo os perfis destas duas zonas integrados. Uma coluna de separação é fatível se os 2 perfis se interceptarem.

\subsubsection{Razão de refluxo mínima}

No método de valor de fronteira a representação do refluxo mínimo é aquela onde o ponto pinch do perfil de enriquecimento intercepta em algum ponto o perfil de esgotamento, e a separação é factível com um número infinito de estágios, ilustrado pela Figura 5.5.

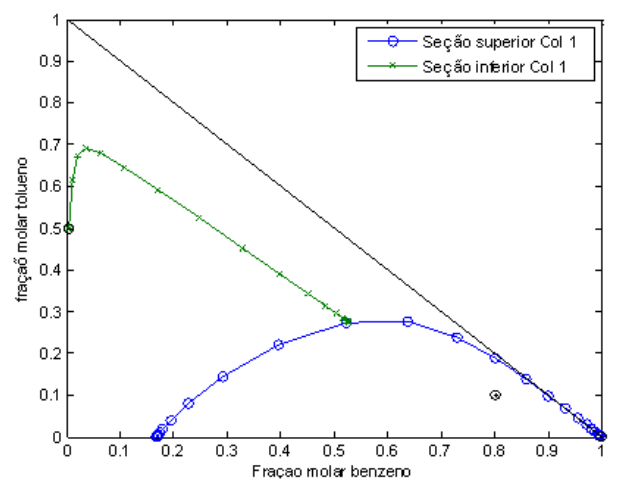

Figura 5.5- Refluxo mínimo método valor de fronteira

Este parâmetro será um das restrições do problema de otimização, garantindo uma separação factível. 


\subsection{Análise de sensibilidade com método de valor de fronteira para as sequências convencionais}

\subsubsection{Parâmetros de inicialização}

A seguir são apresentados os resultados de sensibilidade na sequência, usando diferentes relações de refluxo.

Foi feita uma variação da razão de refluxo para avaliar os efeitos nas demais variáveis dependentes, cargas de calor no refervedor e custo total anualizado, por meio de uma análise de sensibilidade, permitindo obter um valor inicial para a rotina de otimização, cujo objetivo é minimizar o custo total anualizado. Entretanto, nesta análise, foram escolhidos os estágios da coluna e a carga de calor visando observar a incidência geral da razão de refluxo. O comportamento o custo total anualizado em relação a estas variáveis é observado.

Nas Figuras 5.6 estão representadas as cargas de calor em função da razão de refluxo para cada composição da alimentação nas sequências indiretas. Através das relações estabelecidas deste dimensionamento, pode ser observado que existe uma alta dependência na mudança da razão de refluxo, devido a que estes parâmetros, altura e área, serem proporcionais ao fluxo interno de vapor dentro da coluna, que também é determinado por esta relação, através de balanços de matéria.

Nas figuras 5.6 e 5.8, estão representadas as cargas de calor dos condensadores e refervedores das colunas da sequência direta, existindo um acréscimo nas cargas de calor causado principalmente pelo aumento razão de refluxo relacionada através dos balanços de energia no topo e no fundo da coluna. 


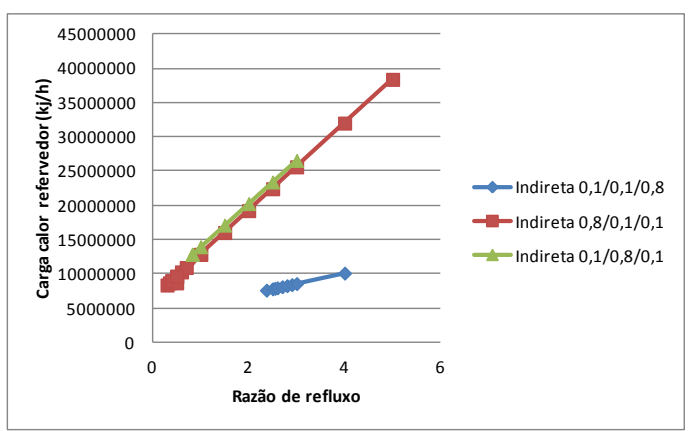

A. Coluna 1

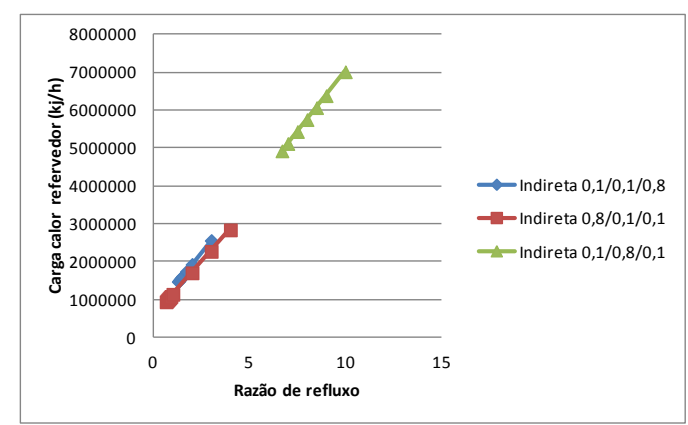

B. Coluna 2

Figura 5.6- Cargas de calor no condensador em uma sequência de separação convencional indireta

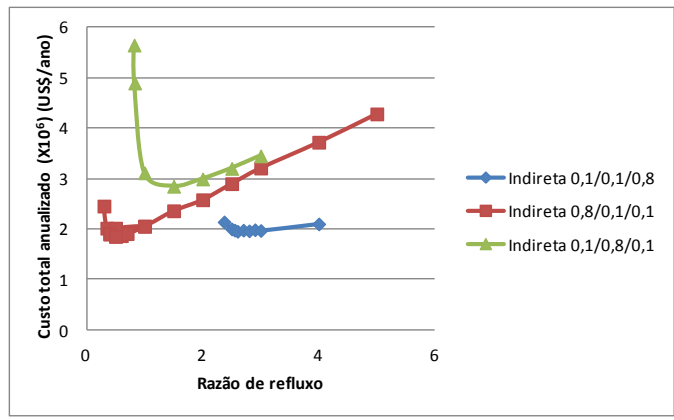

A. Coluna 1

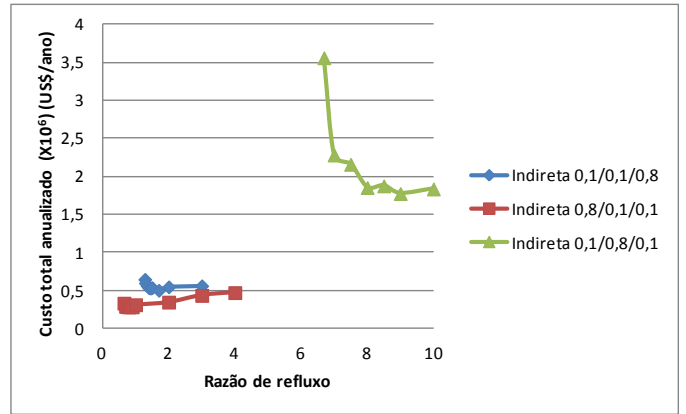

B. Coluna 2

Figura 5.7- Custo total anualizado em uma sequência de separação convencional indireta avaliada a diferentes razões de refluxo

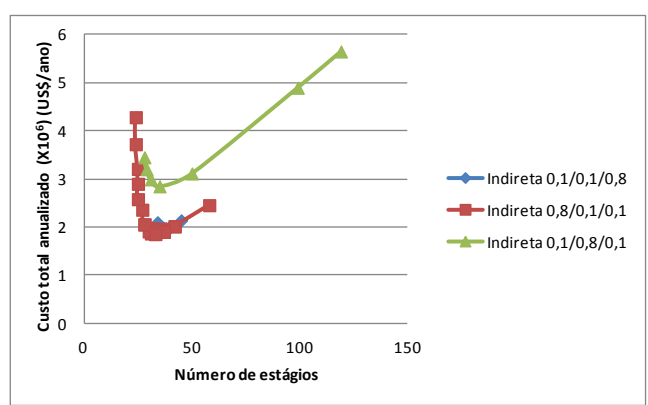

A. Coluna 1

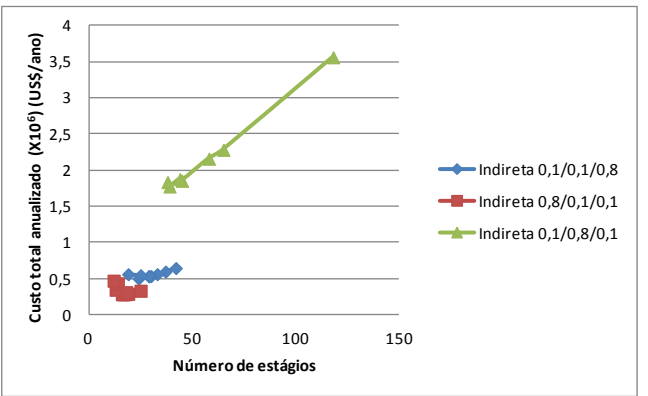

B. Coluna 2

Figura 5.8- Custo total anualizado em uma sequência de separação convencional indireta com diferentes números de estágios

A partir da avaliação preliminar, com o método de valor de fronteira e diferentes condições de alimentação. Além disso, também foram avaliados os diferentes casos nas sequências diretas de colunas de destilação, Tabela 5.12, e as sequências indiretas, Tabela 5.13. Estes resultados obtidos de número de estágios, estágio de localização do estágio de alimentação, usando a análise de sensibilidade, avaliação a razão de refluxo para cada sequência para cada configuração. É observado que oo custo total anualizado para uma sequência indireta, quanto P-xileno é abundante, é menor. Em uma sequência direta, o custo é menor quando o Bezeno está em maior abundância. 
Tabela 5.12- Resultados preliminares para sequência direta na análise de sensibilidade

\begin{tabular}{llll}
\hline & $0,1 / 0,8 / 0,1$ & $0,8 / 0,1 / 0,1$ & $0,1 / 0,1 / 0,8$ \\
\hline $\mathrm{R}_{\min }$ Coluna 1 & 0,73 & 0,63 & 0,24 \\
$\mathrm{R}_{\min }$ Coluna 2 & 0,98 & 1,29 & 4,59 \\
Razão de refluxo a TAC mínimo coluna 1 & 11,5 & 0,75 & 5,00 \\
Razão de refluxo a TAC mínimo coluna 2 & 1,5 & 1,5 & 6,5 \\
Custo total anualizado (TAC) na sequência & & & \\
(US\$) & $5,23 \times 10^{6}$ & $2,31 \times 10^{6}$ & $2,34 \times 10^{6}$ \\
Número de estágios coluna 1 & 43 & 36 & 33 \\
Estágio de alimentação coluna 1 & 20 & 26 & 22 \\
Número de estágios coluna 2 & 40 & 43 & 34 \\
Estágio de alimentação coluna 2 & 21 & 21 & 9 \\
\hline
\end{tabular}

Tabela 5.13- Resultados preliminares para sequência indireta na análise de sensibilidade

\begin{tabular}{llll}
\hline & $0,1 / 0,8 / 0,1$ & $0,8 / 0,1 / 0,1$ & $0,1 / 0,1 / 0,8$ \\
\hline Rmin Coluna 1 & 1,28 & 0,28 & 0,81 \\
Rmin Coluna 2 & 2,37 & 0,30 & 6,69 \\
Razão de refluxo a TAC mínimo coluna 1 & 2,7 & 0,5 & 1,5 \\
Razão de refluxo a TAC mínimo coluna 2 & 1,45 & 0,8 & 8 \\
Custo total anualizado (TAC) na sequência & & & \\
(US\$) & $2,50 \times 10^{6}$ & $2,13 \times 10^{6}$ & $1,85 \times 10^{6}$ \\
Número de estágios coluna 1 & 35 & 31 & 38 \\
Estágio de alimentação coluna 1 & 16 & 13 & 12 \\
Número de estágios coluna 2 & 45 & 39 & 29 \\
Estágio de alimentação coluna 2 & 9 & 8 & 11 \\
\hline
\end{tabular}

O projeto conceitual preliminar foi efetuado para determinar as distribuições dos diferentes produtos através da coluna. Com o uso dos diferentes balanços, é possível determinar estágio a estágio as diferentes mudanças das frações molares dos componentes do sistema, como foi apresentado na Figura 5.4 e Figura 5.5.

Uma utilidade deste método é a possibilidade de gerar um projeto conceitual a partir das características conhecidas dos produtos (frações molares de saída). A partir dessas condições são determinados os demais parâmetros de operação, tanto o dimensionamento quanto requerimentos energéticos para atingir uma separação factível. Desta forma foram determinadas as condições térmicas e o número de estágios para cada coluna em cada sequência. Este método permite observar no diagrama ternário o comportamento de cada zona da coluna, mas à medida em que aumentam os componentes da mistura, já não é possível observar graficamente estes comportamentos, e sim por meio de valor de fronteira focado em métodos algébricos. (FIDKOWSKI, 1991). 
Para a determinação do refluxo mínimo teve que ser avaliado para achar uma intersecção dos perfis de fundo e topo da coluna de separação,

Por outro lado, a localização do estágio de alimentação torna-se uma variável dependente, representada por meio da intersecção dos perfis das zonas da coluna de separação (DOHERTY, 2001).

Nesta parte de desenvolvimento do projeto conceitual do processo, foi levada em conta a consideração de fluxo molar não constante, cuja particularidade está implicitamente relacionada por meio dos balanços efetuados durante a obtenção destes resultados prévios. Posteriormente, esta particularidade será evitada com o uso do método rigoroso para a resolução da coluna, cujos perfis de vazões de liquido e vapor mudaram conforme as condições dos estágios dentro do equipamento.

\subsection{Validação dos métodos rigorosos para uma coluna convencional e para uma sequência termicamente acoplada, DWC.}

\subsubsection{Coluna convencional}

O modelo de ponto de bolha implementado no MATLAB ${ }^{\circledR}$ foi avaliado e testado. Este teste foi feito por comparação com o ASPEN PLUS $\AA_{\text {., }}$ visando garantir uma consistência do modelo. Na Figura 5.9A e B e na Figura 5.10 estão representados os diferentes perfis de frações molares da fase de vapor casos da mistura ternária para a primeira coluna, onde posteriormente, este método será integrado com a rotina de otimização com os parâmetros de entrada do método do valor de fronteira, conforme a Figura 5.3 . 


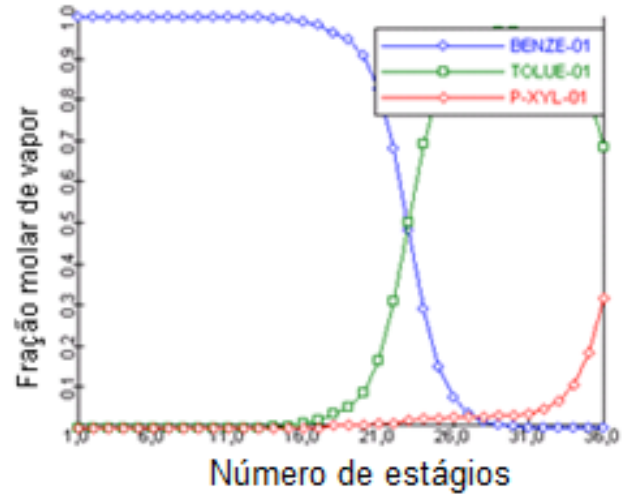

A. Perfil de concentrações da fase de vapor obtido no ASPEN PLUS $囚$.

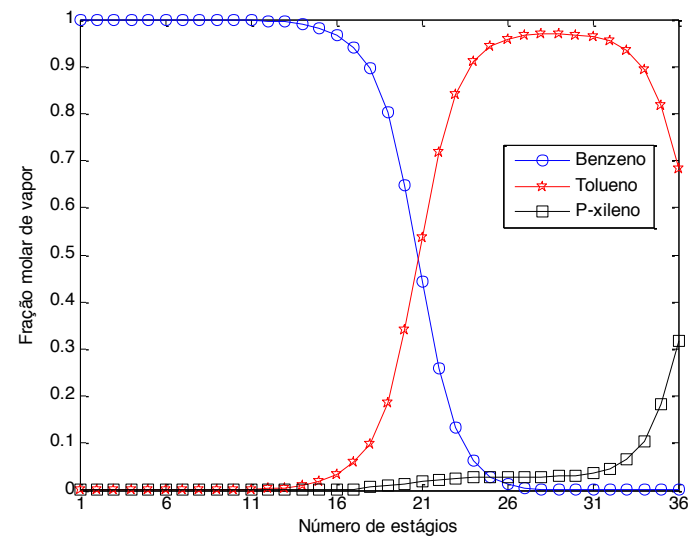

B. Perfil de concentrações da fase de vapor obtido no MATLAB®

Figura 5.9- Perfis de concentações da fase de vapor para mistura ternária Benzeno, Tolueno, $P$-xileno Enquanto a isso, foram também avaliados os perfis dos fluxos da fase de vapor, Figura 5.10 A, B, e as vazões de liquido, Figuras 5.11 A e B, cujo resultado será utilizado para efetuar o dimensionamento real dos equipamentos garantindo uma maior exatidão na solução de integração energética, e ponto para o projeto da coluna com parede dividida, fundamentalmente, baseado nestes métodos de colunas de destilação.

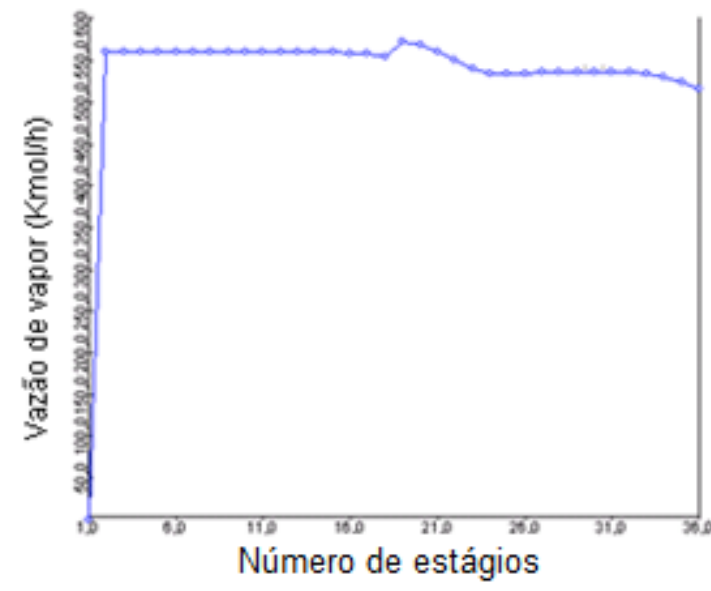

A. Perfil de fluxos internos de vapor obtido no ASPEN PLUS®.

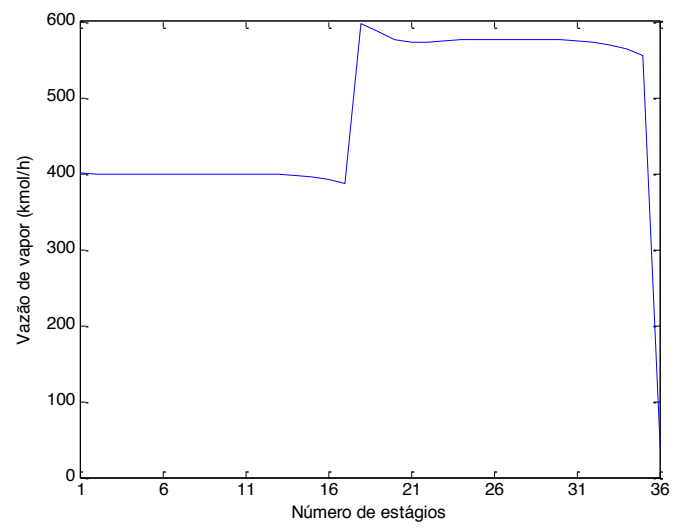

B. Perfil de fluxos internos de vapor obtido no MATLAB

Figura 5.10- Vazões internas de vapor na coluna

No método de ponto de bolha, as vazões de liquido e vapor não são constantes, oferecendo uma maior exatidão ao método. 


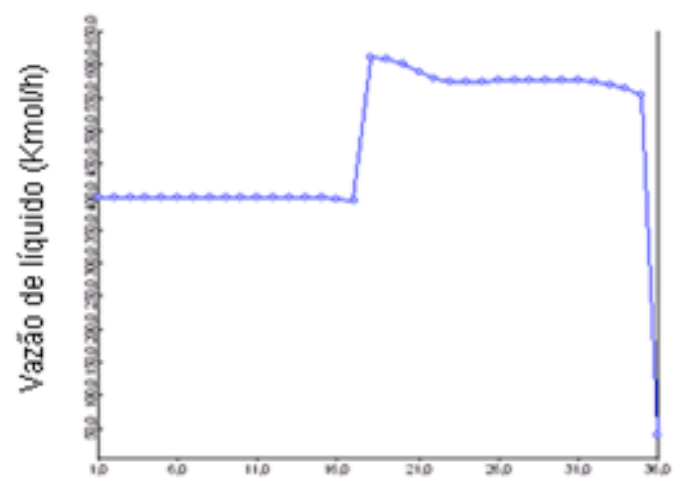

Número de estágios

A. Perfil de fluxos internos de liquido obtidos no ASPEN PLUS®.

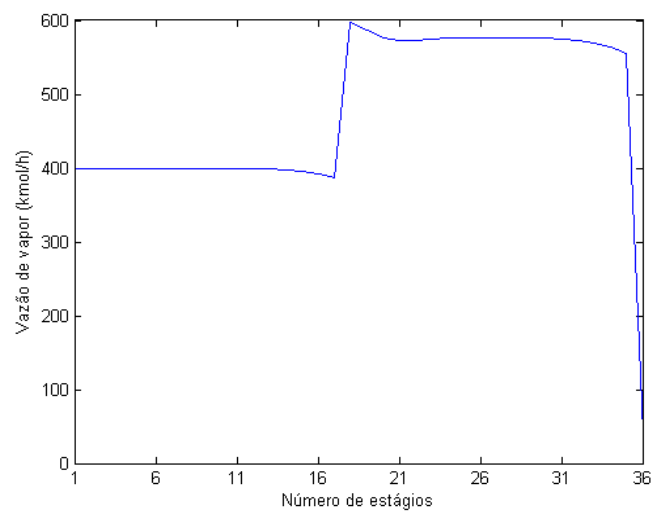

B. Perfil de fluxos internos de liquido obtidos no MATLAB

Figura 5.11- Vazões internas de liquido na coluna

\subsubsection{Solução simultânea de sequências de separação}

Dentro do problema de colunas de destilação, é levada em conta a resolução global das sequências e obtenção dos perfis internos. Por tal motivo, foi levada em conta uma solução simultânea da sequência termicamente acoplada, para uma diminuição do tempo computacional e poder dessa maneira, efetuar uma otimização com diferentes combinações.

Para chegar neste ponto foi adaptada uma solução simultânea de uma sequência indireta. Necessariamente, foi construída uma matriz esparsa que contém os coeficientes tridiagonais de cada estágio das colunas, sendo o ponto fora da diagonal, correspondente ao fluxo que conecta ás 2 colunas, conforme a Figura 4.13. Posteriormente este modelo desenvolvido no software MATLAB® foi validado no software ASPEN PLUS $®$, e foi visualizada a diferença no tempo de resolução comparado com uma resolução efetuada de maneira sequencial e apresentado na Tabela 5.14. Os resultados dos perfis são apresentados na Figura 5.12.

Apesar de ter sido resolvida as otimizações das sequências convencionais, esta visualização permite entender a maneira de como as sequências mais complexas podem ser resolvidas de uma maneira mais rápida e consistente, medidas no tempo computacional empregado para esta solução, reduziram em 57\%, quando comparada com uma solução sequencial das colunas, Tabela 5.14. 


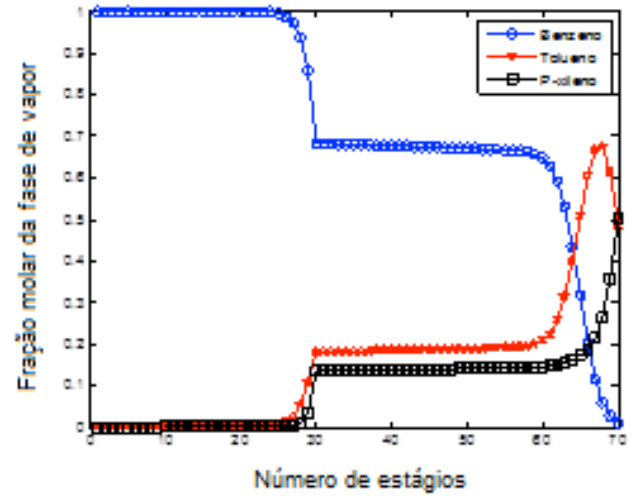

A. Coluna 1 da sequência indireta desenvolvida no MATLAB®

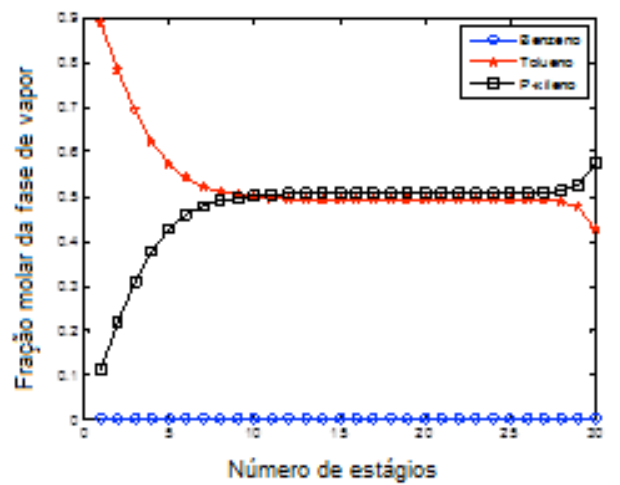

C. Coluna 2 da sequência indireta desenvolvida no MATLAB

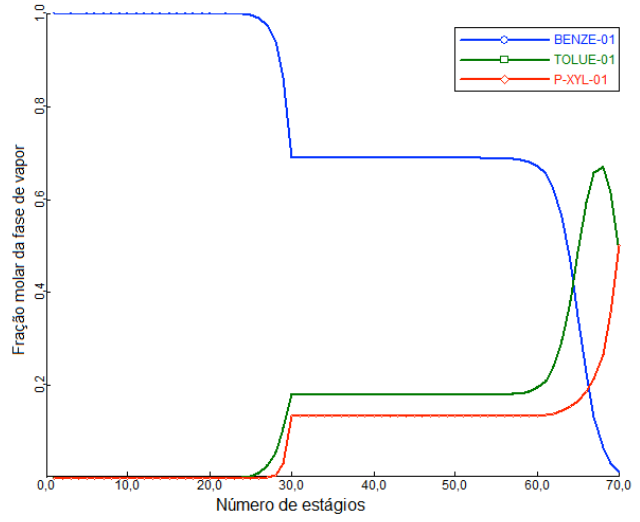

B. Coluna 1 da sequência indireta desenvolvida no ASPEN PLUS $®$.

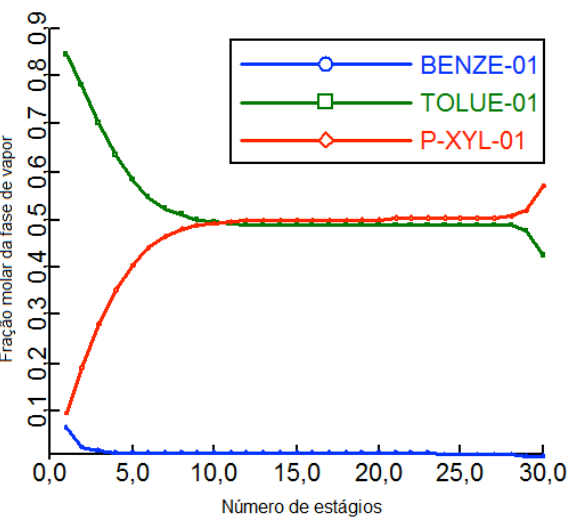

D. Coluna 2 da sequência indireta desenvolvida no ASPEN PLUS $®$.

Figura 5.12- Perfis de composição da fase de vapor para uma sequência indireta resolvida simultaneamente e validadas no ASPEN PLUS®.

Tabela 5.14- Tempo computacional para uma solução sequencial e simultanea para uma sequência convencional indireta

\begin{tabular}{cc}
\hline $\begin{array}{c}\text { Tempo computacional solução sequencial } \\
(\mathrm{seg})\end{array}$ & $\begin{array}{c}\text { Tempo computacional solução } \\
\text { simultânea (seg) }\end{array}$ \\
\hline 52.57 & 22.10 \\
\hline
\end{tabular}

Uma configuração de colunas termicamente acopladas para uma separação ternária, torna-se complexa por causa das conexões das quatro correntes que conectam as diferentes colunas. Usando um método de resolução simultânea, estas limitações são eliminadas, permitindo uma grande flexibilidade, Isto possibilita que nas conexões não sejam especificadas composições nessas vazões (HUTCHINSON et. al., 1974). Por outro lado, uma solução sequencial não é possível, pela dependência das composições gerada através dos balanços por componente, pelo qual a fracionadora não pode ser comparada como um absorvedor e ser simulada antes ou depois de resolver a coluna principal. TOMICH (1970) descreve um modelo de matriz tridiagonal onde a vazão de liquido superior que ingressa à coluna e o 
vapor que ingressa pela parte inferior são tratados como correntes de alimentação. São nessas correntes, que se gera essa dependência de composição na coluna principal, pois nelas unicamente são especificadas unicamente as vazões mas não as composições.

\subsubsection{Coluna termicamente acoplada}

Nos resultados obtidos consideraram-se fluxos molares não constantes a cada iteração. Na Figura 5.13 os diferentes perfis de vazões de liquido e vapor e perfil de concentrações na fase liquida, gerados no MATLABß, são apresentados, e comparados aos de um modelo de uma coluna de parede dividida no simulador HYSYS®. Os dados de entrada para esta separação estão na Tabela 5-15.

Tabela 5.15- Informação para validação de uma coluna termicamente acoplada

\begin{tabular}{lr}
\hline \multicolumn{1}{c}{ Parâmetro } & \multicolumn{1}{c}{ Valor } \\
\hline Número de estágios coluna principal & 70 \\
Número de estágios da fracionadora & 18 \\
Estágio de alimentação na fracionadora & 10 \\
Estágio da saída lateral na coluna principal & 36 \\
Pressão de operação (bar) & 10.5 bar \\
& Benzeno= 0.33 \\
Composição da alimentação & Tolueno=0.33 \\
& P-Xileno=0.34 \\
Vazão de destilado (kmol/h) & 32.19 \\
Razão de refluxo & 4.05 \\
Vazão da saída lateral (kmol/h) & 32.36 \\
Vazão de líquido lateral no estágio $\left(\mathrm{U}_{\mathrm{M} 1}\right)(\mathrm{kmol} / \mathrm{h})$ & 66.44 \\
Vazão de vapor lateral no estágio $\left(\mathrm{W}_{\mathrm{S} 1}\right)(\mathrm{kmol} / \mathrm{h})$ & 115.7 \\
\hline
\end{tabular}

Com estes dados de entrada são gerados os perfis dentro da coluna principal e na fracionadora. Na Figura 5.13 E, F e I e J, é gerado o perfil das vazões de liquido interno tanto na coluna principal quanto na fracionadora.

Dentro da resolução da matriz esparsa mostrada na figura 4.13 é possível resolver simultaneamente as duas colunas, obtendo os perfis de frações liquidas como é mostrado na Figura 5.13 A-D. As das cargas de calor obtidas para o refervedor e o condensador são apresentadas na Tabela 5.16. 


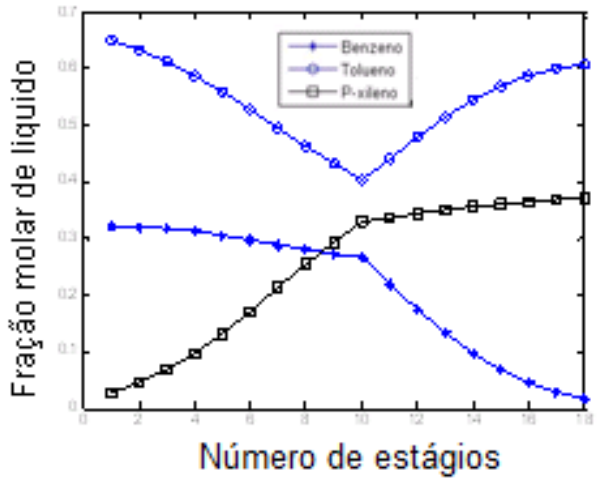

A. Perfil de concentrações da fase líquida na fracionadora obtidas no Matlab

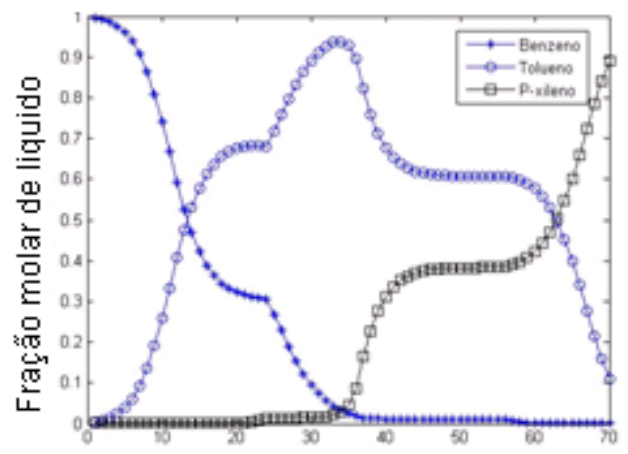

Número de estágios

C. Perfil de concentrações da fase líquida na coluna principal obtidas no Matlab

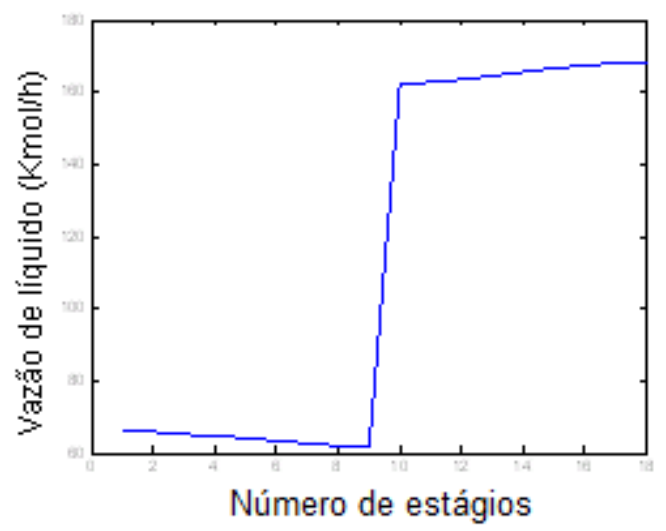

E. Perfil de vazões internas da fase líquida na fracionadora obtidas no Matlab

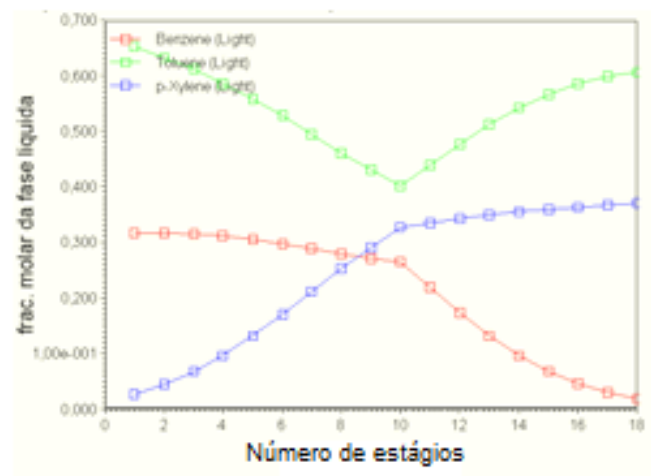

B. Perfil de concentrações da fase líquida na fracionadora obtidas no Aspen Hysys

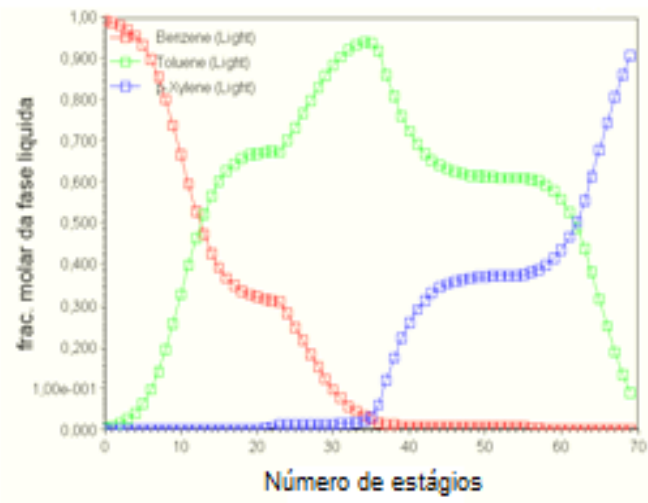

D. Perfil de concentrações da fase líquida na coluna principal obtidas no Aspen Hysys

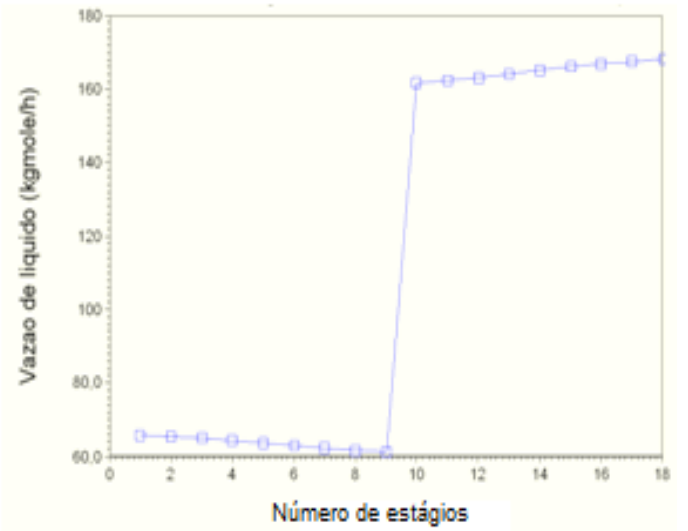

F. Perfil de vazões internas da fase líquida na fracionadora obtidas no Aspen Hysys 


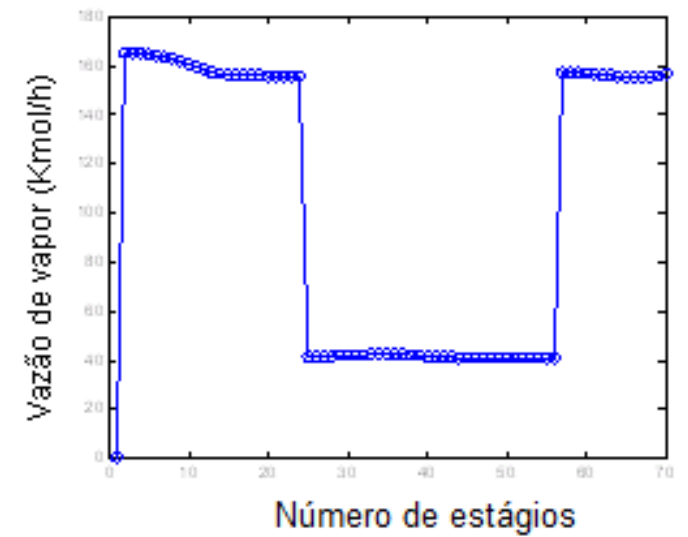

G. Perfil de vazões internas da fase vapor na coluna principal obtidas no Matlab

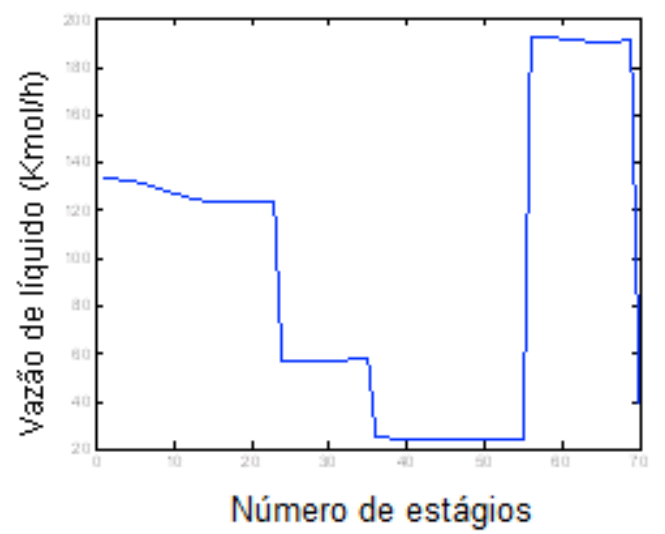

I.

Perfil de vazões internas da fase líquida na coluna principal obtidas no Matlab

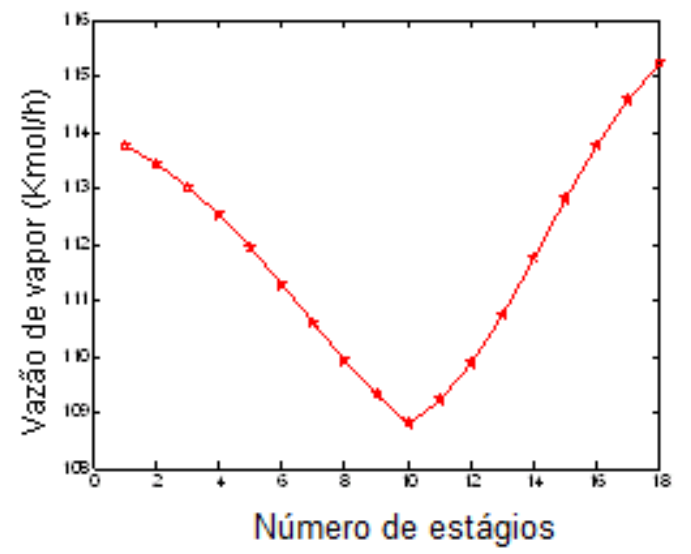

K.

Perfil de vazões internas da fase vapor na fracionadora obtidas no Matlab

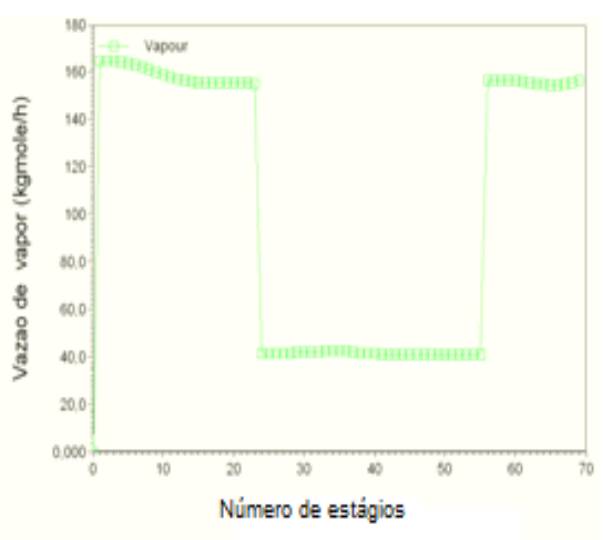

H. Perfil de vazões internas da fase vapor na coluna principal obtidas no Aspen Hysys

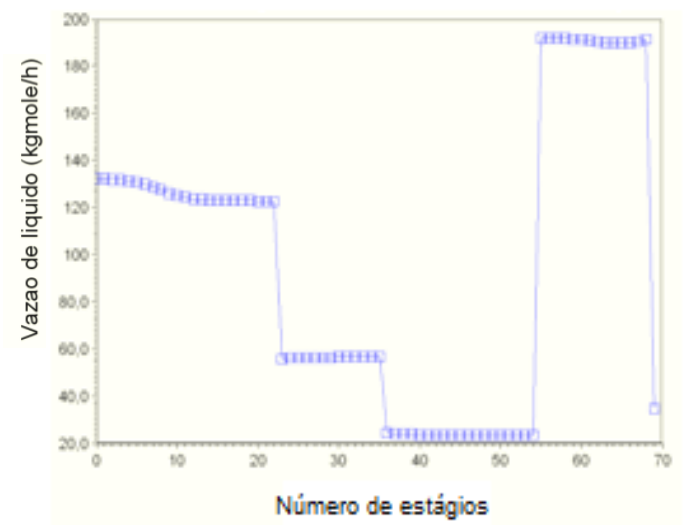

J. Perfil de vazões internas da fase líquida na coluna principal obtidas no Aspen Hysys

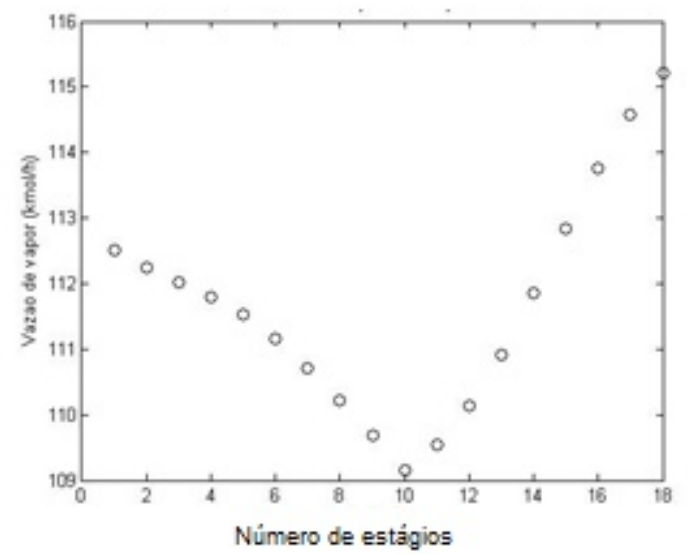

L. Perfil de vazões internas da fase vapor na fracionadora obtidas no Aspen Hysys

Figura 5.13 Comportamnetos dos perfis dentro de uma coluna termicamente acoplada validad no ASPEN Hysys e MATLAB 
Tabela 5.16 Resultados das cargas de calor para uma configuração termicamente acoplada

\begin{tabular}{lc}
\hline Equipamento & $\begin{array}{c}\text { Carga de } \\
\text { calor }\end{array}$ \\
\hline Refervedor KJ/h & $4.926 \times 10^{7}$ \\
Condensador KJ/h & $4.155 \times 10^{7}$ \\
\hline
\end{tabular}

\subsection{Otimização das sequências convencionais de separação}

A partir do modelo de cálculo rigoroso da coluna de destilação, método de ponto de bolha, foram incluídas as funções de custos e as propriedades associadas a este algoritmo para a minimização do custo total anualizado (TAC). Foi testada a incidência da rotina de otimização no tempo computacional, o estabelecimento dos valores iniciais das relações de refluxo e vazões de destilado das diferentes sequências de separação.

\subsubsection{Influência das penalidades na convergência da função objetivo}

Para realizar a otimização das diferentes sequências de separação para diferentes condições de alimentação, estas foram avaliadas mudando o número dos estágios das colunas do sistema e também os estágios de alimentação gerando diferentes combinações. Inicialmente para cada sequência geraram-se 81 combinações que foram tratadas, através de uma otimização com função objetivo com penalidade.

Durante o desenvolvimento da otimização, a função objetivo não estava representadas através de uma função de penalidade, e sim através de restrições para as purezas estabelecidas. A resposta a esta rotina conseguiu atingir um valor mínimo na função objetivo, porém o tempo computacional utilizado para esta convergência foi muito elevado. Por tal motivo foi efetuada uma modificação a partir da inclusão das penalidades à função objetivo, melhorando assim o tempo do cálculo. Na Tabela 5.17 são apresentadas as convergências dos 2 métodos testados para a resolução do problema de otimização.

Tabela 5.17- Resultados das otimizações usando a função objetivo com penalidade, e sem penalidade

\begin{tabular}{|c|c|c|c|c|c|}
\hline \multirow[b]{2}{*}{ Sequência } & \multirow[b]{2}{*}{$\begin{array}{c}\text { Frações molares } \\
\text { da alimentação }\end{array}$} & \multicolumn{2}{|c|}{$\begin{array}{c}\text { Otimização com penalidade na função } \\
\text { objetivo }\end{array}$} & \multicolumn{2}{|c|}{$\begin{array}{l}\text { Otimização sem penalidade na } \\
\text { função objetivo }\end{array}$} \\
\hline & & $\begin{array}{l}\text { TAC X10 } \\
\text { (US\$/ano) }\end{array}$ & Tempo computacional (s) & $\begin{array}{l}\text { TAC X10 } \\
\text { (US\$/ano) }\end{array}$ & $\begin{array}{c}\text { Tempo computacional } \\
(\mathrm{s})\end{array}$ \\
\hline Indireta & $0,8 / 0,1 / 0,1$ & 2,44 & 315,06 & 2,36 & 3851,96 \\
\hline Indireta & $0,1 / 0,1 / 0,8$ & 1,88 & 1698,87 & 1,82 & 6391,09 \\
\hline Direta & $0,1 / 0,8 / 0,1$ & 2,571 & 1097,46 & 2,22 & 2088,97 \\
\hline Direta & $0,1 / 0,1 / 0,8$ & 2,64 & 1572,53 & 2,66 & 11676,99 \\
\hline
\end{tabular}

Dentro dos resultados obtidos sem a inclusão da penalidade, não foram calculados os gradientes das restrições, motivo pelo qual a rotina de busca do valor ótimo, 
utilizou as diferenças finitas. Esta é uma razão possível pela qual não se obteve um bom resultado ao se usar restrições no lugar de penalidades.

\subsubsection{Incidência do valor inicial}

Estudou-se inicialmente a sensibilidade para diferentes valores iniciais para a rotina de otimização. Foram levados em conta os resultados obtidos durante o desenvolvimento do método de valor de fronteira. Posteriormente, o valor inicial de Razão de refluxo foi introduzido dentro da rotina, esperando-se que atingisse as restrições estabelecidas para a pureza de saída dos produtos nas vazões de saída.

Para este caso inicial, nestas condições, não foi possível atingir as restrições da pureza na saída dos produtos, porque não foi encontrado um ótimo dentro da região viável. Por tal motivo, mudou-se o valor inicial desta variável, de maneira a assegurar que a otimização efetuada estivesse dentro da região viável e que fosse encontrado um custo total mínimo para uma razão de refluxo localizada dentro dos limites estabelecidos. Esta estratégia foi aplicada para as outras sequências avaliadas. Na Tabela 5.18 e Tabela 5.19, são apresentados os diferentes resultados para cada condição da alimentação nas sequências, comparando o valor inicial da otimização com o valor no ponto ótimo atingido, para várias relações de refluxo e vazões de destilado.

Tabela 5.18- Valores dos valores ótimos e os valores obtidos com o método de valor de fronteira para a sequência indireta

\begin{tabular}{|c|c|c|c|c|c|c|c|c|c|c|}
\hline \multirow[b]{2}{*}{$\begin{array}{l}\text { Frac. molar } \\
\text { alim. }\end{array}$} & \multicolumn{5}{|c|}{ Resultado método valor de fronteira } & \multicolumn{5}{|c|}{ Resultados otimizações combinatória } \\
\hline & $\begin{array}{l}\text { Rel. } \\
\text { reflux } \\
\text { Col } 1\end{array}$ & $\begin{array}{c}\text { Vaz. Dest. } \\
\text { Col } 1 \\
(\mathrm{kmol} / \mathrm{h})\end{array}$ & $\begin{array}{l}\text { Rel. } \\
\text { reflux } \\
\text { Col } 2\end{array}$ & $\begin{array}{c}\text { Vaz. Dest. } \\
\text { Col } 2 \\
(\mathrm{kmol} / \mathrm{h})\end{array}$ & $\begin{array}{l}\text { TAC X10 } \\
\text { (US\$/ano) }\end{array}$ & $\begin{array}{l}\text { Rel. } \\
\text { reflux } \\
\text { Col } 1\end{array}$ & $\begin{array}{c}\text { Vaz. Dest. } \\
\text { Col } \\
1(\mathrm{kmol} / \mathrm{h})\end{array}$ & $\begin{array}{l}\text { Rel. } \\
\text { reflux } \\
\text { Col } 2\end{array}$ & $\begin{array}{c}\text { Vaz. Dest. } \\
\text { Col } 2 \\
(\mathrm{kmol} / \mathrm{h})\end{array}$ & $\begin{array}{l}\text { TAC X10 } \\
\text { (US\$/ano) }\end{array}$ \\
\hline $0,8 / 0,1 / 0,1$ & 2 & 179,81 & 9 & 159,63 & 4,76 & 0,41 & 184,98 & 0,53 & 156,38 & 2,44 \\
\hline $0,1 / 0,1 / 0,8$ & 2,7 & 38,54 & 1,45 & 20,18 & 2,50 & 3,13 & 38,47 & 2,25 & 19,23 & 1,88 \\
\hline $0,1 / 0,8 / 0,1$ & 1,5 & 179,81 & 8 & 20,18 & 4,69 & 1,20 & 189,98 & 9,10 & 20,68 & 3,22 \\
\hline
\end{tabular}

Tabela 5.19- Comparação dos valores ótimos com os valores obtidos com o método de valor de fronteira para a sequência direta

\begin{tabular}{|c|c|c|c|c|c|c|c|c|c|c|}
\hline \multirow[b]{2}{*}{$\begin{array}{l}\text { Frac. molar } \\
\text { alim. }\end{array}$} & \multicolumn{5}{|c|}{ Resultado método valor de fronteira } & \multicolumn{5}{|c|}{ Resultados otimizações combinatória } \\
\hline & $\begin{array}{l}\text { Rel. } \\
\text { reflux } \\
\text { Col } 1\end{array}$ & $\begin{array}{c}\text { Vaz. Dest. } \\
\text { Col } 1 \\
(\mathrm{kmol} / \mathrm{h})\end{array}$ & $\begin{array}{l}\text { Rel. } \\
\text { reflux } \\
\text { Col } 2\end{array}$ & $\begin{array}{c}\text { Vaz. Dest. } \\
\text { Col } 2 \\
(\mathrm{kmol} / \mathrm{h})\end{array}$ & $\begin{array}{l}\text { TAC } \times 10^{6} \\
\text { (US\$/ano) }\end{array}$ & $\begin{array}{l}\text { Rel. } \\
\text { reflux } \\
\text { Col } 1\end{array}$ & $\begin{array}{c}\text { Vaz. Dest. } \\
\text { Col } \\
1(\mathrm{kmol} / \mathrm{h})\end{array}$ & $\begin{array}{l}\text { Rel. } \\
\text { reflux } \\
\text { Col } 2\end{array}$ & $\begin{array}{c}\text { Vaz. Dest. } \\
\text { Col } 2 \\
(\mathrm{kmol} / \mathrm{h})\end{array}$ & $\begin{array}{l}\text { TAC X10 } \\
\text { (US\$/ano) }\end{array}$ \\
\hline $0,8 / 0,1 / 0,1$ & 0,7 & 161,45 & 10,5 & 18,36 & 1,29 & 0,79 & 155,31 & 8,19 & 18,58 & 2,85 \\
\hline $0,1 / 0,1 / 0,8$ & 5 & 20,18 & 6,5 & 18,36 & 2,32 & 3,08 & 19,28 & 13,40 & 18,89 & 2,64 \\
\hline $0,1 / 0,8 / 0,1$ & 11,5 & 20,18 & 10,5 & 159,63 & 2,32 & 5,34 & 19,55 & 1,36 & 159,69 & 2,99 \\
\hline
\end{tabular}


Para separações multicomponentes, foi aplicado um procedimento de obtenção de parâmetros preliminares para uma configuração de colunas termicamente acopladas, tipo Petlyuk, tais como número de estágios, valores de limite inferior e superior para relações de refluxo, para serem inseridos dentro de uma otimização com um algoritmo de cálculo da coluna mais rigoroso, com especificações de pureza menores do que 99\%. No entanto, no método anterior, em que são feitas as hipóteses de fluxo molar constante ou de volatilidades relativas constantes, o tempo computacional para a convergência numérica do sistema de separação é muito importante, e a consistência da solução pode levar a um resultado não factível ou a um resultado não ótimo. (AMMINUDIN, SMITH, \& TOWLER, 2001).

\subsubsection{Determinação da sequência com mínimo custo total anualizado}

No caso da sequência direta com abundância de benzeno, o aumento nos custos é devido ao aumento do custo de capital que corresponde ao número de estágios necessários para uma separação ótima, apesar da diminuição da carga de calor gerada, conforme pode ser observado na Tabela 5.20

Tabela 5.20- Cargas de calor geradas para os resultados das diferentes sequências.

\begin{tabular}{cccc}
\hline \multicolumn{4}{c}{ Sequência direta } \\
$\begin{array}{c}\text { Fração molar } \\
\text { alimentação }\end{array}$ & $\begin{array}{c}\text { Carga de calor dos } \\
\text { Refervedores da sequência } \\
\mathrm{kj} / \mathrm{h}\end{array}$ & $\begin{array}{c}\text { Carga de calor dos } \\
\text { Condensadores da } \\
\text { sequência kj/h }\end{array}$ & $\begin{array}{c}\text { TAC } \\
\text { (US\$/ano) }\end{array}$ \\
\hline $0,1 / 0,8 / 0,1$ & $1,56 \mathrm{E}+07$ & $1,39 \mathrm{E}+07$ & $2,99 \mathrm{E}+06$ \\
$0,8 / 0,1 / 0,1$ & $1,50 \mathrm{E}+07$ & $1,42 \mathrm{E}+07$ & $2,85 \mathrm{E}+06$ \\
$0,1 / 0,1 / 0,8$ & $1,41 \mathrm{E}+07$ & $1,14 \mathrm{E}+07$ & $2,64 \mathrm{E}+06$ \\
\hline & \multicolumn{4}{c}{ Sequência indireta } \\
\hline $0,1 / 0,8 / 0,1$ & $2,97 \mathrm{E}+07$ & $2,78 \mathrm{E}+07$ & $3,22 \mathrm{E}+06$ \\
$0,8 / 0,1 / 0,1$ & $1,64 \mathrm{E}+07$ & $1,56 \mathrm{E}+07$ & $2,44 \mathrm{E}+06$ \\
$0,1 / 0,1 / 0,8$ & $9,86 \mathrm{E}+06$ & $7,21 \mathrm{E}+06$ & $1,88 \mathrm{E}+06$ \\
\hline
\end{tabular}
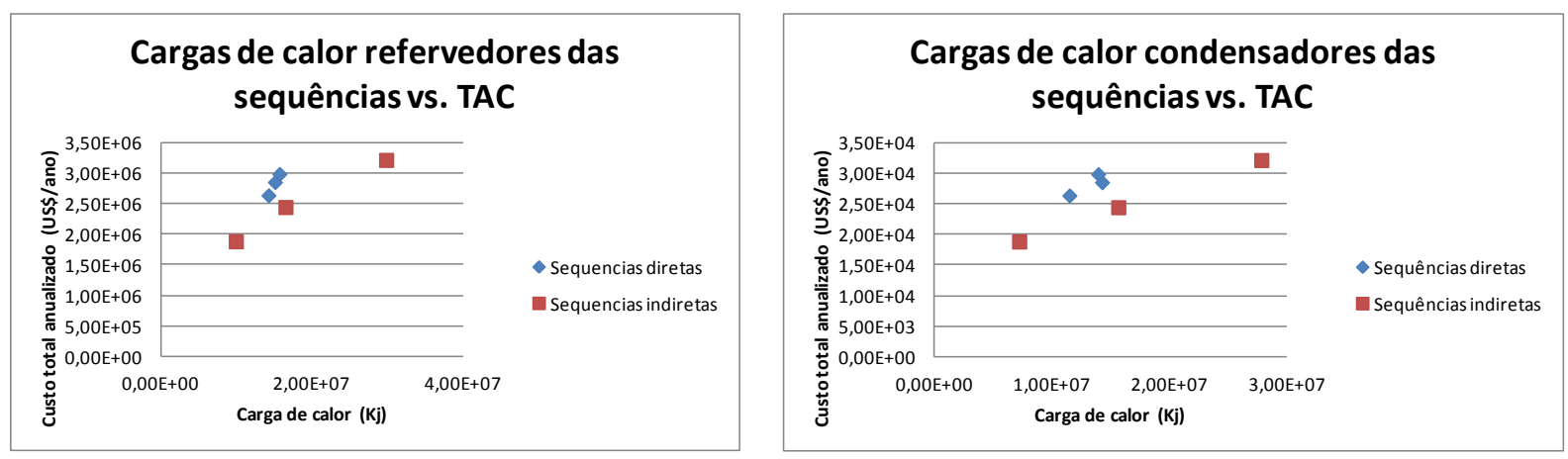

Figura 5.14- Representação do custo total anualizada em função das cargas de calor

O efeito das cargas de calor no custo total anualizado está relacionado às vazões internas de vapor, que fazem com que o diâmetro das colunas aumente, apesar de 
possibilitarem uma maior capacidade de separação, tanto na sequência direta quanto na sequência indireta. Onde está presente uma maior proporção de componente intermédio, este aumento é causado pela separação deste que deve ser efetuada nas 2 colunas para separar este componente do pesado ou do leve.

Alguns exemplos práticos estão relacionados com a condição térmica da alimentação, que depende em grande medida do consumo de energia do refervedor. Outra mudança de processo está altamente relacionada com a razão de refluxo da coluna, onde um aumento na razão de refluxo há uma demanda maior de energia tanto no refervedor quanto no condensador. Como resultado, o fluxo de vapor na seção de fundo da coluna deve aumentar mesmo com as demandas energéticas do condensador. Esta situação, reduz a temperatura de fundo, e portanto existem pequenas possibilidades de uma redução energética. Além disso, o fluxo de vapor na seção de fundo aumenta, pela possibilidade de uma maior temperatura do produto de fundo. (GADALLA, 2005).

\subsubsection{Numero de estágios}

Desde o ponto de vista do número de estágios, estão apresentados na Figura 5-16, os diferentes comportamentos do custo total anualizado no número de estágios incluídos nas colunas.

Na Figura 5.15 são apresentados os resultados para a sequência indireta com abundancia de P-xileno, segundo as restrições das purezas de cada coluna no fundo. Os parâmetros referentes ao custo total anualizado é menor, são apresentados na Tabela 5.21. Nestes resultados, a convergência de cada um das otimizações efetuadas mudando o número de estágios e o estágio de alimentação, depende de uma maneira muito significativa nos valores das variáveis de projeto, Existe uma mudança, no caso da razão de refluxo e outras fixas como são as condições da alimentação, e no caso do número de estágios para cada caso particular, também, o valor inicial da convergência da otimização efetuada em cada combinação, e a condição numérica, no caso da determinação das derivadas, em cada otimização para cada caso avaliado. (LIMA, 2006). 

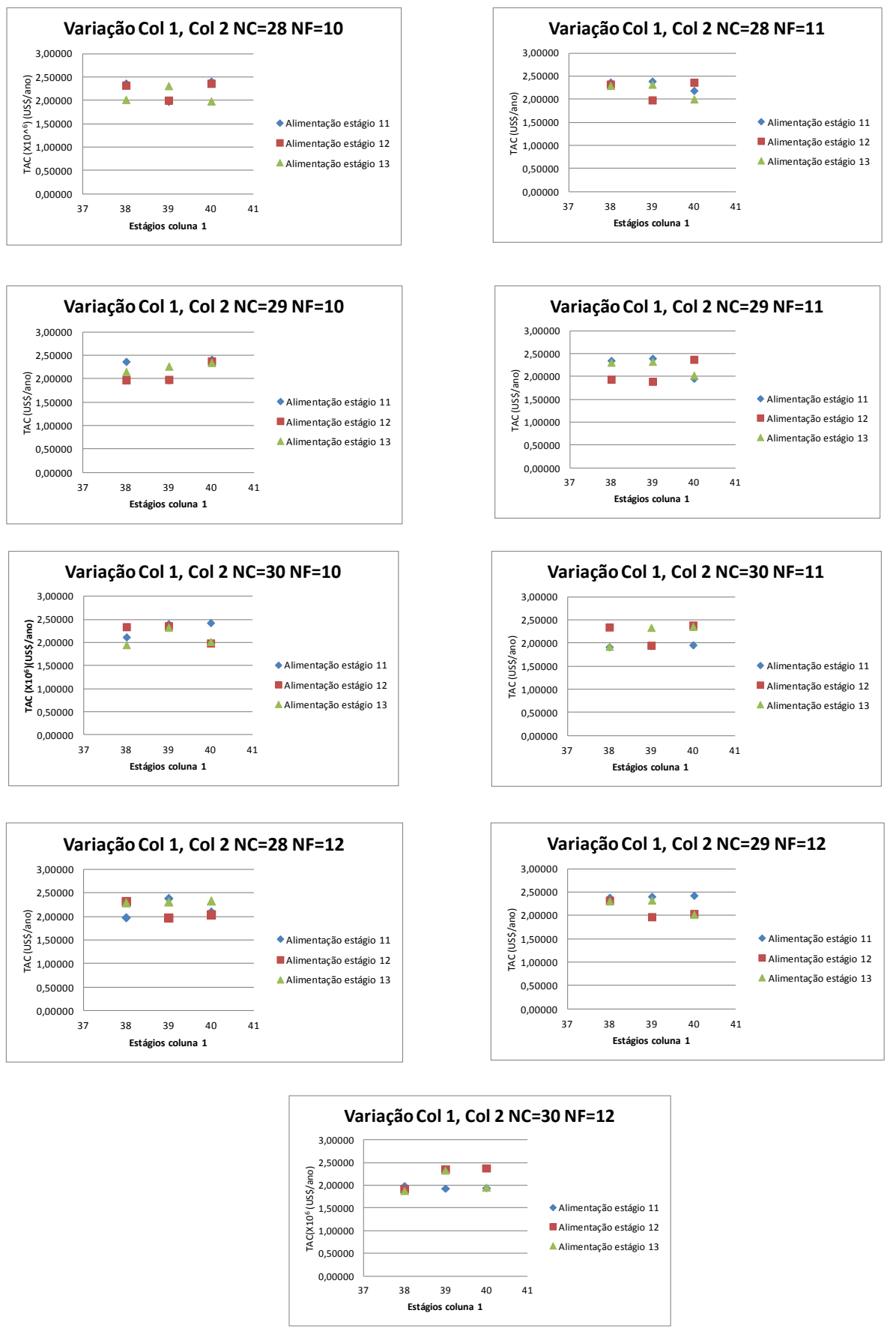

Figura 5.15- Resultados do TAC com variação do número de estágios na coluna 1, com sequência indireta e abundância em P-xileno (80\%) na alimentação (NF, estágio de alimentación e NC, número de estágios) 
Tabela 5.21- Parâmetros de projeto para sequência indireta com custo mínimo

\begin{tabular}{|c|c|c|}
\hline Parâmetro & Coluna 1 & Coluna 2 \\
\hline Número de estágios & 38 & 30 \\
\hline Estágio alimentação & 13 & 12 \\
\hline Vazão Destilado (kmol/h) & 38,47 & 19,23 \\
\hline Razão de refluxo & 3,13 & 2,25 \\
\hline Altura (m) & 30,50 & 21,99 \\
\hline Carga calor Condensador $(\mathrm{kj} / \mathrm{h})$ & $-5,24 E+06$ & $-1,96 E+06$ \\
\hline Carga calor Refervedor (kj/h) & $7,94 \mathrm{E}+06$ & $1,91 E+06$ \\
\hline Área Coluna $\left(\mathrm{m}^{2}\right)$ & 3,05 & 0,65 \\
\hline Área Refervedor $\left(\mathrm{m}^{2}\right)$ & 69,70 & 10,09 \\
\hline Área Condensador $\left(\mathrm{m}^{2}\right)$ & 36,31 & 16,72 \\
\hline Custo Capital (US\$/ano) & $160,14 \mathrm{E}+04$ & $51,11 \mathrm{E}+04$ \\
\hline Custo Operação (US\$/ano) & $17,90 \mathrm{E}+04$ & $4,30 E+04$ \\
\hline \multirow{2}{*}{$\begin{array}{l}\text { Fração molar nas vazões de } \\
\text { fundo (restrições) }\end{array}$} & P-Xileno & Tolueno \\
\hline & 0,9900 & 0,9945 \\
\hline TAC (US\$/ano) & $1,88 \mathrm{E}$ & \\
\hline
\end{tabular}

\subsection{Otimização em sistemas termicamente acoplados}

A seguir são apresentados os resultados das diferentes otimizações combinatórias da configuração termicamente acoplada, coluna com parede dividida, apresentados na Tabela 5-22.

Tabela 5.22- Resultados otimização combintaroria DWC

\begin{tabular}{|c|c|c|c|c|c|c|c|c|c|c|c|c|c|c|c|}
\hline $\begin{array}{l}\text { Frações } \\
\text { molares da } \\
\text { alimentação }\end{array}$ & $\begin{array}{l}\text { Num estágios } \\
\text { prefac }\end{array}$ & $\begin{array}{c}\text { Estágio } \\
\text { alimentação }\end{array}$ & $\begin{array}{l}\text { Num } \\
\text { estágios } \\
\text { col } \\
\text { principal }\end{array}$ & $\begin{array}{l}\text { Estágio } \\
\text { Conexão } \\
\text { superior }\end{array}$ & $\begin{array}{l}\text { Estágio } \\
\text { Saida } \\
\text { lateral }\end{array}$ & $\begin{array}{l}\text { Estágio } \\
\text { Conexão } \\
\text { inferior }\end{array}$ & $\begin{array}{c}\text { Vazão } \\
\text { Destilado } \\
(\mathrm{kmol} / \mathrm{h})\end{array}$ & $\begin{array}{l}\text { Razão de } \\
\text { refluxo }\end{array}$ & $\begin{array}{l}\text { Vazão de } \\
\text { liquido } \\
\text { conexão } \\
\text { superior } \\
(\mathrm{kmol} / \mathrm{h})\end{array}$ & $\begin{array}{c}\text { Vazão } \\
\text { saida } \\
\text { lateral } \\
(\mathrm{kmol} / \mathrm{h})\end{array}$ & $\begin{array}{l}\text { Vazão de } \\
\text { vapor } \\
\text { conexão } \\
\text { inferior } \\
(\mathrm{kmol} / \mathrm{h})\end{array}$ & $\begin{array}{c}\text { Fração } \\
\text { molar } \\
\text { benzeno }\end{array}$ & $\begin{array}{c}\text { Fração } \\
\text { molar } \\
\text { tolueno }\end{array}$ & $\begin{array}{c}\text { Fração } \\
\text { molar P- } \\
\text { xileno }\end{array}$ & $\begin{array}{l}\text { TAC } \times 10^{6} \\
\text { (US\$/ano) }\end{array}$ \\
\hline$\overline{0,1 / 0,1 / 0,8}$ & 19 & 9 & 43 & 7 & 24 & 36 & 15 & 23,37 & 89,07 & 15,44 & 100,86 & 1,00 & 0,98 & 0,99 & 4,53 \\
\hline $0,8 / 0,1 / 0,1$ & 31 & 11 & 40 & 11 & & & 154,23 & 7,97 & 150,78 & & 250,71 & 1,00 & 0,95 & & 5,45 \\
\hline $0,1 / 0,8 / 0,1$ & 38 & 11 & 50 & 19 & 26 & 39 & 19,00 & 20,20 & 234,37 & 144,40 & 241,61 & 1,00 & 0,99 & 0,99 & 5,85 \\
\hline
\end{tabular}

Para a obtenção destes resultados as variáveis que estão relacionadas com os estágios, no caso do número de estágios nas colunas, estágio de alimentação, estágio de saída lateral, e os estágios das conexões, são variadas sequencialmente. Isto implica em um problema combinatório, devido a que os valores estabelecidos inicialmente na sequência não correspondem ao valor ótimo, como é mostrado na Tabela 5.23. 
Tabela 5.23- Custo total anualizado para os estágios estabelecidos iniciais para uma alimentação com frações molares de 0,1 mol de Benzeno 0,1 mol de Tolueno e 0,8 mol de P-Xileno

\begin{tabular}{lll}
\hline \multicolumn{1}{c}{ Variável } & \multicolumn{1}{c}{$\begin{array}{c}\text { Valores } \\
\text { especificados }\end{array}$} & \multicolumn{1}{c}{$\begin{array}{c}\text { Valores } \\
\text { ótimos }\end{array}$} \\
\hline Número de estágios prefacionadora & 20 & 19 \\
Estágio alimentação & 10 & 9 \\
Número de estágios coluna principal & 42 & 43 \\
Estágio de Conexão superior & 6 & 7 \\
Estágio de Saída lateral & 25 & 24 \\
Estágio de Conexão inferior & 37 & 36 \\
TAC $\times 10^{6}$ (US\$/ano) & 6,94 & 4,53 \\
\hline
\end{tabular}

\subsubsection{Incidência dos valores iniciais das vazões nas conexões, saídas de produto e razão de refluxo.}

Durante o desenvolvimento da rotina de otimização da coluna termicamente acoplada, os valores iniciais das variáveis continuas, foram especificadas levando em conta as restrições das frações molares nas saídas do sistema, visando facilitar uma convergência dentro da região viável especificadas segundo as restrições. Para as vazões das conexões de liquido e vapor da configuração, existe uma forte sensibilidade com estes valores iniciais. O qual, o valor inicial não pode ser especificado arbitrariamente, devido principalmente às restrições de vazão internas tanto de vapor quando de liquido como foi estabelecida nas restrições de desigualdade, e que são dependentes da vazão de destilado e da razão de refluxo. Por outro lado, existe a possibilidade de não atingir as restrições operacionais de produção, frações molares nas saídas da coluna. Como é apresentado na Figura 5.17 para uma especificação na alimentação com frações molares de $0.1 \mathrm{~mol}$ de benzeno, $0.1 \mathrm{~mol}$ de Tolueno e 0,8 mol de P-xileno, para esta situação, o valor inicial da Figura 5.16A, é 15,43 kmol/h para a conexão superior e na conexão inferior é $200,86 \mathrm{kmol} / \mathrm{h}$. Pode-se ver como este valor inicial não respeita as restrições de fração molar nos estágios onde estão localizadas as saídas de produto. No entanto, na Figura 5.16B, estes valores no caso da conexão superior é $89,06 \mathrm{kmol} / \mathrm{h}$, e da conexão inferior é 100,86 kmol/h. A incidência do valor inicial das conexões arbitrariamente, não garante obter um custo mínimo. 


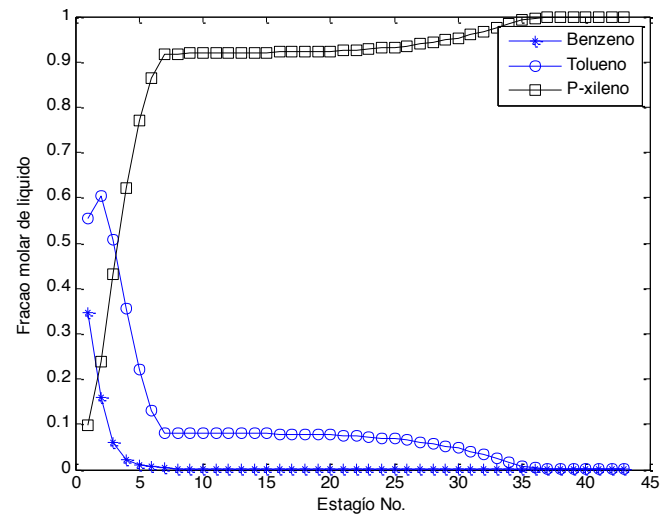

A. Perfil de concentrações na coluna principal fora das restrições de recuperação nas saídas de produto,

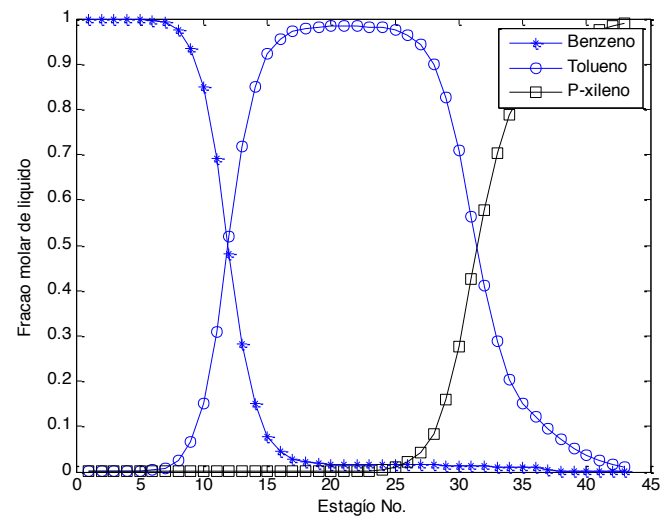

B. Perfil de concentrações na coluna principal dentro das restrições de recuperação nas saídas de produto

Figura 5.16- Perfis de concentração da fase liquida na coluna principal, a diferentes pontos iniciais de otimização

De acordo com esta base, um valor inicial arbitrário destas correntes de conexão gera uma distorção nos perfis de concentrações nas duas colunas. Este comportamento também foi investigado em sistemas onde existem quedas de pressão internas. Foi visto que os valores das vazões nas conexões incidem diretamente nos perfis de concentrações e nesse caso, de pressão interna, em sistemas termicamente acoplados resolvidos mediante métodos rigorosos. (SANGAL, et. al., 2012).

Além disso, as restrições relacionadas com as vazões internas tornam-se sempre ativas, para este sistema, garantindo que não existam vazões internas negativas, o que pode ocasionar uma não convergência na resolução da matriz esparsa em cada avaliação da função objetivo.

\subsubsection{Custo de capital e custo de operação}

\subsection{Consumo de energia}

$\mathrm{Na}$ Tabela 5.24 são apresentadas as cargas de calor no refervedor e no consendasor para uma coluna com parede dividida para os diferentes casos de composições da alimentação. 
Tabela 5.24- Cargas de calor para diferentes condições de alimentação em uma configuração termicamente acoplada

\begin{tabular}{lcc}
$\begin{array}{c}\text { Frações molares } \\
\text { da alimentação }\end{array}$ & $\begin{array}{c}\text { Carga de calor } \\
\text { refervedor } \mathrm{kj} / \mathrm{h}\end{array}$ & $\begin{array}{c}\text { Carga de calor } \\
\text { condensador } \\
\mathrm{kj} / \mathrm{h}\end{array}$ \\
\hline $0,1 / 0,1 / 0,8$ & $1,12 \mathrm{E}+07$ & $1,12 \mathrm{E}+07$ \\
$0,8 / 0,1 / 0,1$ & $1,18 \mathrm{E}+07$ & $1,24 \mathrm{E}+07$ \\
$0,1 / 0,8 / 0,1$ & $4,25 \mathrm{E}+07$ & $4,26 \mathrm{E}+07$ \\
\hline
\end{tabular}

No caso deste problema de separação, a carga de energia foi maior na configuração da coluna DWC do que nos casos de sistemas convencionais, como é apresentado na Tabela 5.20, levando para resultados ótimos maiores nas diferentes frações de alimentação, comparado com a sequência indireta, onde existe uma maior abundância de P-Xileno, Tabela 5.25.

Tabela 5.25- Custos de capital e de operação para diferentes condições de alimentação em uma configuração termicamente acoplada

\begin{tabular}{ccc}
\hline $\begin{array}{c}\text { Frações molares } \\
\text { da alimentação }\end{array}$ & $\begin{array}{c}\text { Custo de capital } \\
\text { (US\$/ano) }\end{array}$ & $\begin{array}{c}\text { Custo de } \\
\text { operação } \\
\text { (US\$/ano) }\end{array}$ \\
\hline $0,1 / 0,1 / 0,8$ & $3,34 \mathrm{E}+06$ & $1,97 \mathrm{E}+06$ \\
$0,8 / 0,1 / 0,1$ & $4,61 \mathrm{E}+06$ & $1,77 \mathrm{E}+06$ \\
$0,1 / 0,8 / 0,1$ & $4,83 \mathrm{E}+06$ & $2,00 \mathrm{E}+06$ \\
\hline
\end{tabular}

Por outro lado, no cálculo do custo de capital para esta configuração, foi necessário levar em conta esta sequência como é apresentada na Figura 5.2, cujos equipamentos correspondem a 2 equipamentos de troca de calor, representados no estágio $1_{1}$ e $N_{1}$, para que este modelo de custos usado seja adequado para este sistema.

\subsection{Comparação da otimização}

Os resultados obtidos para cada uma das sequências otimizadas de maneira com diferentes combinações de número de estágios e estágios de alimentação, para o caso de sequências convencionais além do estágio de saída lateral com as conexões, como é a coluna com parede dividida.

Encontrou-se uma diminuição do custo total anualizado de $58,36 \%$ quando na alimentação está presente uma maior abundância de componente pesado, p-Xileno, quando separada com uma configuração de colunas de separação de maneira indireta, como é apresentado na Tabela 5-26. 
Tabela 5.26- Comparação econômica dos resultados obtidos nas configurações convencionais e termicamente acoplada para uma alimentação $0,1 \mathrm{~mol}$ benzeno/0,1 mol Tolueno $/ 0,8 \mathrm{~mol}$ p-xileno

\begin{tabular}{lccccccccc}
\hline Configuração & $\begin{array}{c}\text { Núm } \\
\text { estágios } \\
\text { col. 1 }\end{array}$ & $\begin{array}{c}\text { Núm } \\
\text { estágios } \\
\text { col. 2 }\end{array}$ & $\begin{array}{c}\text { Estágio } \\
\text { alimentação } \\
\text { col 1 }\end{array}$ & $\begin{array}{c}\text { Estágio } \\
\text { alimentação } \\
\text { col. 2 }\end{array}$ & $\begin{array}{c}\text { Estágio } \\
\text { de saída } \\
\text { lateral }\end{array}$ & $\begin{array}{c}\text { Estágio } \\
\text { Conexão } \\
\text { superior }\end{array}$ & $\begin{array}{c}\text { Estágio } \\
\text { Conexão } \\
\text { inferior }\end{array}$ & $\begin{array}{c}\text { TAC X10 } \\
\text { (US\$/ano) }\end{array}$ & $\begin{array}{c}\text { Redução } \\
\text { do TAC } \\
(\%)\end{array}$ \\
\hline Indireta & 38 & 30 & 13 & 12 & N/A & N/A & N/A & 1,88 & 58,36 \\
Direta & 34 & 33 & 21 & 33 & N/A & N/A & N/A & 2,64 & 41,71 \\
DWC & 19 & 50 & 9 & N/A & 7 & 24 & 36 & 4,53 & - \\
\hline
\end{tabular}

Igualmente, agrupando os resultados das otimizações combinatórias no caso de abundância de benzeno, componente leve, exsite uma reduzão do custo total anualizado de 45,96\% quando usado a sequência indireta de colunas de separação, como observado na Tabela 5.27.

Tabela 5.27- Comparação econômica dos resultados obtidos nas configurações convencionais e termicamente acoplada para uma alimentação $0,8 \mathrm{~mol}$ benzeno/0,1 mol Tolueno $/ 0,1 \mathrm{~mol} p$-xileno

\begin{tabular}{lccccccccc}
\hline Configuração & $\begin{array}{c}\text { Núm } \\
\text { estágios } \\
\text { col. 1 }\end{array}$ & $\begin{array}{c}\text { Núm } \\
\text { estágios } \\
\text { col. 2 }\end{array}$ & $\begin{array}{c}\text { Estágio } \\
\text { alimentação } \\
\text { col 1 }\end{array}$ & $\begin{array}{c}\text { Estágio } \\
\text { alimentação } \\
\text { col. 2 }\end{array}$ & $\begin{array}{c}\text { Estágio } \\
\text { de saída } \\
\text { lateral }\end{array}$ & $\begin{array}{c}\text { Estágio } \\
\text { Conexão } \\
\text { superior }\end{array}$ & $\begin{array}{c}\text { Estágio } \\
\text { Conexão } \\
\text { inferior }\end{array}$ & $\begin{array}{c}\text { TAC X10 } \\
\text { (US\$/ano) }\end{array}$ & $\begin{array}{c}\text { Redução } \\
\text { do TAC } \\
(\%)\end{array}$ \\
\hline Indireta & 31 & 40 & 12 & 7 & N/A & N/A & N/A & 2,44 & 45,96 \\
Direta & 50 & 42 & 25 & 20 & N/A & N/A & N/A & 2,85 & 36,95 \\
DWC & 31 & 40 & 11 & N/A & 24 & 11 & 31 & 5,44 & - \\
\hline
\end{tabular}

Por outro lado, na Tabela 5.28, são obtidos os resultados com o custo total anualizado menor no caso de uma sequência direta quando existe uma grande cuantidade do componente intermédio, Tolueno, com uma reduzão de 33,96\%.

Tabela 5.28- Comparação econômica dos resultados obtidos nas configurações convencionais e termicamente acoplada para uma alimentação 0,1 mol benzeno/0,8 mol Tolueno $/ 0,1$ mol p-xileno

\begin{tabular}{lccccccccc}
\hline Configuração & $\begin{array}{c}\text { Núm } \\
\text { estágios } \\
\text { col. 1 }\end{array}$ & $\begin{array}{c}\text { Núm } \\
\text { estágios } \\
\text { col. 2 }\end{array}$ & $\begin{array}{c}\text { Estágio } \\
\text { alimentação } \\
\text { col 1 }\end{array}$ & $\begin{array}{c}\text { Estágio } \\
\text { alimentação } \\
\text { col. 2 }\end{array}$ & $\begin{array}{c}\text { Estágio } \\
\text { de saída } \\
\text { lateral }\end{array}$ & $\begin{array}{c}\text { Estágio } \\
\text { Conexão } \\
\text { superior }\end{array}$ & $\begin{array}{c}\text { Estágio } \\
\text { Conexão } \\
\text { inferior }\end{array}$ & $\begin{array}{c}\text { TAC X10 } \\
\text { (US\$/ano) }\end{array}$ & $\begin{array}{c}\text { Redução } \\
\text { do TAC } \\
\text { (\%) }\end{array}$ \\
\hline Indireta & 31 & 40 & 12 & 7 & N/A & N/A & N/A & 3,02 & 33,33 \\
Direta & 43 & 40 & 20 & 21 & N/A & N/A & N/A & 2,99 & 33,96 \\
DWC & 38 & 50 & 11 & N/A & 26 & 19 & 39 & 5,85 & - \\
\hline
\end{tabular}

Apesar de ter obtido um custo total anualizado maior para as colunas com parede dividida, depois de serem otimizadas as diferentes sequências para diferentes composições da alimentação, existe ainda a possibilidade de que esta configuração leve a um custo menor para determinadas composições da alimentação, ou usando um componente mais abundante em menor proporção dos que foram avaliados neste estudo, mas mais estudos devem ser empreendidos. 


\section{CONCLUSÕES}

Neste estudo verificou-se que para o projeto de separação de uma mistura ternária há 8 graus de liberdade para as sequências convencionais e 11 para uma configuração com parede dividida. Estas variáveis são caracterizadas entre variáveis continuas; vazões e razão de refluxo, e variáveis inteiras, relacionadas com o número de estágios e a localização de estágios de entrada e saída do processo.

Foi desenvolvido o projeto conceitual das sequências convencionais, resolvido através do método de valor de fronteira, em que foram obtidas as informações de número de estágios e localização dos estágios de entrada e saída destas sequências. Esta informação foi utilizada para inicializar o método de ponto de bolha.

O método de ponto de bolha foi adaptado para o projeto das diferentes configurações, resolvendo os balanços iterativamente, por meio da obtenção da matriz tridiagonal para sequências convencionais, e para uma configuração com parede dividida foi construída uma matriz esparsa, gerando-se elementos fora da diagonal correspondentes às conexões entre as colunas do sistema.

Foram otimizadas configurações, convencionais e com parede dividida, minimizando o custo total anualizado, usando esta função objetivo com restrições de penalidade, permitindo uma convergência a um ponto de mínimo local em um tempo computacional menor do que uma função objetivo sem penalidade, permitindo que sejam efetuadas múltiplas otimizações porque para este projeto estão relacionadas com as diferentes combinações em casa configuração.

Foi observada uma diminuição de $58,36 \%$ quando usada uma sequência indireta otimizada combinatoriamente, comparada com os demais resultados das outras configurações estudadas, no caso de uma composição da alimentação do sistema de 0,1 mol benzeno, 0,1 mol Tolueno, 0,8 mol p-xileno. Igualmente para uma composição da alimentação com frações molares de 0,8 mol benzeno, 0,1 mol Tolueno, 0,1 mol p-xileno, a sequência indireta reduz em 45,96\% o custo total anualizado mínimo. Para o caso 0,1 mol benzeno, 0,8 mol Tolueno, 0,1 mol p-xileno, a sequência direta reduz o custo total anualizado em $33,96 \%$. 


\section{CONTINUIDADE DO TRABALHO}

Seria interessante no futuro realizar casos de estudo para misturas não ideais, usando diferentes composições na alimentação, e também com diferentes purezas na saída dos produtos, observando os diferentes comportamentos relacionados com a diminuição de custos e consumo de energia para uma determinada separação.

Uma contribuição interessante eria também analisar outros sistemas de configurações de destilação, analisando as possíveis vantagens que estas configurações puderem oferecer, do ponto de vista econômico.

Outros algoritmos rigorosos de resolução de sistemas de destilação de maneira simultânea, visando reduzir o tempo computacional poderiam ser adaptados facilitando possíveis otimizações e oferecendo uma maior versatilidade frente a outras configurações mais complexas.

Dentro das especificações de sistemas de destilação multicomponente, seria possível estabelecer como variável de projeto, uma diferença de pressão entre as colunas das sequências, estudando a influência que esta variável tem dentro do contexto global das sequências de separação, como uma restrição do problema.

Por fim, seria interessante também considerar outras condições de alimentação, em outras misturas, avaliando a capacidade de encontrar a separação ótima do ponto de vista econômico para uma configuração termicamente acoplada 


\section{BIBLIOGRAFIA}

AGRAWAL, R. (1996). Synthesis of Distillation Column Configurations for a Multicomponent Separation. Ind. Eng. Chem. Res., 1059-1071.

AMMINUDIN, K. A., SMITH, R. \& TOWLER, G. P. (2001). Design and optimization of fully thermally coupled distillation columns. Part 1: Preliminary Design and Optimization Methodology. Trans IChemE, 701-715.

BYRD, H. N. (2007). Steering exact penalty methods for nonlinear programming. Optimization technology center, 1-24.

CABALLERO, J. A., \& GROSSMANN, I. (2001). Generalized Disjunctive Programming Model for the Optimal Synthesis of Thermally Linked Distillation Columns. Ind. Eng. Chem. Res., 2260-2274.

CABALLERO, J. A., REYES-LABARTA, J., \& GROSSMAN, I. (2003). Synthesis of integrated distillation systems. Computer Aided Chemical Engineering, 59-64.

CABALLERO, J. G. (2004). Design of distillation sequences: from conventional to fully thermally coupled distillation systems. Computers \& Chemical Engineering, 2307-2329.

CERDA, J., \& WESTERBERG, A. W. (1981). Shortcut methods for complex distillation columns. Ind. Eng. Chem. Process Des. Dev., 546-557.

DOHERTY, M. F. (2001). Conceptual desing of distillation system. New York: McGraw-Hill chemical engineering series.

DOUGLAS, J. M. (1988). Conceptual design of chemical processes. New York: McGraw-Hill.

EDGAR, T. F. (1988). Optimization of chemical processes. New York: McGraw-Hill.

EMTIR, M., \& ETOUMI, A. (2009). Enhancement of conventional distillation configurations for ternary mixtures separation. Clean Techn Environ Policy, 123-131. 
Energy, U. D. (2003). How To Calculate The True Cost of Steam. Washington D.C.: OIT.

FIDKOWSKI, Z. M. (1991). Nonideal multicomponent distillation: Use of bifurcation theory for design. American institute of Chemical engineering, 37, 1791.

FLOQUET, P., PIBOLEAU, L., \& DOMENECH, S. (1988). Mathematical programming tools for chemical engineering process design synthesis. Chemical Engineering and Processing: Process Intensification, 99-113.

GADALLA, M. O. (2005). Reducing $\mathrm{CO}_{2}$ emissions and energy consumption of heatintegrated distillation systems. Enviromental science and technology, 6860-6870.

GLINOS, K. N., \& MALONE, M. F. (1985). Design of sidestream distillation columns. Ind. Eng. Chem. Process. Des. Dev., 822-828.

GRIVA Igor, N. t. (2009). Linear and nonlinear optimization. Philadelphia: SIAM. Society for industrial an applied mathematics.

GUTIERREZ, R., SEGOVIA, J., \& HERNANDEZ, S. (2008). Reducing energy consumption and $\mathrm{CO} 2$ emissions in. Chemical Engineering Research and Design, 145-152.

HALVORSEN I., S. S. (2003). Minimum Energy Consumption in Multicomponent Distillation. 3. Ind. Eng. Chem. Res, 616-629.

HENLEY, E., \& SEADER, J. D. (2000). Equilibrium-stage separatiom operations in chemical engineering. New York: John Wilwy and sons Inc.

HUTCHISON H.; SHEWCHUK C. A computational method for multiple distillation towers. 52 (1974). 325-336.

KAIBEL, G. (1987). Distillation columns with vertical partitions. Chem Eng Technol , 92-98.

KAIBEL, G. A. (2010). Dividing wall columns: Fundamentals and recent advances. Chemical Engineering and Processing: Process Intensification, 139-146.

KING, C. J. (1982). Separation processes. New Delhi: McGraw-Hill. 
KISS, A. R. (2011). Energy efficient control of BTX dividing wall column. Computers and chemical engineering, 2896- 2904.

LIMA, R. S. (2006). Efficient reactive distillation optimization using stochastic optimizers. Chemical engineering science, 1718-1739.

LONING, S., C. HORST, C., \& HOFFMANN, U. (2000). Theoretical Investigations on the Quaternary System n-Butanol, Butyl Acetate, Acetic Acid and Water. Chemical Engineering \& Technology, 789-794.

Marshall Swifts Valuation Service. (Abril de 2011). Chemical engineering. Fonte: http://accessintelligence.imirus.com/Mpowered/book/vchem11/i1/p1

NIKOLAIDES, I. P., \& MALONE, M. F. (1988). Approximate Design and Optimization of a Thermally Coupled Distillation with Prefractionator. Ind. Eng. Chem. Res., 811818

OLUJIC, Z., GADALLA, M., RIJKE, A., \& JANSENS, P. (2008). Enhancing Thermodynamic Efficiency of Energy Intensive Distillation Columns. Chem. Biochem. Eng. Q., 383-392.

PETERS, M., \& TIMMERHAUSS, K. (1991). Plant Design and Economics for Chemical Engineering. Singapore: McGraw-Hill.

PETLYUK, F. (2004). Distillation theory and its application to optimaol design of separation units. Cambridge: Cambridge series in chemical engineering.

POLING, B. E., PRAUSNITZ, J. M., \& O'CONELL, J. P. (2001). The propierties of gases and liquids. New York: McGraw-Hill.

S., H., \& HERNANDEZ, G. ( 2004). Comparison of Energy Consumptions and Total Annual Costs Between Heat Integrated and Thermally Linked Distillation Sequences. Chem. Biochem. Eng. Q., 137-143.

SANDER, S., FLISCH, C., GEISSLER, E., SCHOENMAKERS, H., RYLL, O., \& HASSE, H. (2007). Methyl acetate hydrolysis in a reactive distillation column. Chemical Engineering Research and Design, 149-154. 
SCHULTZ, M., STEWART, D., HARRIS, J. M., ROSENBLUM, S. P., SHAKUR, M. S., \& O'BRIEN, D. E. (2002). Reduce Costs with dividing-wall columns. Cep Magazine, 64-71.

SEIDER, W. D. (1999). Product and process design principles. New York: John Wiley and sons Inc.

SHAH, P. B. (2002). New synthesis framework for the optimization of complex distillation systems. AIChE Journal, 527-550.

STICHLMAIR, J. (1998). Distillation: principles and practices. New York: John Wiley and sons Inc.

TEJA, A. S., \& RICE, P. (1981). Generalized Corresponding States Method for the Viscosities of Liquid Mixtures. Ind. Eng. Chem. Fundam, 77-81.

TOMICH, J. (1974). A new simulation method for equilibrium stage processes. AIChE Journal, 229-232.

U.S. Energy information administration. (2012). Monthly Energy Review. Washington D.C.: EIA.

WOLFF, E. A., \& SKOGENSTAD, S. (1995). Operation of Integrated Three-Product (Petlyuk) Distillation. Ind. Eng. Chem. Res., 2094-2103.

YEOMANS, H. G. (2000). Disjunctive Programming Models for the Optimal Design. Ind. Eng. Chem. Res., 39 (6), 1637-1648. 


\section{APÊNDICE A. MODELOS DE DIMENSIONAMENTO DE COLUNAS DE DESTILAÇÃO}

\section{Altura}

No cálculo da altura, foi usado a descrição empírica de O'Conell, onde estão relacionados, o número de estágios achados no modelo de valor de fronteira $N$, e o espaçamento entre elas $H_{t}$. Esta descrição é levada em conta a eficiência dos estágios,

$$
\begin{aligned}
& \frac{E_{o}-a}{1-a}-\exp \left(-\sqrt{\propto \frac{\mu}{\mu_{0}}}\right)=0 \\
& N-\frac{N^{T}}{E_{j}^{0}}=0 \\
& H_{t}=[0.3-0.6] \\
& H_{\text {min }^{-}}-3 H_{t}=0 \\
& H-H_{\text {min }}+H_{t} N=0
\end{aligned}
$$

Onde $a$ e $\mu_{0}$ são parâmetros que não têm um significado físico, são valores numéricos para a eficiência. $E_{o}$, é a eficiência dos estágios, $\propto$, corresponde à volatilidade relativa relacionado com o componente mais pesado, $\mu$ é a viscosidade em cP. Na determinação da viscosidade da mistura foi utilizado métodos de contribuição de grupos de componentes, onde estes valores de viscosidade estão em função da temperatura (TEJA \& RICE, 1981).

\section{Diâmetro}

Para a determinação do diâmetro da coluna, $D$ foi levado em conta no modelo do vapor ao interior, as propriedades da mistura, as condições de operação, através de correlações.

Foi determinada a velocidade de inundação nos estágios, em função das propriedades da mistura, $M_{V}$, peso molecular da fase de vapor; $\rho_{l}, \rho_{v}$ que são as densidades do liquido e do vapor, respectivamente, além da tensão superficial $\sigma$, cujos valores estão em função da temperatura. 
$C_{f}=\frac{C_{0}}{1-C_{1} f^{C_{2}}}$

$C_{0}=252 \mathrm{~m} / \mathrm{s}$

$C_{1}=2,0$

$C_{0}=1,0$

$F l=C_{f}\left(\frac{A_{n}}{A_{m}}\right)\left(\frac{\sigma}{\sigma_{0}}\right)^{0,2} \sqrt{\rho_{l}-\rho_{v}}$

$A_{C}=\frac{M_{V}}{F l \sqrt{\rho_{V}}}=0$

$D_{C}=\sqrt{\frac{4 A_{C}}{\pi}}$

Onde $F l$ é o fator de inundação, $\frac{A_{n}}{A}$, relação entre as áreas, onde é recomendado usar o valor de 0,8 (DOUGLAS, 1988), $A_{C}$ é a área da coluna.

Modelos de dimensionamento dos trocadores de calor

O tamanho dos trocadores de calor depende principalmente das cargas de calor requeridos para esfriamento e aquecimento, além do coeficiente de transferência de calor. Para o cálculo da área dos trocadores de calor, são calculadas as temperaturas medias logarítmicas:

$\Delta T_{a v_{C}}-\frac{\left(T_{D}-T_{o u t}^{c w}\right)-\left(T_{D}-T_{i n}^{c w}\right)}{\ln \left[\frac{\left(T_{D}-T_{o u t}^{c w}\right)}{\left(T_{D}-T_{i n}^{c w}\right)}\right]}=0$

$\Delta T_{a v_{R}}-T_{s t m}-T_{B}=0$

Área do refervedor

$A_{H, r}-\frac{\dot{Q}_{B}}{U_{r e f} \Delta T_{a v_{R}}}=0$

Área do condensador

$A_{H, c}-\frac{\dot{Q}_{C}}{U_{c o n d} \Delta T_{a v_{C}}}=0$ 
Onde $T_{D}$ é a temperatura de saída do destilado, $T_{B}$ temperatura de saída do fundo dos produtos do processo, $T_{\text {in }}^{c w}$, $T_{\text {out }}^{c w}$, são as temperaturas de entrada e saída da água de esfriamento, $T_{s t m}$, é a temperatura de entrada do vapor no refervedor $\Delta T_{a v_{C}}, \Delta T_{a v_{R}}$, são as temperaturas medias logarítmicas do condensador e refervedor, respectivamente, $A_{H, r}, A_{H, c}$, são as áreas dos trocadores de calor, refervedor $\mathrm{e}$ condensador, respectivamente.

\section{Custos de capital da coluna}

Este modelo de custos providencia, a partir de estes fatores, uma correlação para a determinação do custo da carcaça mesmo como o seu interior, para obter o custo total da coluna:

$C_{c o l}=C_{S}+C_{t}$

O modelo é sensível a diferentes fatores tais como o diâmetro, a altura, espessura das paredes. A coluna dentro destes modelos é um recipiente a pressão. O custo de instalação inclui material de suporte e aberturas de acesso. (DOUGLAS, 1988).

$$
\begin{aligned}
& C_{S}-C_{0, S}\left(\frac{D_{C}}{D_{0}}\right)\left(\frac{H}{H_{0}}\right)^{a_{S}}=0 \\
& a_{S}=0.82
\end{aligned}
$$

Onde $C_{S}$, corresponde aos custos da carcaça cilíndrica, $H$ é a altura da coluna, $d$ é o diâmetro, $d_{0}$ parâmetro de correlação de custos referente ao diâmetro da coluna com valor de $1 \mathrm{~m}, H_{0}$, parâmetro de correlação de custos referente à altura com valor de $5 \mathrm{~m}$. (DOUGLAS, 1988).

O fator $C_{0, S}$, esta relacionado com as características do material $F_{p}$, também com as condições de pressão da coluna , $F_{m}$, o fator de custo direto $F_{D}$ e também do fator de custo indireto, $F_{l}$.

O índice $M \& S$, corresponde ao quarto trimestre de 2011 (Marshall Swifts Valuation Service, 2011), $M \& S_{\text {base }}$, corresponde ao ano de 1970 (DOHERTY, 2001).

$$
\begin{aligned}
& \boldsymbol{C}_{0, S}-\left(\frac{M \& S}{M \& S_{\text {base }}}\right)\left[F_{m} F_{p}-1+F_{l} F_{D}\right] c_{0, S_{\text {base }}}=0 \\
& C_{0, t_{\text {base }}}=U S \$ 5000
\end{aligned}
$$


$F_{p}=1$

$M \& S_{\text {base }}=301$

$M \& S_{2011}=1536,5$

$F_{l}=1.38$

$F_{D}=3.00$

$F_{m}=1.00$

Tabela A.1- Materiais de construção de colunas de destilacao

\begin{tabular}{ccl} 
& $F_{m}$ (Material da carcaça) \\
\hline Revestido & Sólido & Material \\
1 & 1 & Aço Carbono \\
2.30 & 3.50 & Inox. 304 \\
2.60 & 4.25 & Inox. 316 \\
4.50 & 9.75 & Monel \\
4.89 & 10.76 & Titânio
\end{tabular}

De igual maneira, o custo interno da coluna está relacionado com o custo dos estágios.

$C_{t}-C_{0, t}\left(\frac{D}{D_{0}}\right)^{a_{t}}\left(\frac{H}{H_{0}}\right)=0$

$\boldsymbol{C}_{\mathbf{0}, \boldsymbol{t}}-\left(\frac{M \& S}{M \& S_{\text {base }}}\right)\left[F_{S}+F_{t}+F_{m}\right] c_{0, t_{\text {base }}}=0$

$a_{t}=1.8$

$C_{0, t_{\text {base }}}=U S \$ 500$

$M \& S_{\text {base }} \$ 301$

$F_{S}=1$ Tabela $4-2$

$F_{t}=0$ Tabela $4-3$

Onde, $F_{T}$, Tipo de etapa, $F_{S}$, Espaço entre as estágios

Tabela A.2- Parâmetro das dimensões dos estágios

\begin{tabular}{cl}
\hline$F_{S}$ & Espaçamento \\
\hline 1 & $0.6 \mathrm{~m}$ \\
1.3 & $0.45 \mathrm{~m}$ \\
2.0 & $0.30 \mathrm{~m}$ \\
\hline
\end{tabular}


Tabela A.3- Parâmetro das características dos estágios

\begin{tabular}{cl}
\hline$F_{t}$ & Configuração \\
\hline 0.0 & Rede \\
0.0 & Prato \\
0.0 & Crivo \\
0.3 & Válvula \\
1.6 & Tampa de bolha \\
3.2 & $\quad$ Koch \\
$F_{m}$ & (Material dos pratos) \\
0.0 & Aço Carbono \\
1.5 & Inox. \\
8.5 & Monel \\
\hline
\end{tabular}

\section{Custo dos trocadores de calor}

Os trocadores de calor mais comuns são de carcaça e tubos para sistemas de vapor-líquido, cuja fabricação pode ser de diferentes configurações. Para determinação do custo dos trocadores, de calor em função da área de transferência de calor. Devido às diferentes configurações, materiais de construção, custos de instalação, pressão de operação, são levados em conta através de fatores neste trocador de calor.

$$
\begin{aligned}
& C_{H}-C_{0, H}\left(\frac{A_{H}}{A_{0}}\right)^{a_{H}}=0 \\
& \boldsymbol{C}_{\mathbf{0}, \boldsymbol{H}}-\left(\frac{M \& S}{M \& S_{\text {base }}}\right)\left[\left(F_{d}+F_{p}\right) F_{m}-1+F_{l} F_{D}\right] c_{0, H_{\text {base }}}=0 \\
& a_{H}=0.65 \\
& C_{0, H_{\text {base }}}=\$ 8700 \\
& F_{p}=0 \\
& M \& S_{\text {base }}=301 \\
& F_{D}=2.30 \\
& F_{I}=2.30
\end{aligned}
$$

Tabela A.4- Material de trocador de carcaça e tubo

\begin{tabular}{ll}
\hline$F_{m}$ & \multicolumn{1}{c}{ Material } \\
\hline 1.0 & Aço Carbono / Aço Carbono \\
1.2 & Aço Carbono \\
1.8 & Molibdênio / Molibdênio \\
1.6 & Aço Carbono / Molibdênio \\
3.0 & Aço inox / Aço inox \\
2.2 & Aço Carbono/ Aço inox \\
3.9 & Monel / Monel \\
2.7 & Aço Carbono/ Monel \\
12.0 & Titânio / Titânio \\
7.0 & Aço Carbono / Titânio \\
\hline
\end{tabular}




\section{Custos de operação}

Os custos de operação para sistemas de destilação estão associados diretamente com as demandas de vapor e fluído de esfriamento nos trocadores de calor, este custo esta relacionado com a vazão de vapor requerido segundo as demandas de calor no refervedor para uma determinada separação. Por outra parte, o custo da água de esfriamento, esta relacionada com a vazão de água requerida na carga de calor no condensador:

$$
\begin{gathered}
\frac{\dot{Q_{B}}}{\Delta H_{s t m}}-\dot{W}_{r}=0 \\
\frac{\dot{Q_{C}}}{C_{p_{l q}}\left(T_{\text {out }}^{H}-T_{\text {in }}^{C}\right)}-\dot{W}_{C}=0
\end{gathered}
$$

Onde $W_{r}$, e $\dot{W}_{C}$ são as vazões de vapor de aquecimento e água de esfriamento, respectivamente, $C_{p_{l q}}$ é a capacidade calorífica em função da temperatura da água de esfriamento. $\Delta H_{s t m}$, entalpia de vaporização do fluxo de vapor no refervedor, $T_{o u t}^{H}$, $T_{i n}^{C}$, temperaturas de entrada e saída da água no condensador.

Para a determinação da vazão de vapor, no caso do refervedor, foram estabelecidas as seguintes condições:

- A pressão de vapor de aquecimento é 10 vezes a pressão de operação da coluna.

- O combustível utilizado é fuel oil. Para este combustível, foi levado em conta o índice de preço de combustíveis fósseis, $P_{\text {Comb }}$ (US\$/MMBTU) (U.S. Energy information administration, 2012). Para a determinação deste custo, se relaciona a entalpia de vaporização do vapor, a vazão de vapor no refervedor.

$$
C_{\text {Comb }}=\frac{W_{r} * \Delta H_{s t m}}{P C S * \eta} *
$$

Onde PCS é o poder calorífico superior do combustível, e $\eta$, é a eficiência da caldeira, segundo o PCS.

- O custo da geração de vapor está associado ao custo de combustível por meio da seguinte relação:

$$
C_{\text {vap }}=C_{\text {Comb }}(1+0,30)
$$


Onde $C_{v a p}$, é o custo do vapor no sistema, $C_{C o m b}$, é o custo do combustível. Esta relação contempla os custos inerentes emissões, manutenção, reagentes para o tratamento da água no refervedor, e custos de pessoal. (Energy, 2003). 


\section{APÊNDICE B. PROGRAMAS PARA SEQUÊNCIAS CONVENCIONAIS E COLUNA COM PAREDE DIVIDIDA}

Rotina de otimização combinatória para uma coluna com parede dividida

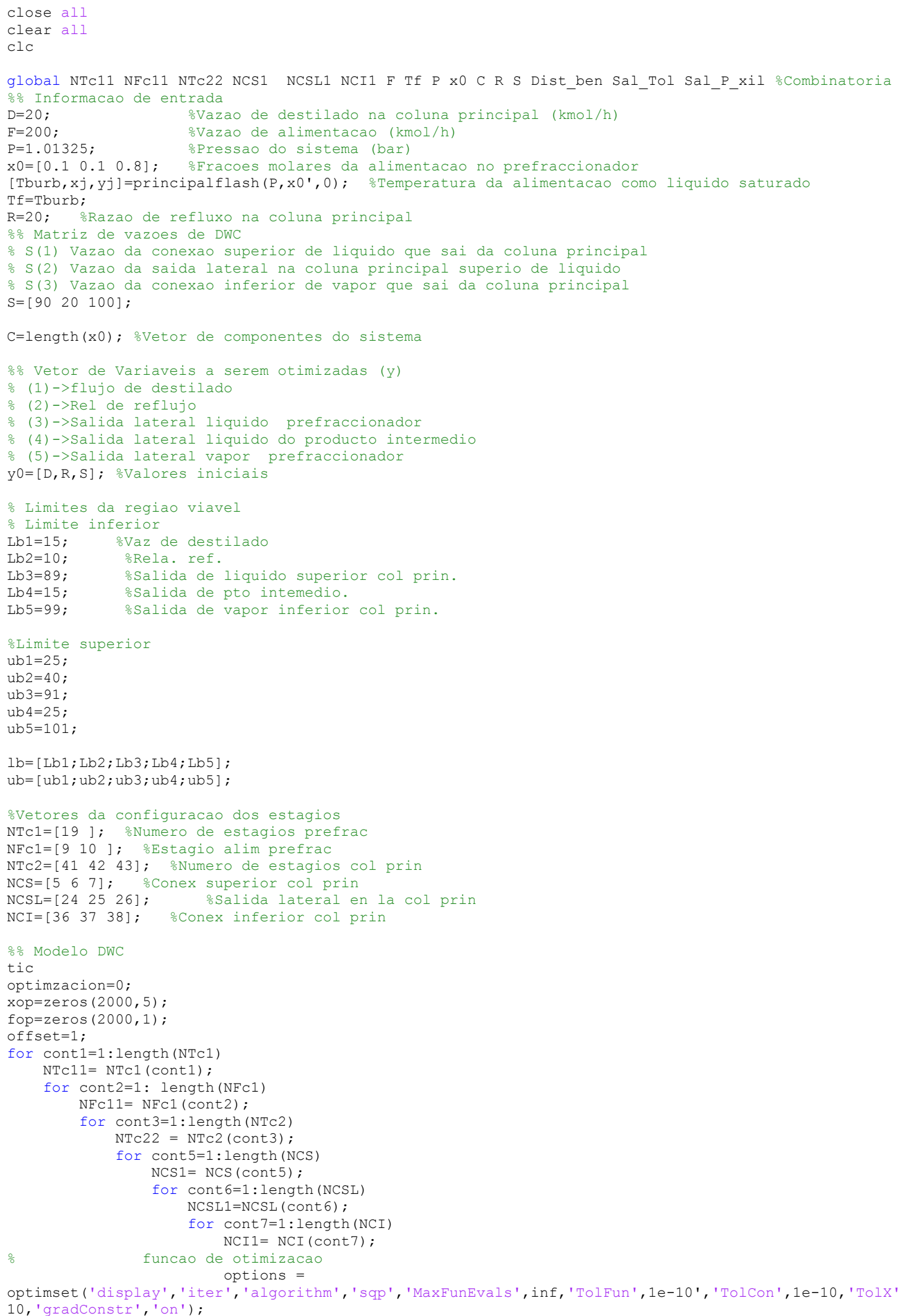




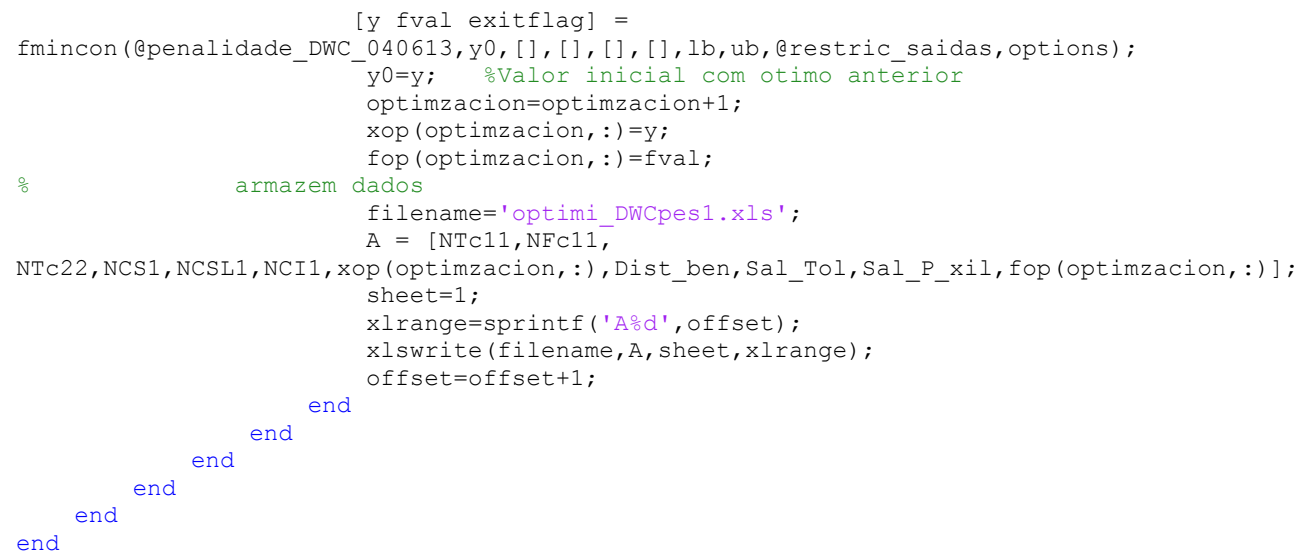

\section{Função de otimização com penalidade para uma coluna com parede dividida}

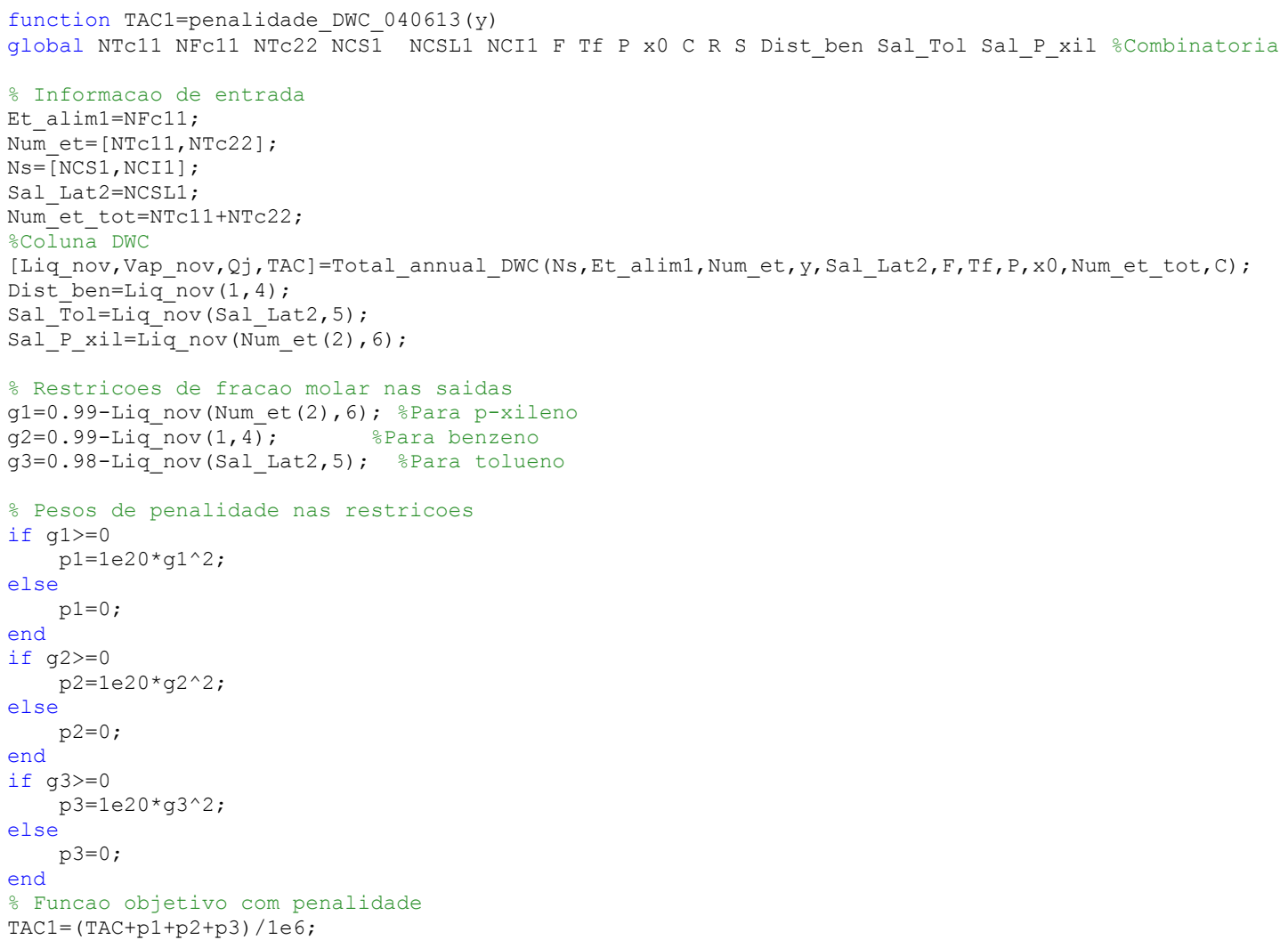

\section{Restrições das vazões das conexões}

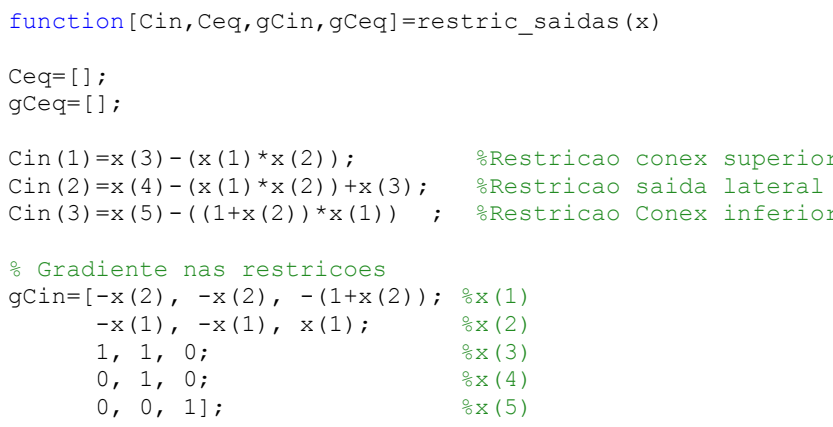




\section{Custo total anualizado para uma coluna com parede dividida}

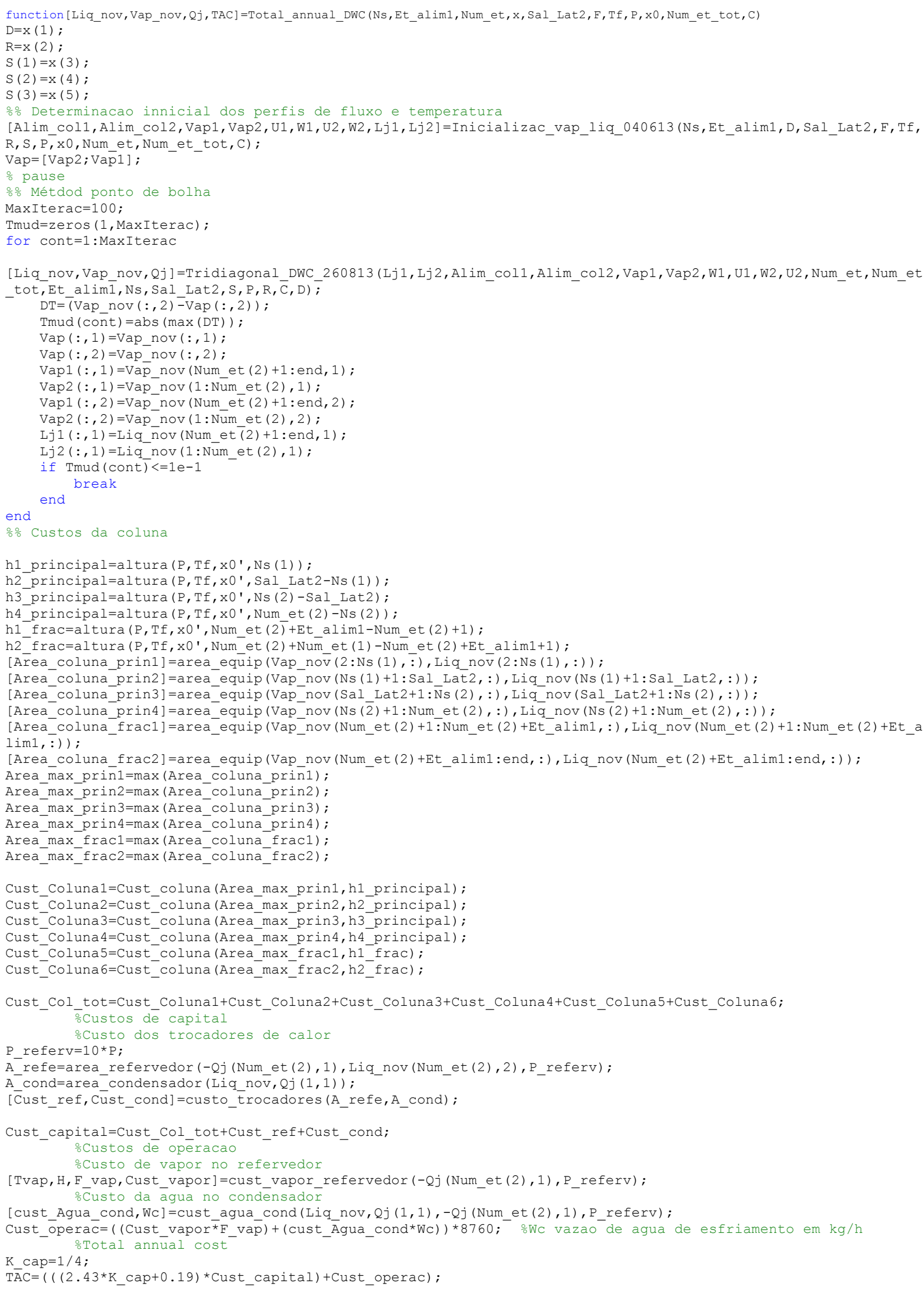




\section{Inicialização de vazões internos e temperatura para uma coluna com parede dividida}

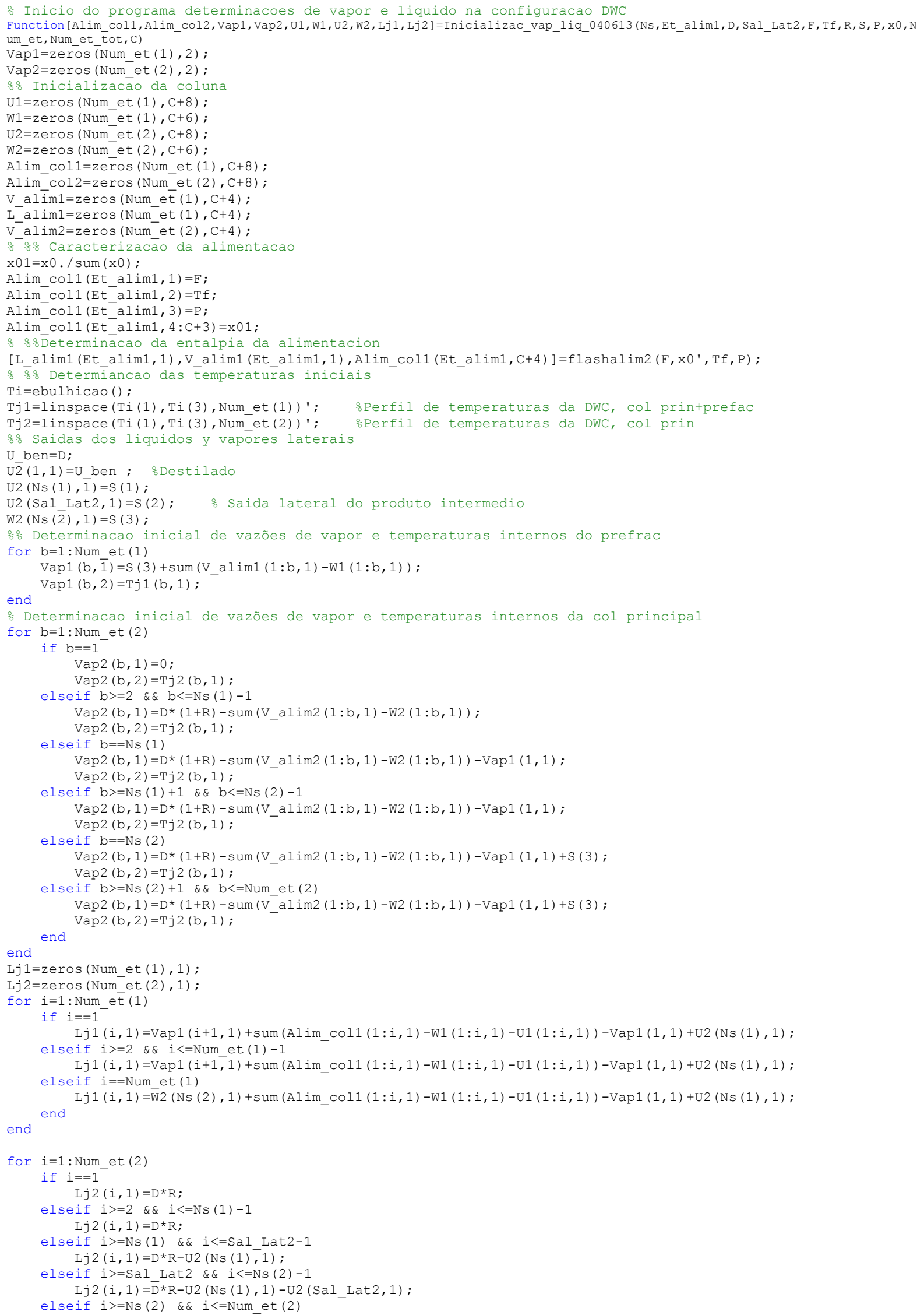



en

end

\section{Modelo da coluna com parede dividida e geração da matriz esparsa}

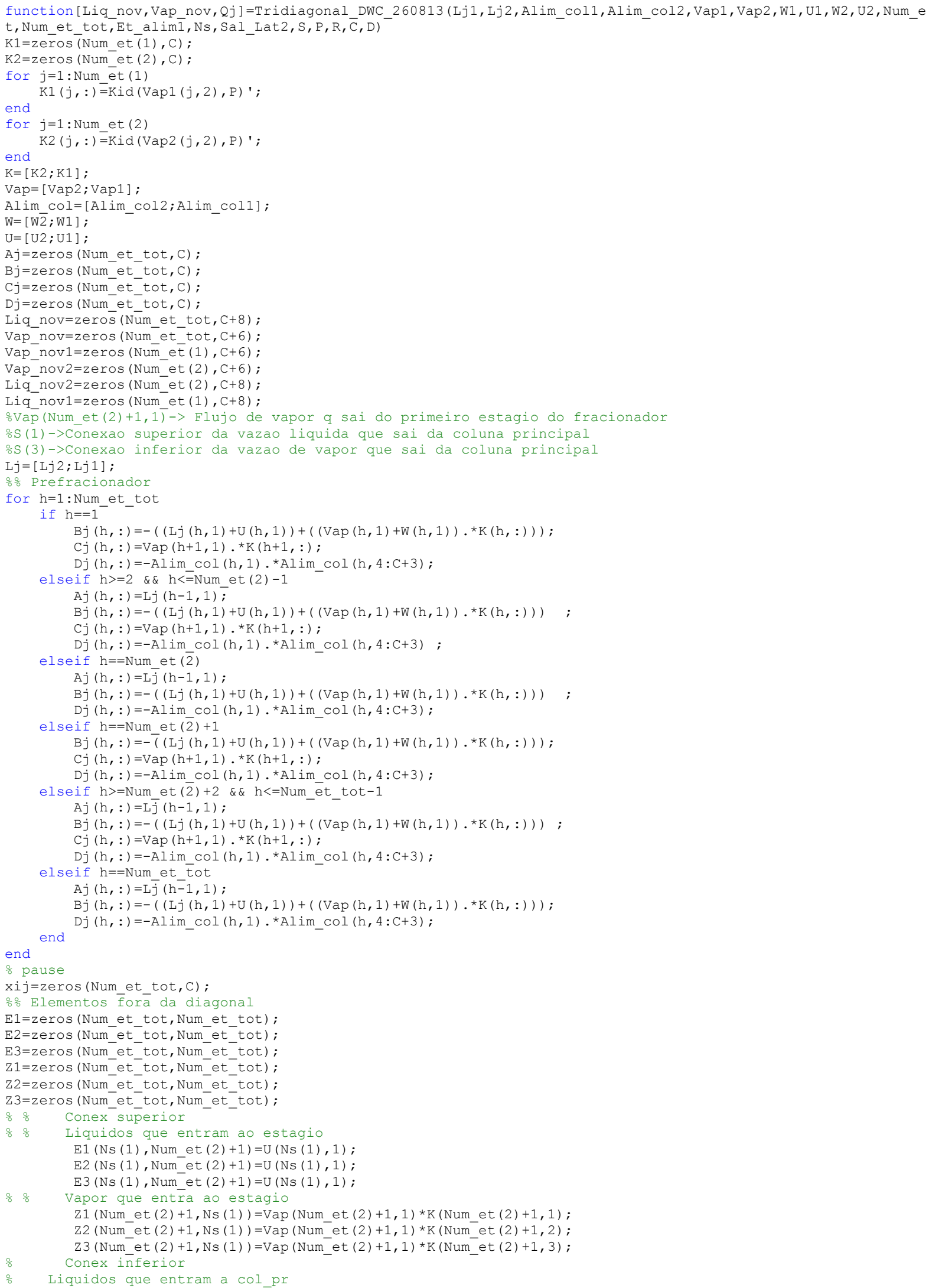




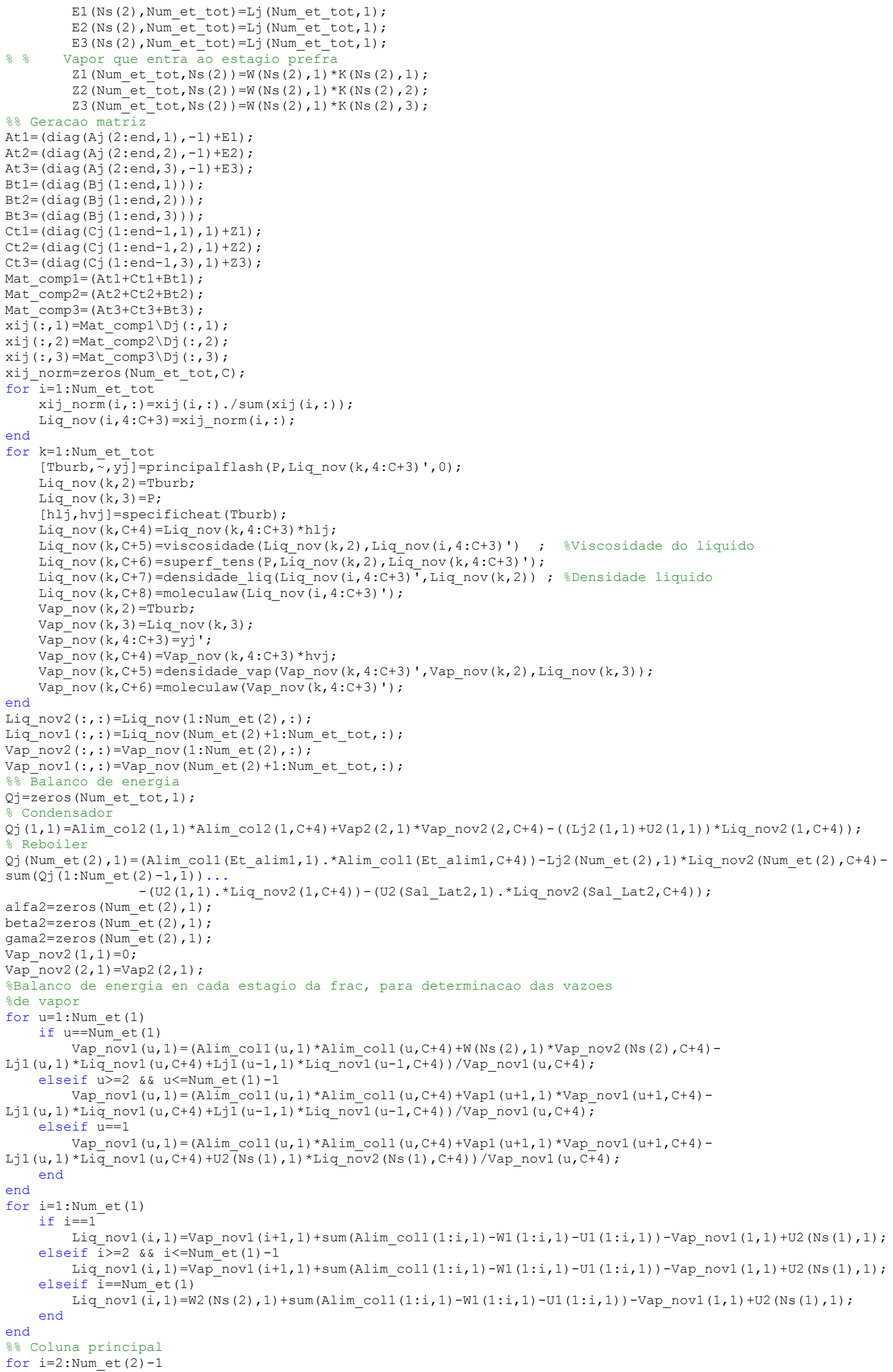




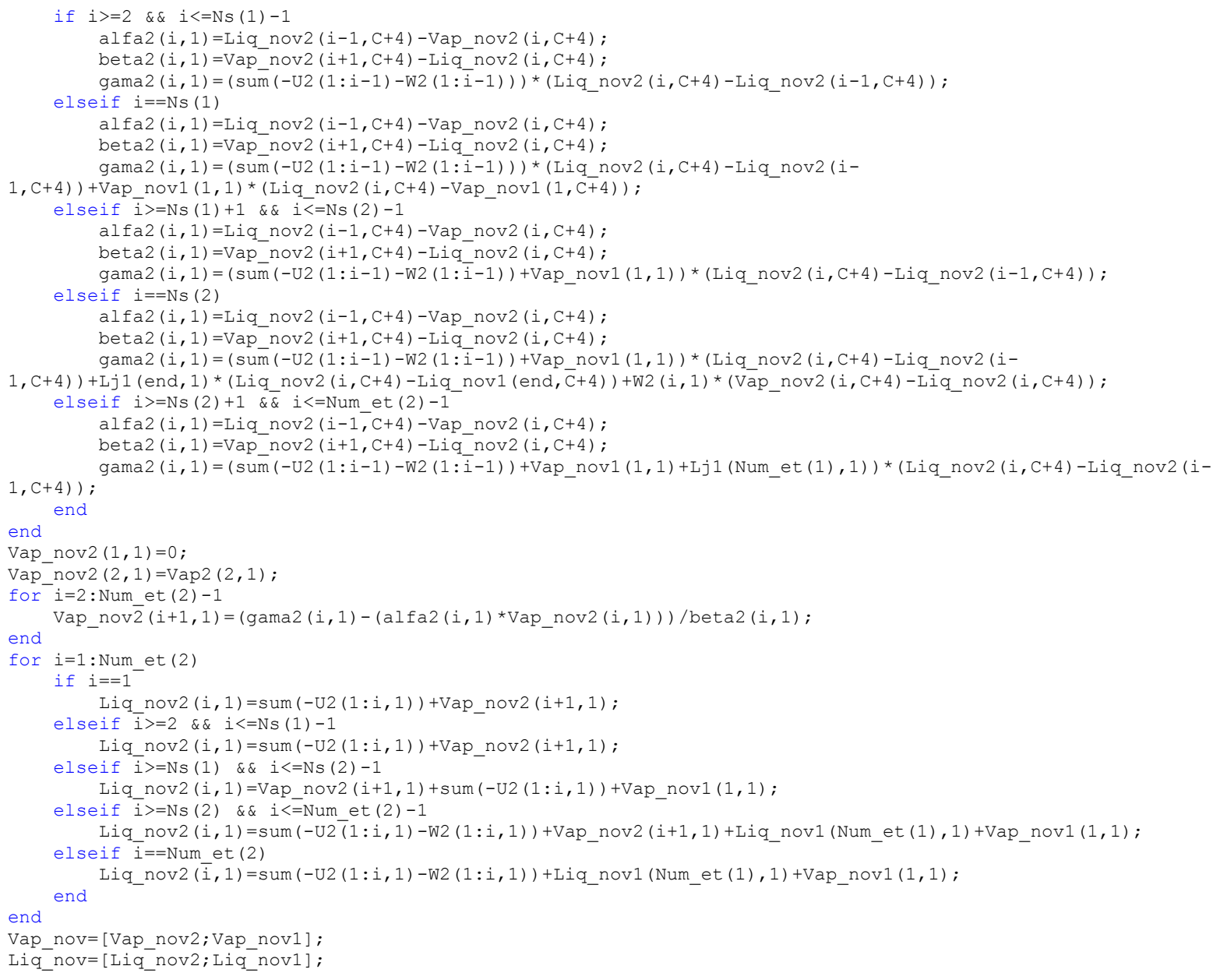

\section{Determinação das condições da alimentação (flash)}

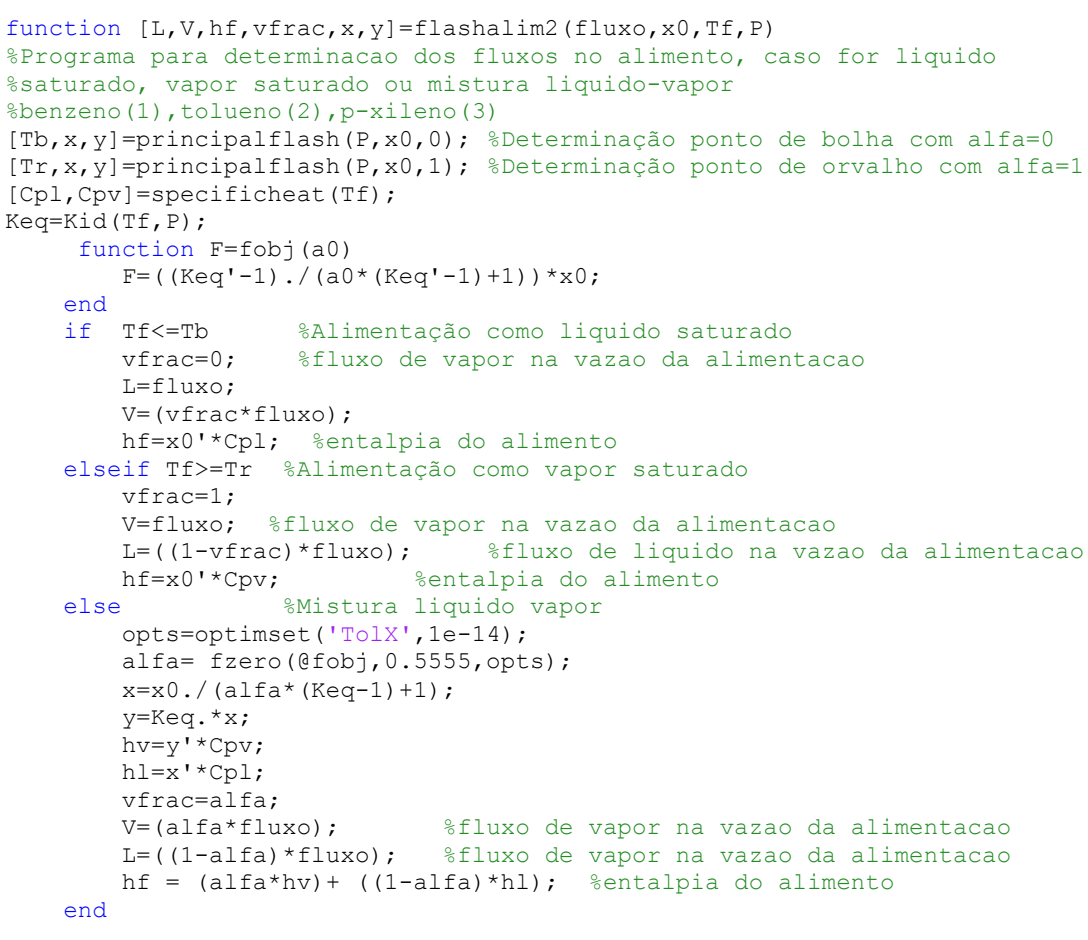




\section{Programa pressão de vapor}

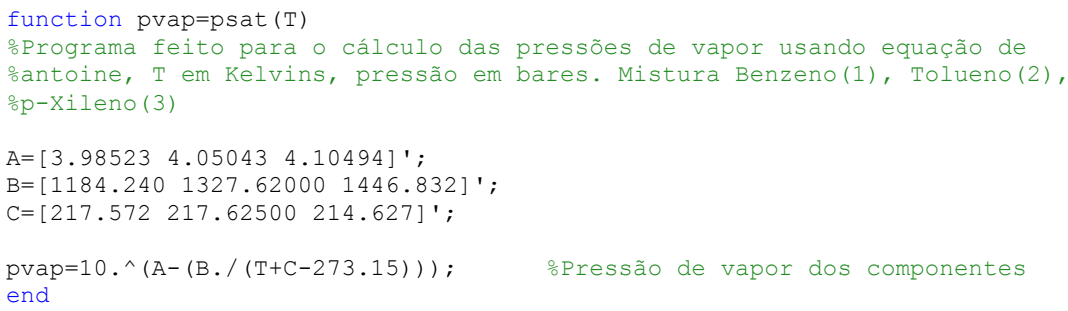

\section{Constantes de equilibrio}

function $\mathrm{K}=\mathrm{Kid}(\mathrm{T}, \mathrm{P})$

$\mathrm{K}=\mathrm{psat}(\mathrm{T}) \cdot / \mathrm{P}$;

end

\section{Programa para determinação do ponto de bolha}

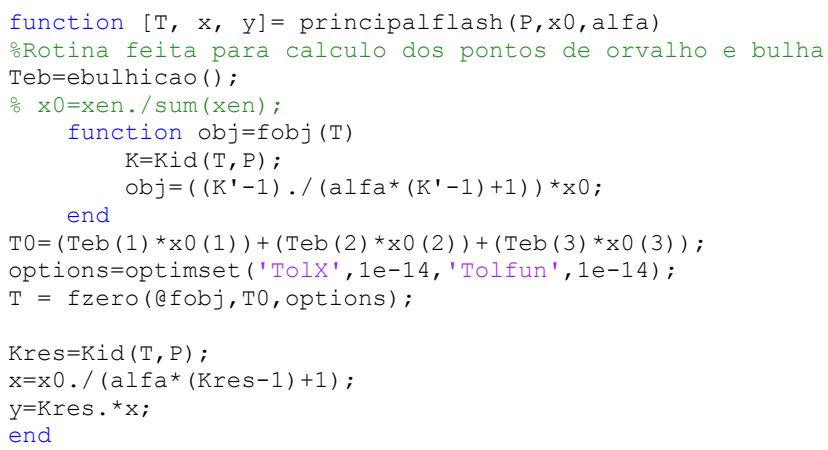

Determinação das entalpias das fases liquidas e de vapor

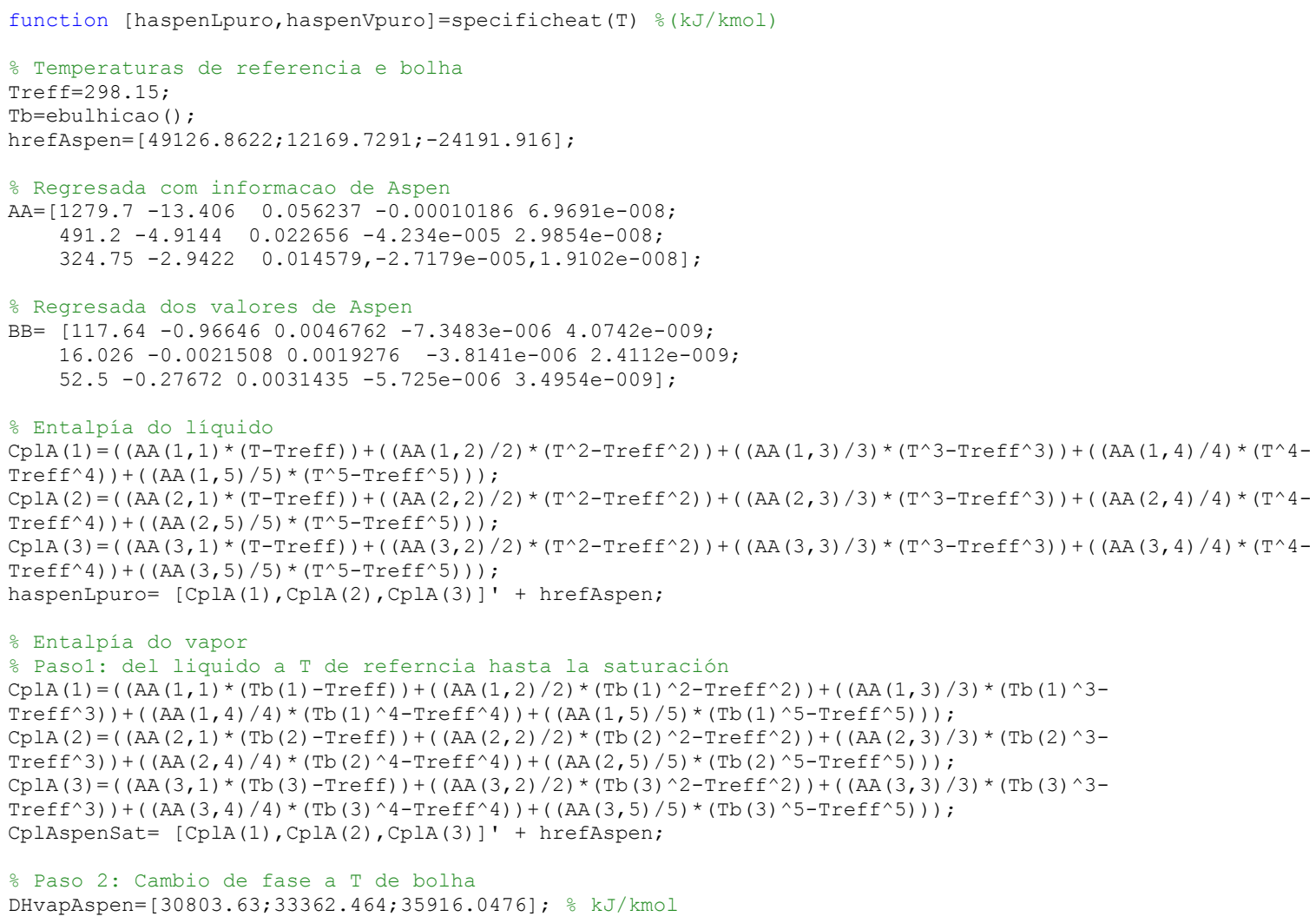


ocapacidade calorifica do gas ideal ( $\mathrm{kj} / \mathrm{kmol} \mathrm{k})$

$\operatorname{CpgiAs}(1)=\left((B B(1,1) *(T-T b(1)))+\left((B B(1,2) / 2) *\left(T^{\wedge} 2-T b(1) \wedge 2\right)\right)+\left((B B(1,3) / 3) *\left(T^{\wedge} 3-T b(1) \wedge 3\right)\right)+\left((B B(1,4) / 4) *\left(T^{\wedge} 4-\right.\right.\right.$ $\left.\left.\left.\operatorname{Tb}(1)^{\wedge} 4\right)\right)+\left((\mathrm{BB}(1,5) / 5) *\left(\mathrm{~T}^{\wedge} 5-\mathrm{Tb}(1)^{\wedge} 5\right)\right)\right) ;$ oEntalpía $(\mathrm{kJ} / \mathrm{kmol})$

$\operatorname{CpgiAs}(2)=\left((B B(2,1) *(T-T b(2)))+\left((B B(2,2) / 2) *\left(T^{\wedge} 2-T b(2) \wedge 2\right)\right)+\left((B B(2,3) / 3) *\left(T^{\wedge} 3-T_{b}(2) \wedge 3\right)\right)+\left((B B(2,4) / 4) *\left(T^{\wedge} 4-\right.\right.\right.$ $\left.\left.\left.\mathrm{Tb}(2)^{\wedge} 4\right)\right)+\left((\mathrm{BB}(2,5) / 5) *\left(\mathrm{~T}^{\wedge} 5-\mathrm{Tb}(2)^{\wedge} 5\right)\right)\right) ;$

$\operatorname{CpgiAs}(3)=\left((B B(3,1) *(T-T b(3)))+\left((B B(3,2) / 2) *\left(T^{\wedge} 2-T b(3) \wedge 2\right)\right)+\left((B B(3,3) / 3) *\left(T^{\wedge} 3-T b(3) \wedge 3\right)\right)+\left((B B(3,4) / 4) *\left(T^{\wedge} 4-\right.\right.\right.$ $\left.\left.\left.\mathrm{Tb}(3)^{\wedge} 4\right)\right)+\left((\mathrm{BB}(3,5) / 5) *\left(\mathrm{~T}^{\wedge} 5-\mathrm{Tb}(3)^{\wedge} 5\right)\right)\right)$;

CpgiAs=CpgiAs' ;

haspenVpuro $=$ CplAspenSat + DHvapAspen+CpgiAs;

end

Determinação da viscosidade em função da temperatura para a mistura Benzeno, Toluen, p-xileno

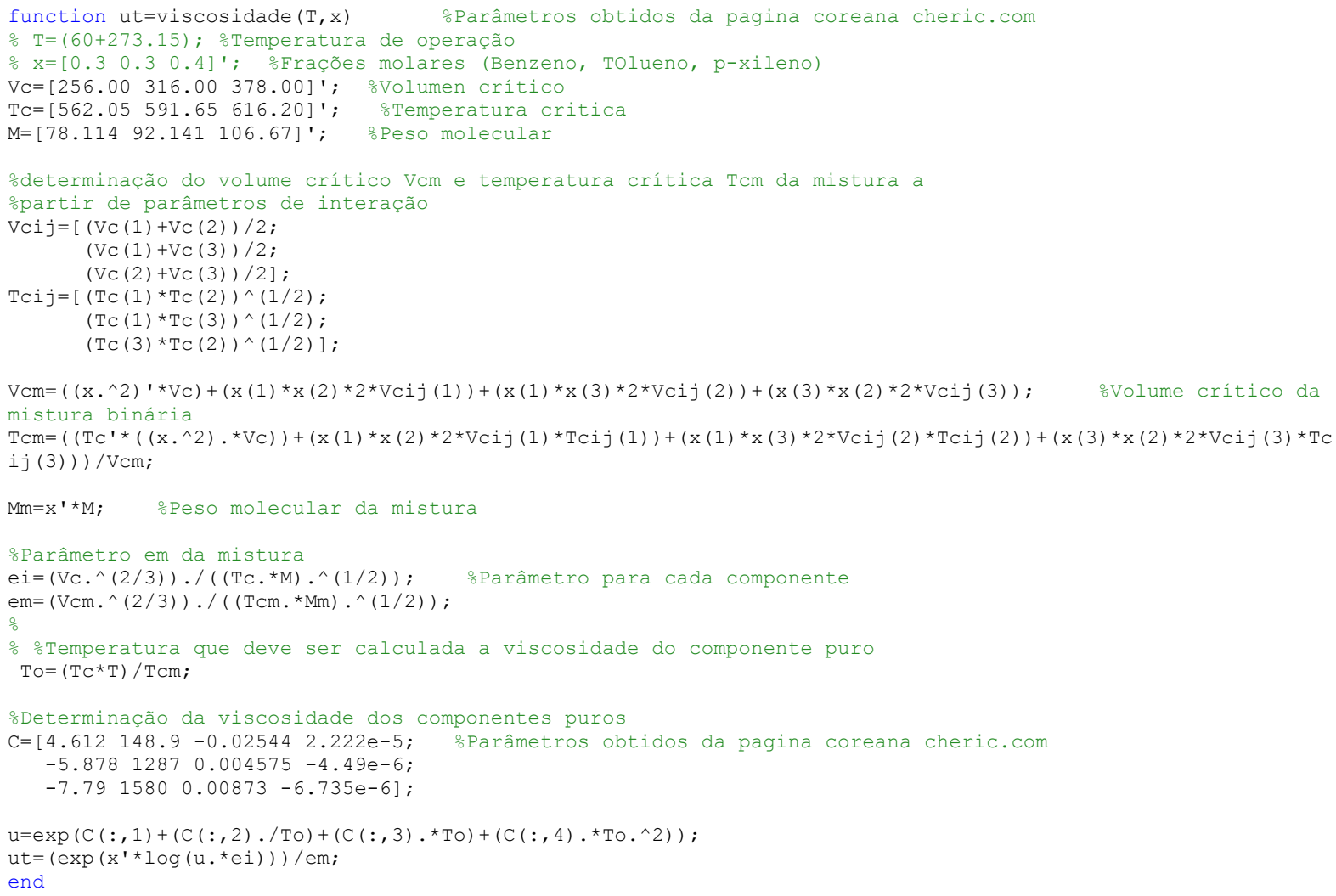

\section{Tensão superficial da mistura em função da temperatura}

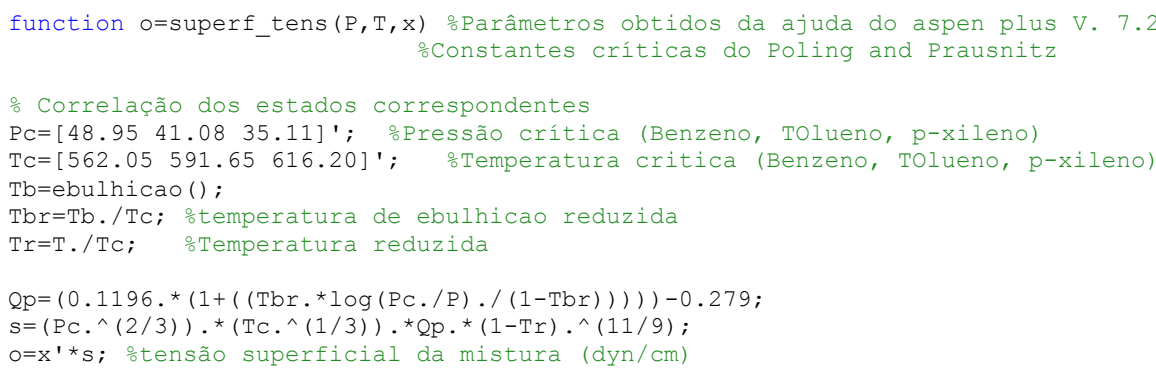

\section{Densidade da mistura como liquido}

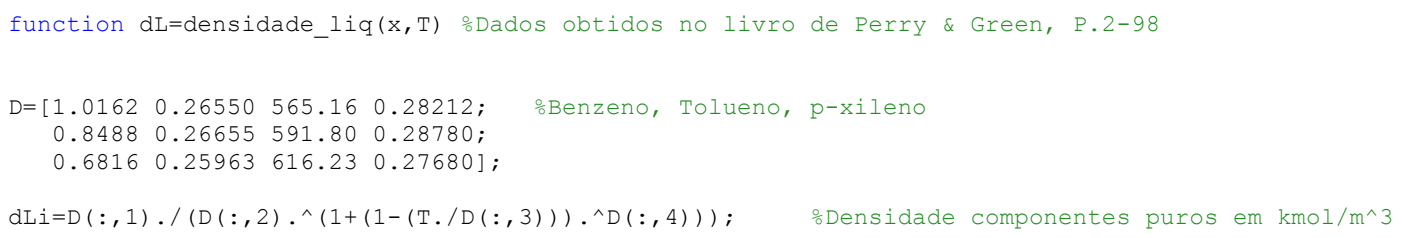


$\mathrm{dLmol}=\mathrm{dLi}{ }^{\prime}{ }^{*} \mathrm{x}$

odensidade da fase líquida $\mathrm{kmol} / \mathrm{m}^{\wedge} 3$

peso mol= moleculaw $(\mathrm{x})$;

$\mathrm{dL}=\mathrm{dLmol} \mathbf{\prime}^{*}$ peso mol; $\frac{\circ}{\circ}$ densidade da mistura em fase liquida em kg/m^3

\section{Densidade da mistura como vapor}

function $d V=$ densidade $\operatorname{vap}(\mathrm{x}, \mathrm{T}, \mathrm{P})$ oDados obtidos no livro de Perry \& Green, P.2-98 $\mathrm{dV}=\left(\mathrm{P} .{ }^{*}\right.$ moleculaw $\left.(\mathrm{x})\right) /(\mathrm{R} * \mathrm{~T}) ; \%$ Densidade do vapor usando correlação do gas ideal ( $\left.\mathrm{kg} / \mathrm{m}^{\wedge} 3\right)$ end

\section{Peso molecular da mistura}

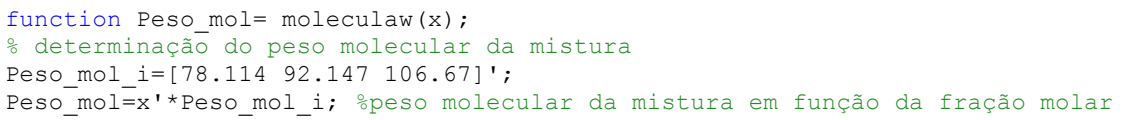

\section{Matriz tridiagonal para uma coluna convencional}

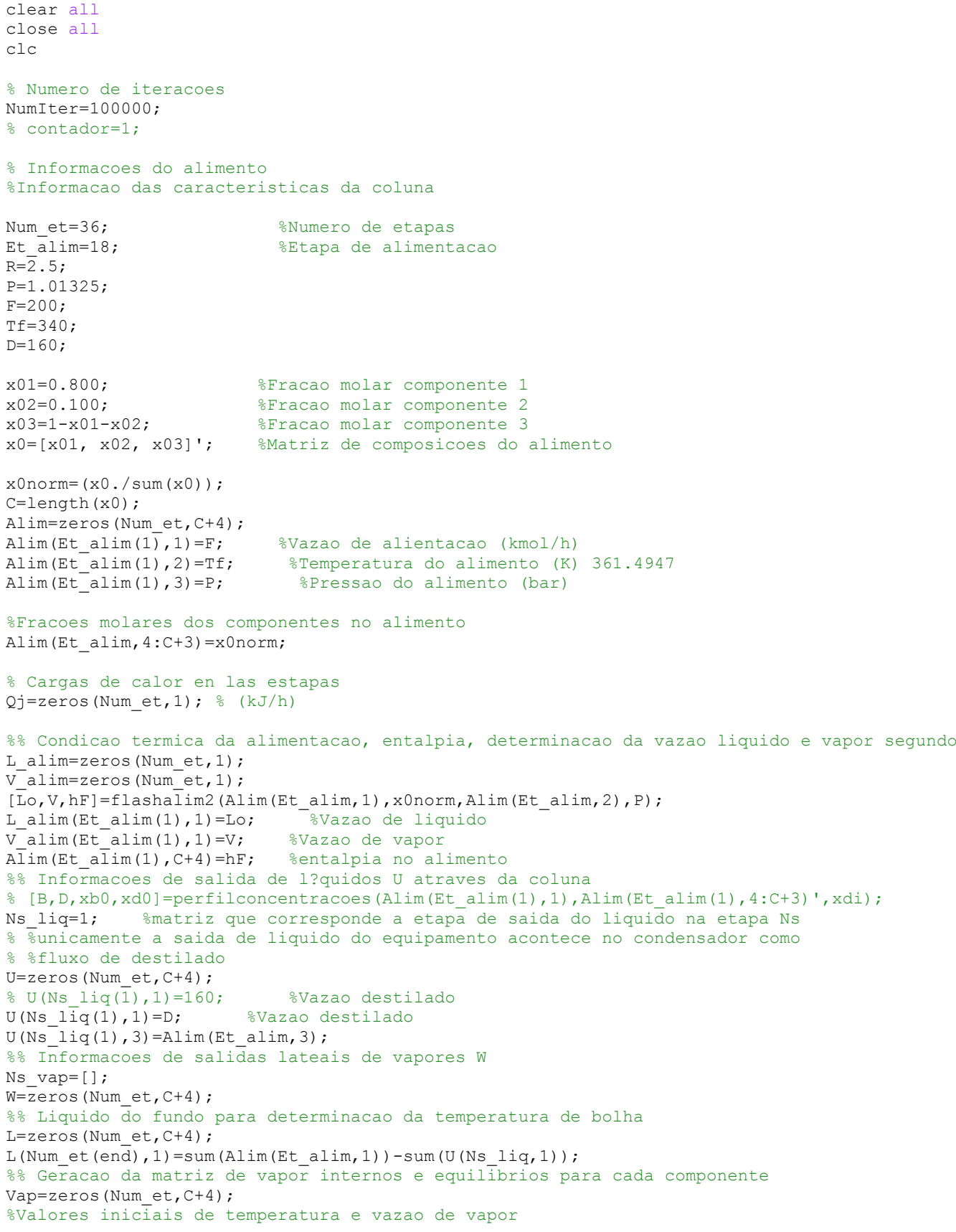




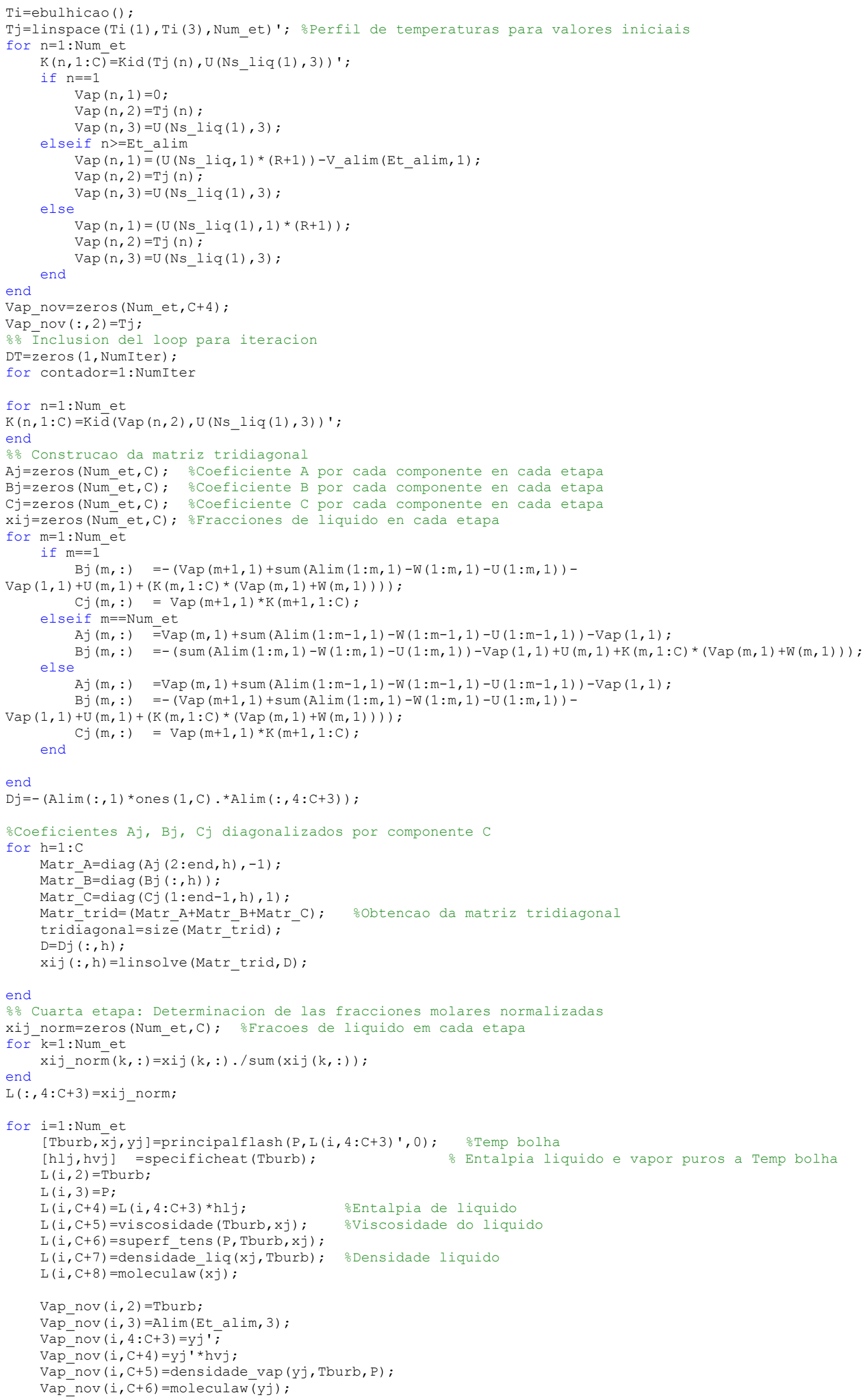




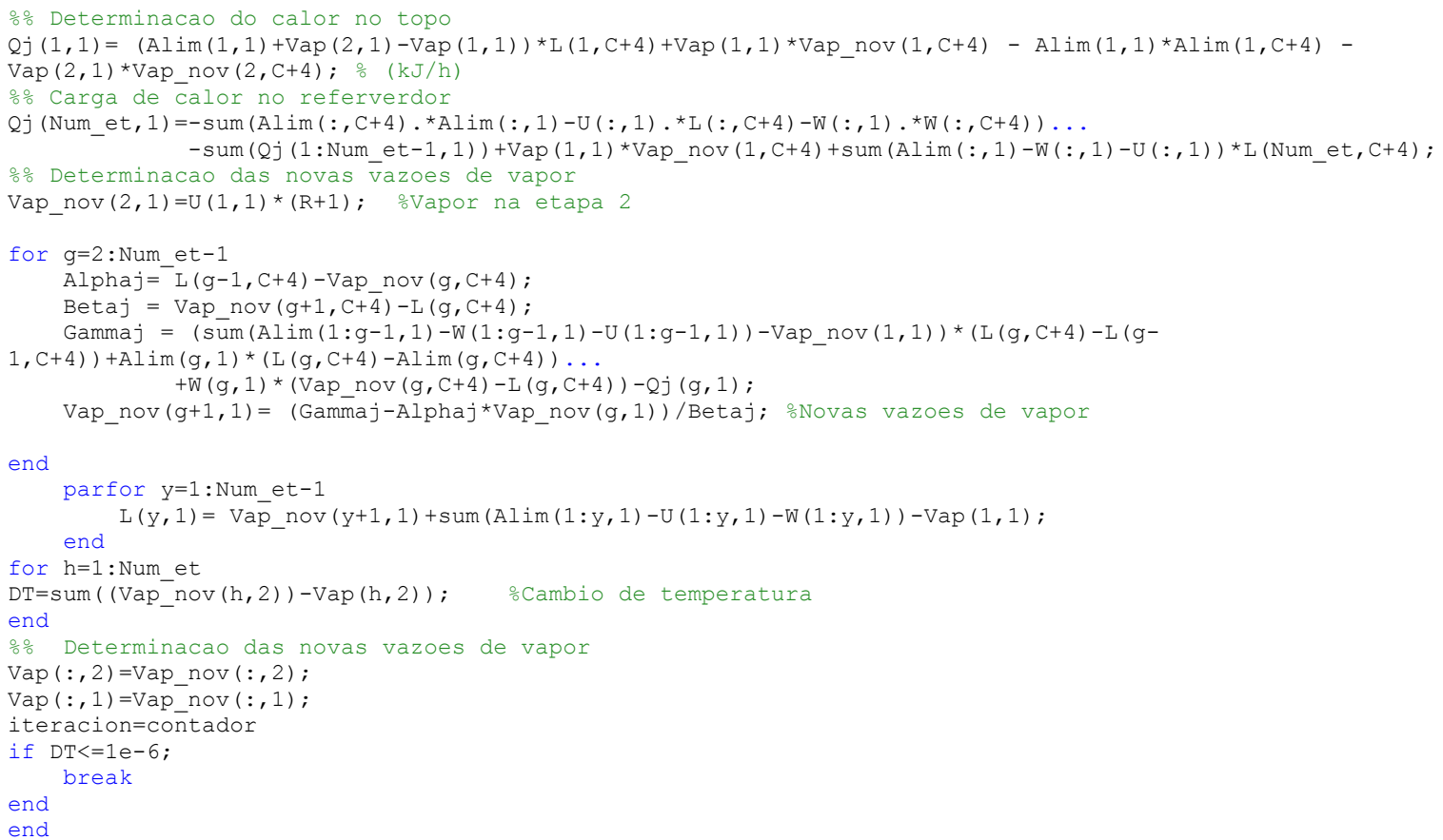

\section{Custos para uma sequência convencional}

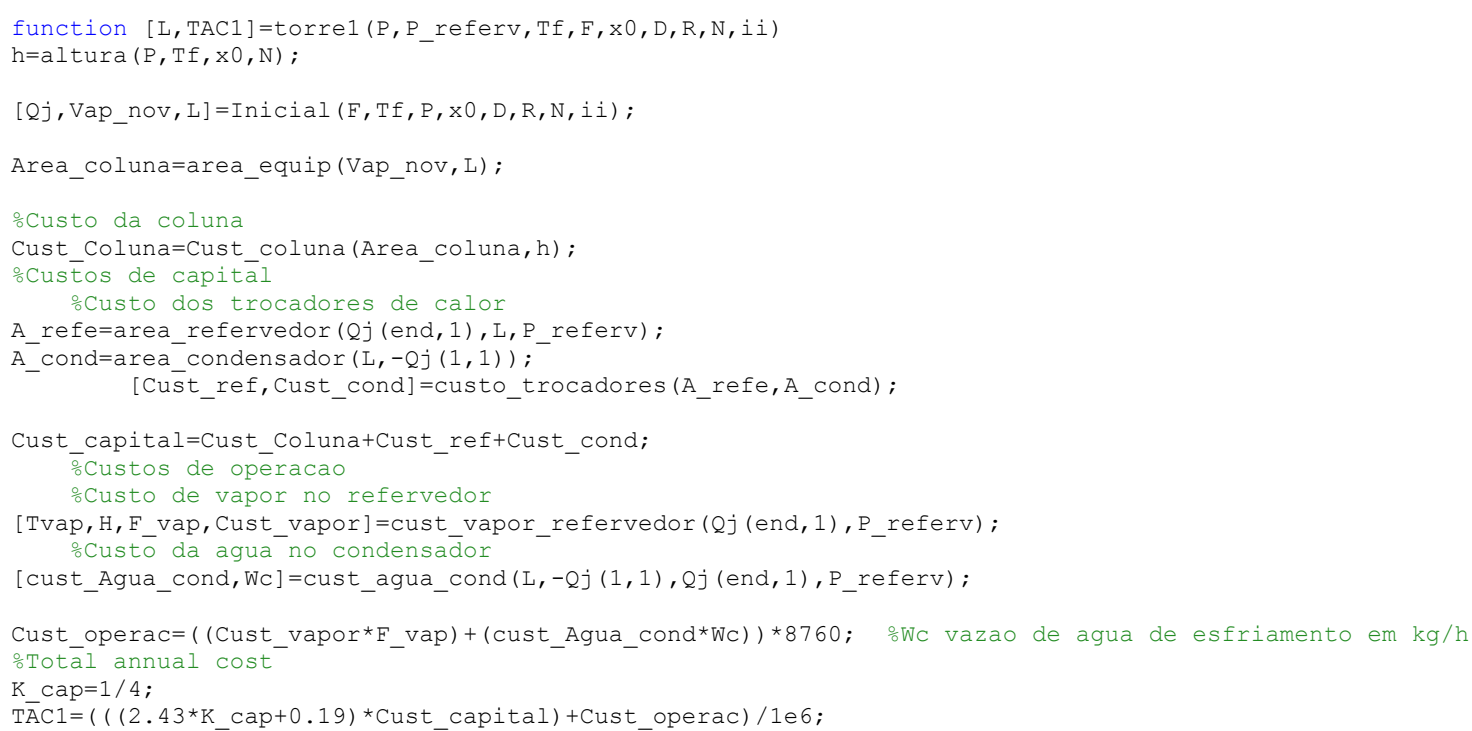

\section{Solução simultânea para uma sequência convencional indireta}

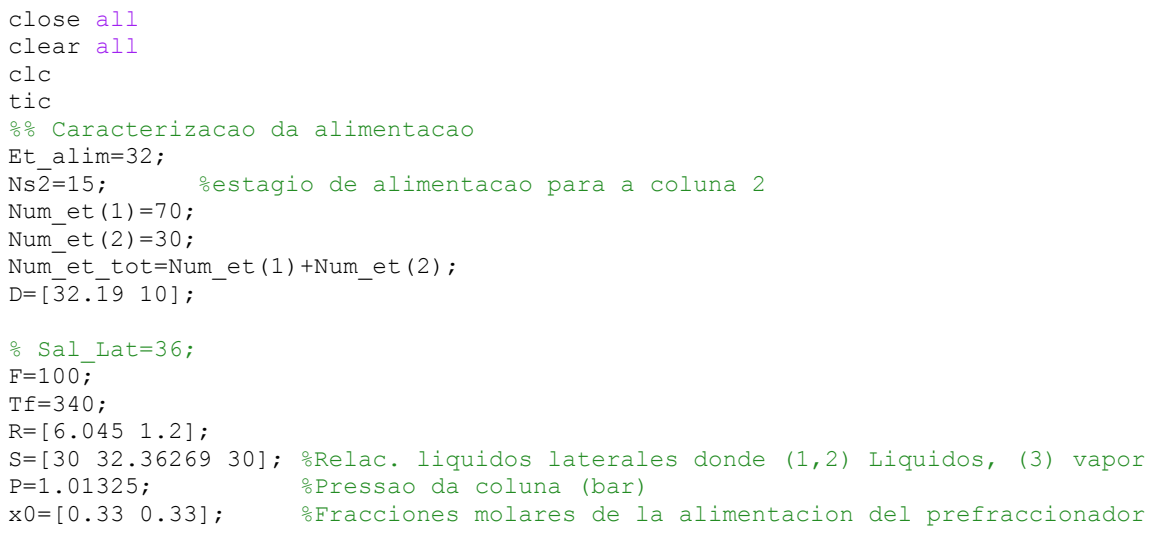




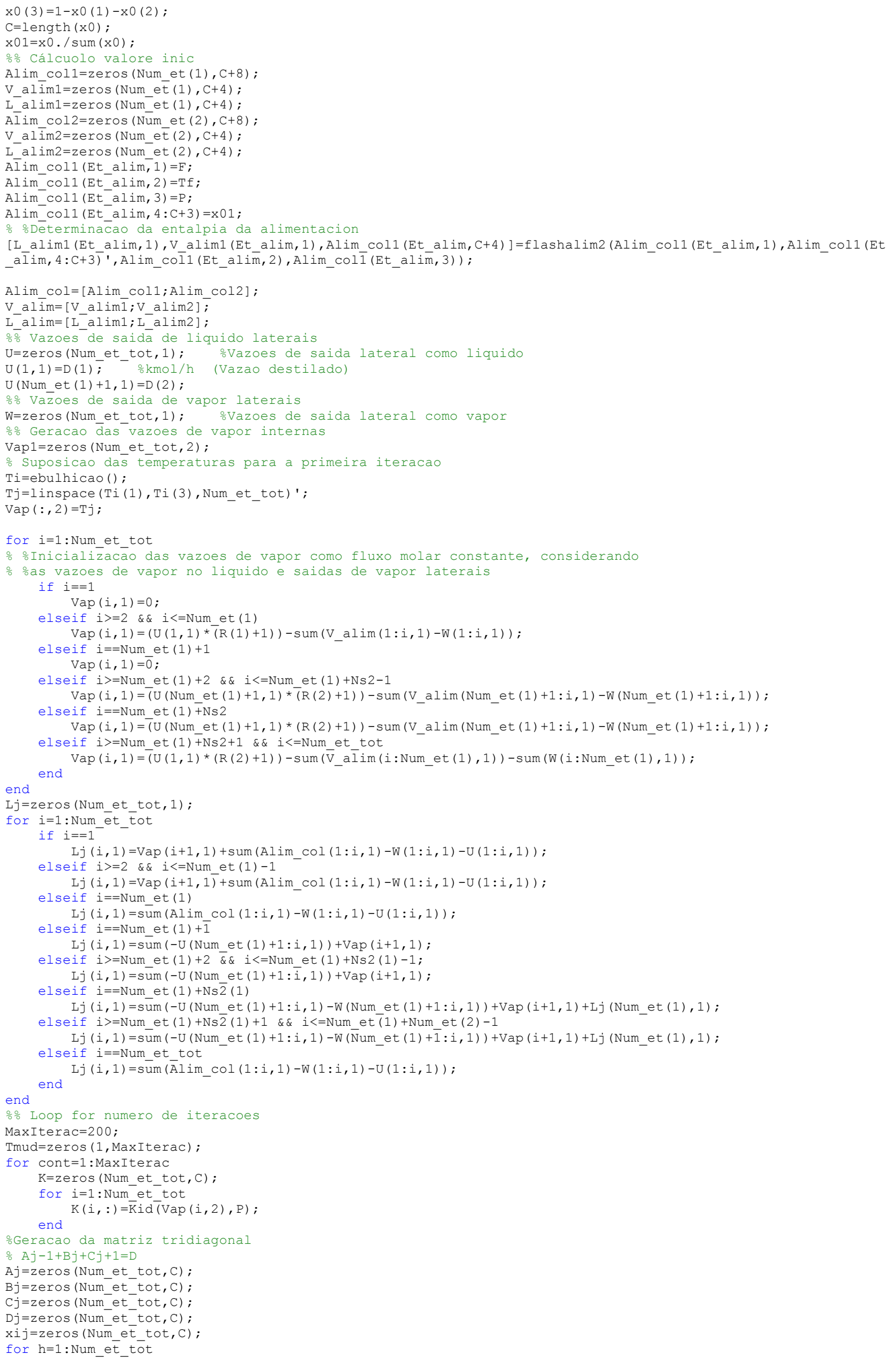




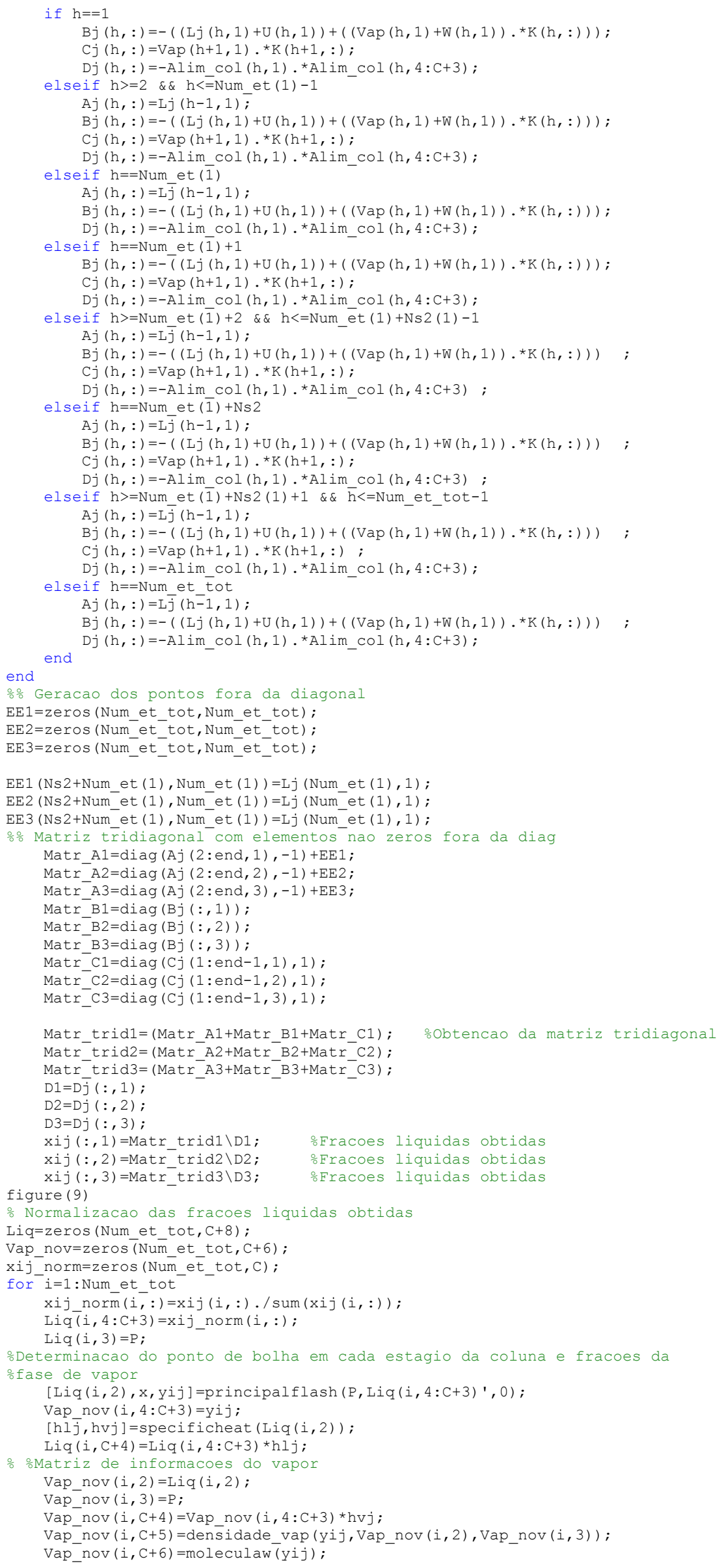


\% Matriz de informacoes do liquido

Liq $(i, C+5)=\operatorname{viscosidade}(\operatorname{Liq}(i, 2), x)$;

$\operatorname{Liq}(i, C+6)=$ superf tens $(\operatorname{Liq}(i, 3), \operatorname{Liq}(i, 2), x)$

Liq $(i, C+7)=$ densidade_liq $(x, \operatorname{Liq}(i, 2))$;

end

$\operatorname{Liq}(i, C+8)=\operatorname{moleculaw}(x)$;

\%음 Determinacao das cargas de calor do refervedor e do condensador

$Q j=$ zeros (Num_et_tot, 1$)$;

Qj $(1,1)=A l i m \_c o l(1,1) * A l i m \_c o l(1, C+4)+\operatorname{Vap}(2,1) * \operatorname{Vap} \_n o v(2, C+4)-((\operatorname{Lj}(1)+U(1,1)) * \operatorname{Liq}(1, C+4))$;

\% oalor no refervedor

Qj (Num_et $(1), 1)=\operatorname{sum}\left(\left(\operatorname{Alim} \_c o l(1:\right.\right.$ Num_et $(1), C+4) .{ }^{*}$ Alim_col $(1:$ Num_et $\left.(1), 1)\right)-$

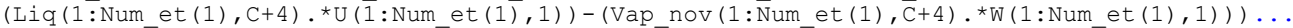

$-\operatorname{sum}(Q \bar{j}(1:$ Num et $(1)-1,1))+\bar{V} a p(1,1) * \operatorname{Vap} \operatorname{nov}(1, C+4)-L \bar{j}(\operatorname{Num}$ et $(1)){ }^{*}$ Liq $\left(\operatorname{Num}^{-}\right.$et $\left.(1), C+4\right)$;

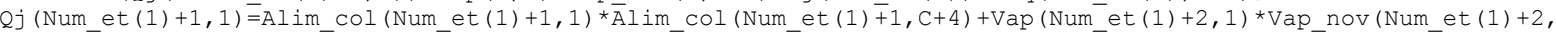
$\mathrm{C}+4)-\left(\overline{(} \mathrm{Lj}\left(\operatorname{Num} \_\right.\right.$et $\left.(1)+1, \overline{1}\right)+\mathrm{U}\left(\operatorname{Num} \_\right.$et $\left.\left.(1)+1,1\right)\right) *$ Liq $\left(\operatorname{Num} \_\right.$et $\left.\left.(\overline{1})+1, \mathrm{C}+4\right)\right)$;

Qj (Num_et_tot, 1$)=\operatorname{sum}(($ Alim_col $($ Num_et $(1)+1:$ Num_et_tot, C+4). *Alim_col (Num_et $(1)+1:$ Num_et_tot, 1$))-$

$(\operatorname{Liq}($ Num et $(1)+1:$ Num et tot, $\mathrm{C}+4) . * \mathrm{U}($ Num et $(1)+1:$ Num et tot, 1$))-$

$\left(\right.$ Vap nov $($ Num et $(1)+1$ : Num et tot, $C+4) .{ }^{\star} \bar{W}($ Num et $(1)+1$ : Num et tot, 1)) ) ...

- sum $\left(Q j\left(\bar{N} u m \_e t(1)+1: \bar{N} u m_{-}\right.\right.$et_tot-1,1)) +Vap $($Num_et $(1)+\overline{1}, 1) \star V a p \_n o v\left(N u m \_e t(1)+1, C+4\right)-$

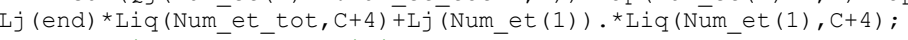

\% $\frac{0}{\circ}$ Determinacao dos coeficientes alfa, beta, gama, Novas vazoes de vapor e liquido

$\operatorname{Vap} \operatorname{nov}(1,1)=\operatorname{Vap}(1,1)$;

Vap nov (Num et $(1)+1,1)=\operatorname{Vap}($ Num et $(1)+1,1)$;

Vap_nov $(2,1 \overline{)}=\operatorname{Vap}(2,1)$;

Vap_nov (Num_et $(1)+2,1)=\operatorname{Vap}($ Num_et $(1)+2,1)$;

for $i=1:$ Num et tot

if $i>=2 \quad \& \& \quad i<=$ Num et $(1)-1$

$\operatorname{Vap} \operatorname{nov}(i+1,1)=\left(Q j(i, 1)-\left(\operatorname{Alim} \operatorname{col}(i, 1) .{ }^{\star} \operatorname{Alim} \operatorname{col}(i, C+4)\right)-\left(\operatorname{Lj}(i-1,1) .{ }^{\star} \operatorname{Liq}(i-\right.\right.$

$1, C+4))+\left((\operatorname{Lj}(i, 1)+U(i, 1)) .{ }^{\star} \operatorname{Liq}(i, C+4)\right)+\left((\operatorname{Vap}(i, 1)+W(\bar{i}, 1)) \cdot{ }^{\star} \operatorname{Vap} \_\right.$nov $\left.\left.(i, C+4)\right)\right) / \operatorname{Vap} \_$nov $(i+1, C+4) ;$ elseif $i>=$ Num_et $(1)+2$ \&\& $i<=$ Num_et $(1)+$ Ns $2-1$

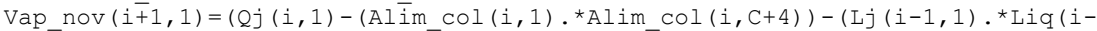

$\left.1, C+4))+\left((\operatorname{Lj}(i, 1)+U(i, 1)) .{ }^{\star} \operatorname{Liq}(i, C+4)\right)+\left((\operatorname{Vap}(i, 1)+W(\bar{i}, 1)) .{ }^{*} \operatorname{Vap} \operatorname{nov}(i, C+4)\right)\right) / \operatorname{Vap} \operatorname{nov}(i+1, C+4)$ elseif $i==$ Num et $(1)+$ Ns2

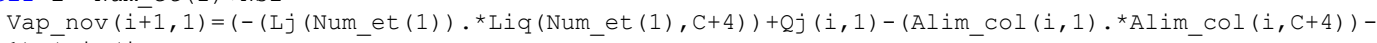

$\left(\operatorname{Lj}(i-1,1) .{ }^{\star} \operatorname{Liq}(i-\right.$

$\left.1, C+4))+\left((\operatorname{Lj}(i, 1)+U(i, 1)) .{ }^{*} \operatorname{Liq}(i, C+4)\right)+\left((\operatorname{Vap}(i, 1)+W(i, 1)) .{ }^{*} \operatorname{Vap} \_n o v(i, C+4)\right)\right) / \operatorname{Vap} \_$nov $(i+1, C+4) ;$

elseif $i>=$ Num et $(1)+$ Ns $2+1$ \&\& $i<=$ Num et tot -1

$\operatorname{Vap} \operatorname{nov}(i \overline{+} 1,1)=\left(Q j(i, 1)-\left(\operatorname{Alim} \operatorname{col}(\bar{i}, 1) .{ }^{\star A l i m} \operatorname{col}(i, C+4)\right)-\left(\operatorname{Lj}(i-1,1) \cdot{ }^{\star} \operatorname{Liq}(i-\right.\right.$

$\left.1, C+4))+\left((\operatorname{Lj}(i, 1)+U(i, 1)) \cdot{ }^{\star} \operatorname{Liq}(i, C+4)\right)+\left((\operatorname{Vap}(i, 1)+W(\bar{i}, 1)) \cdot{ }^{*} \operatorname{Vap} \_n o v(i, C+4)\right)\right) / \operatorname{Vap} \_$nov $(i+1, C+4) ;$

nd end

for $i=1:$ Num et tot

if $i>=1^{-} \& \&-i<=$ Num et $(1)-1$

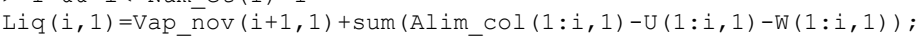

elseif $i==$ Num_et $(1)$

Liq $(i, 1)=\operatorname{sum}(\operatorname{Alim} \operatorname{col}(1: i, 1)-U(1: i, 1)-W(1: i, 1))$;

elseif $i>=$ Num et $(1)+1 \quad \& \& \quad i<=$ Num et $(1)+$ Ns $2-1$

$\operatorname{Liq}(i, 1)=\bar{V} a p \_n o v(i+1,1)+\operatorname{sum}\left(\operatorname{Al} i m \_c o l\left(N u m \_e t(1)+1: i, 1\right)-U\left(N u m \_e t(1)+1: i, 1\right)-\right.$

W (Num_et $(1)+1: i, 1)) ; \bar{o}+\operatorname{Liq}($ Num_et $(1), 1)$;

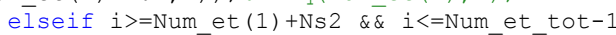

$\operatorname{Liq}(i, 1)=\bar{V} a p \operatorname{nov}(i+1,1)+\operatorname{sum}(\operatorname{Al} i m \operatorname{col}($ Num et $(1)+1: i, 1)-U(N u m$ et $(1)+1: i, 1)-$

$W($ Num et $(1)+1: i, 1))+$ Liq (Num et $(1), 1)$ :

e- $\operatorname{seif} i==$ Num et tot

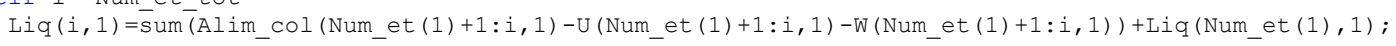

end end

$\operatorname{DT}(:, 1)=(\operatorname{Vap} \operatorname{nov}(:, 2)-\operatorname{Vap}(:, 2))$

Tmud $($ cont $)=a \bar{b} s(\max (\mathrm{DT}))$;

$\operatorname{Vap}(:, 2)=\operatorname{Vap} \operatorname{nov}(:, 2)$;

$\operatorname{Vap}(:, 1)=\operatorname{Vap} \operatorname{nov}(:, 1)$

$\operatorname{Lj}(:, 1)=\operatorname{Liq}(:, 1)$;

if Tmud (cont) $<=1 e-6$

break

end

end

toc

figure (2);

plot (Liq (1:Num_et (1),4), 'bo-') ;

hold on

plot (Liq (1:Num_et (1),5), 'rp-') ;

hold on

plot (Liq (1:Num et (1),6), ' ks-') ;

hold off

title('Perfil de concentracoes de liquido nas etapas Coluna principal')

xlabel ('Estagío No.')

ylabel ('Fracao molar de liquido')

legend('Benzeno', 'Tolueno', 'P-xileno');

figure (3):

plot (Liq(Num_et (1) +1: Num_et_tot, 4), 'bo-') ;

hold on

plot (Liq (Num et (1) +1: Num et tot, 5), 'rp-') ;

hold on

plot (Liq (Num_et (1) +1: Num_et_tot, 6), 'ks-') ;

hold off

title('Perfil de concentracoes de liquido nos estágios Coluna 2')

xlabel ('Estagío No.') 
ylabel ('Fracao molar de liquido')

legend('Benzeno', 'Tolueno', 'P-xileno');

\section{Função objetivo com penalidade para sequências convencionais}

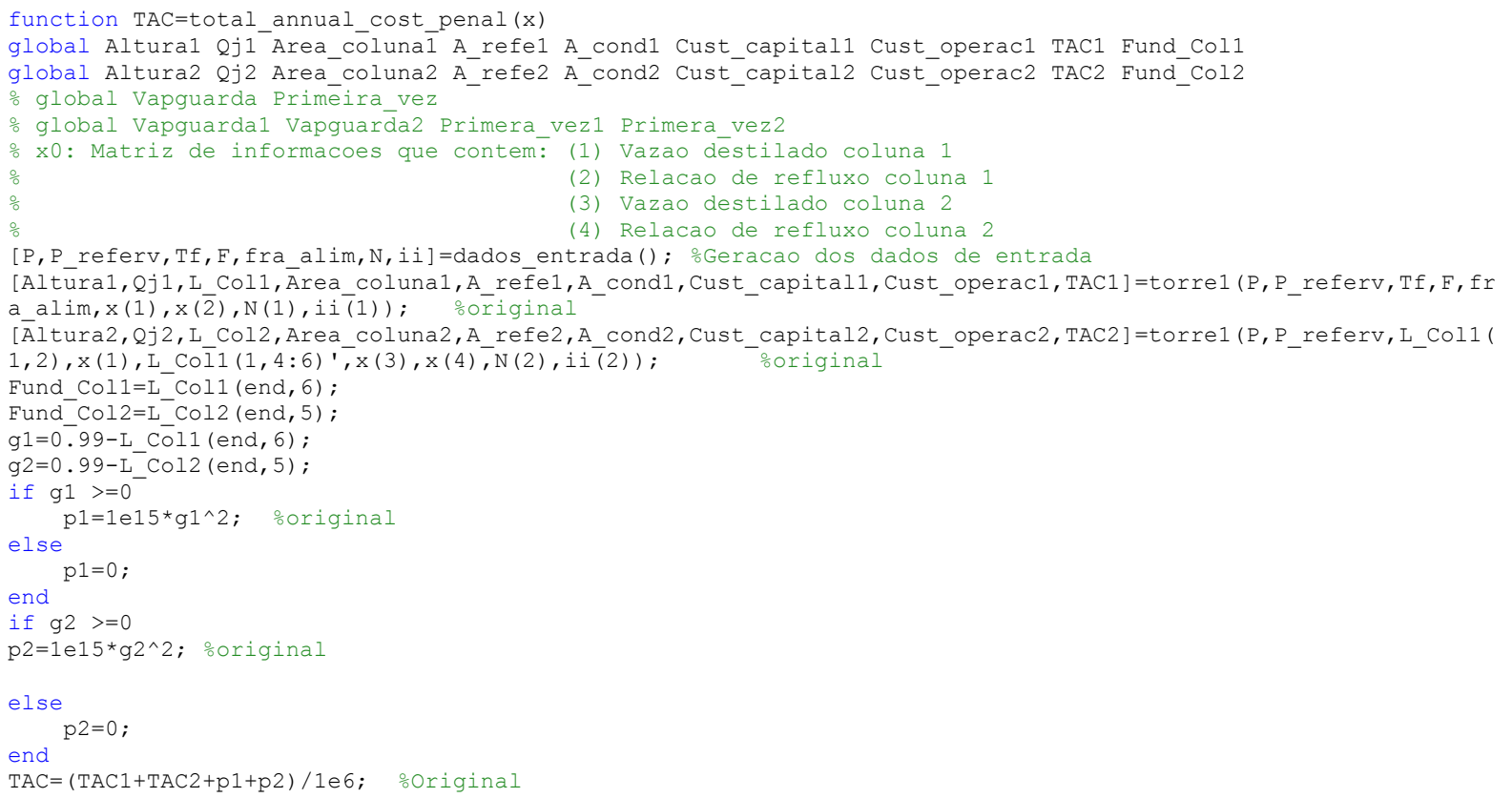

\section{Otimização combnatoria para sequências convencionais}

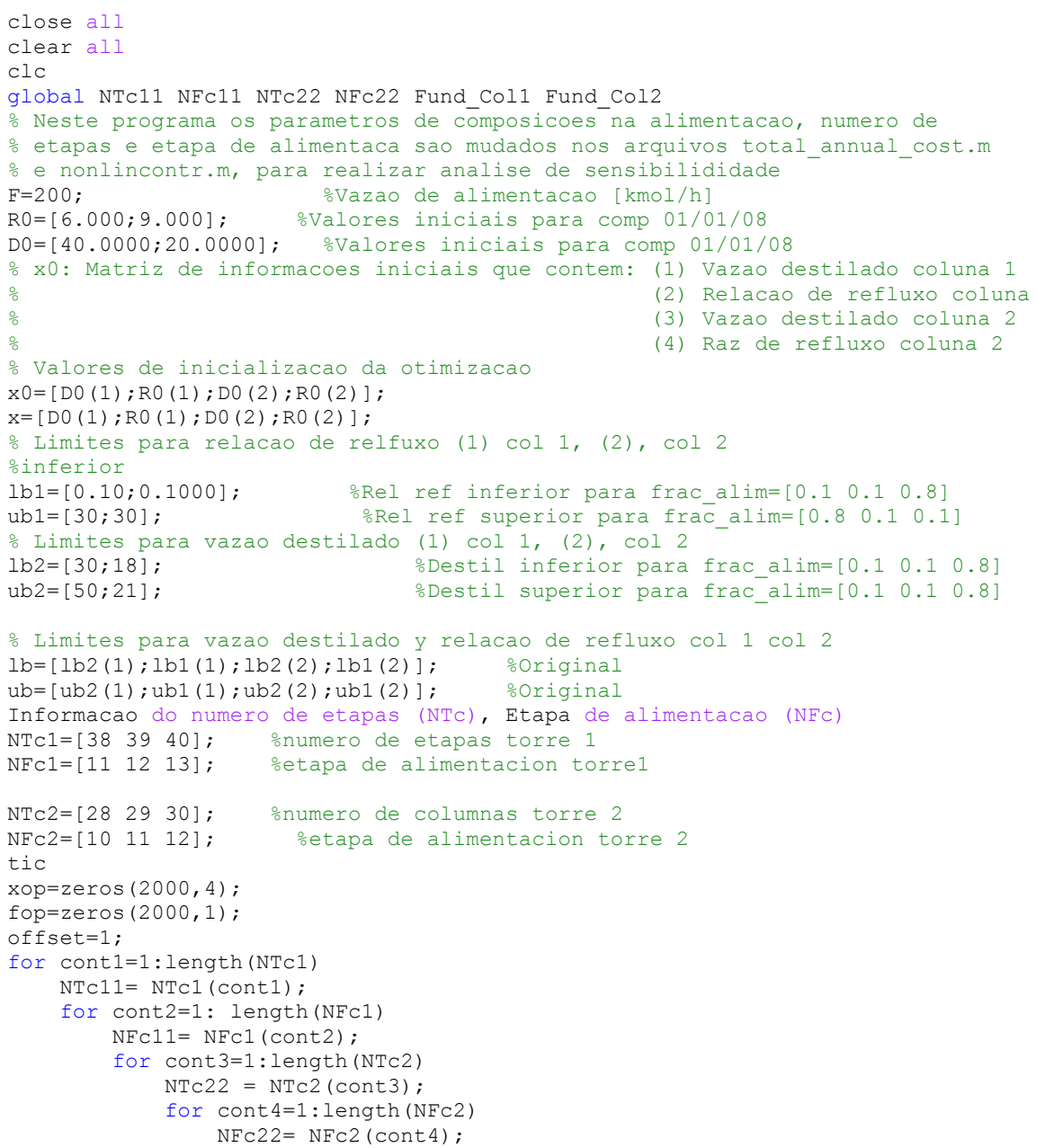




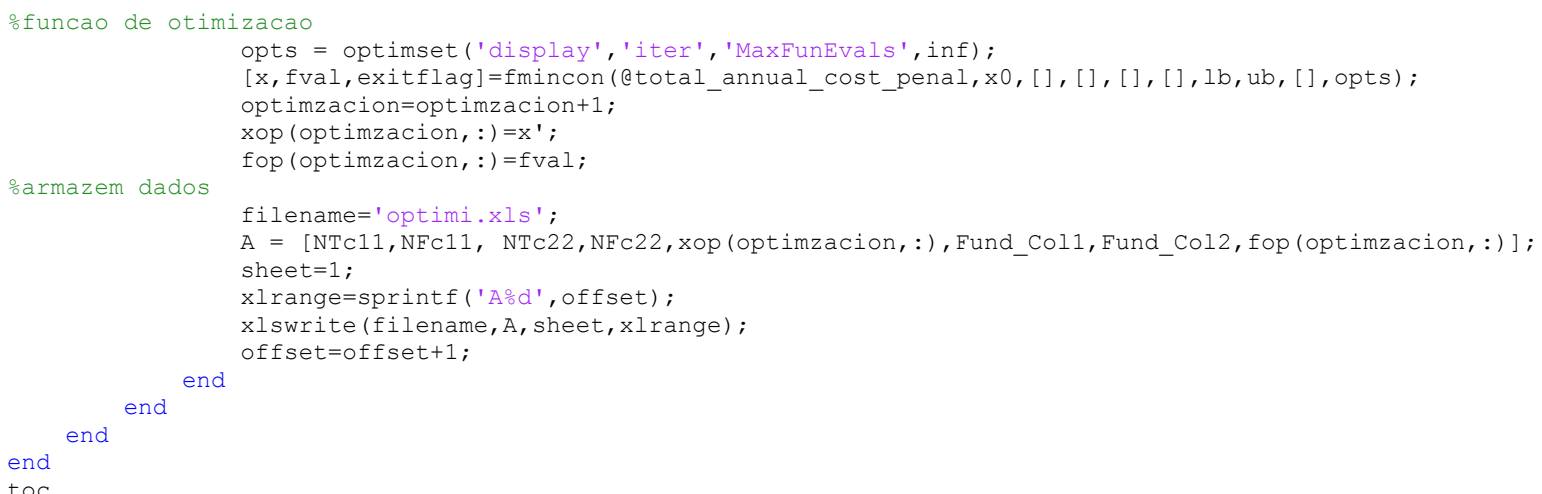

\section{Valor de fronteira para uma sequência convencional}

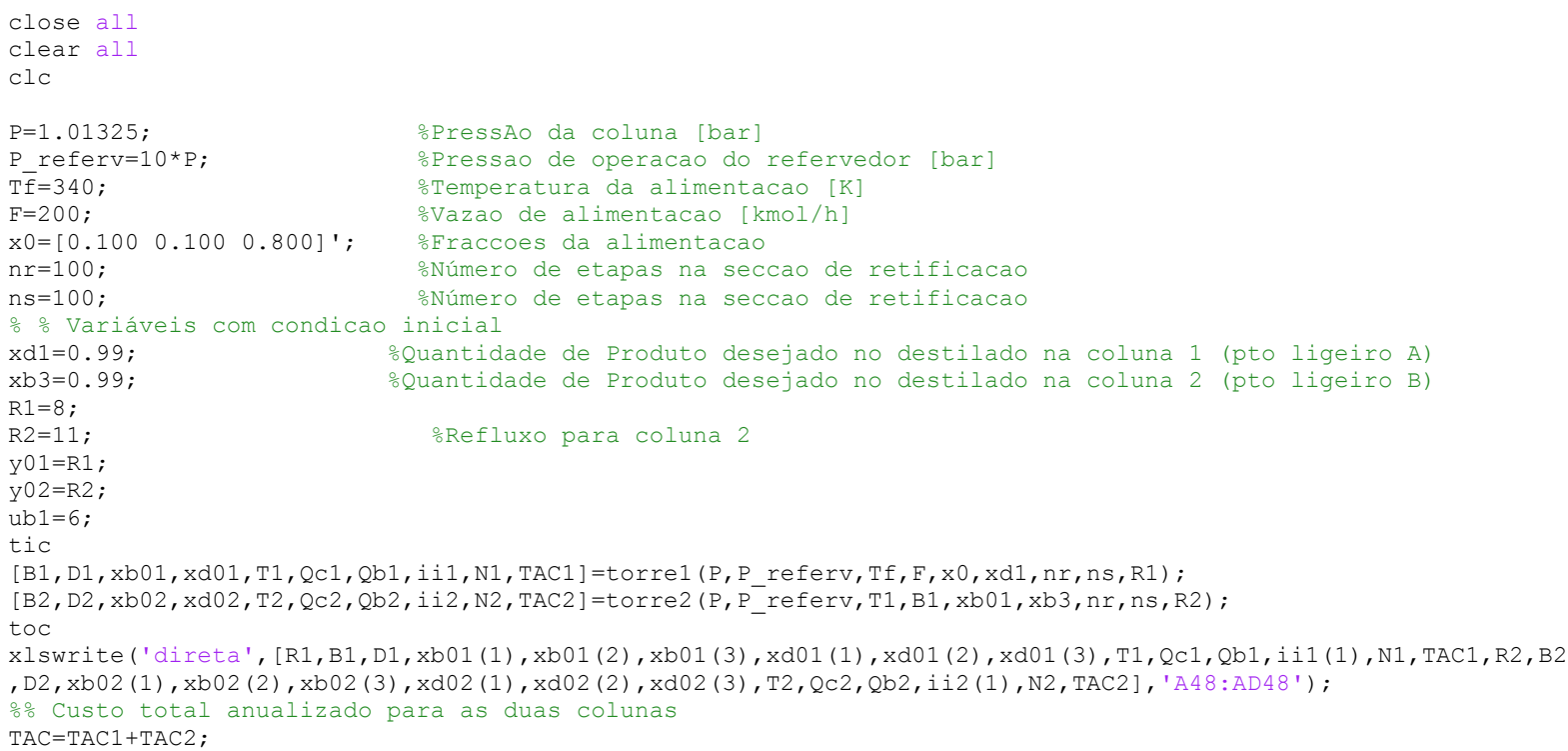

\section{Valor de fronteira para uma coluna convencional}

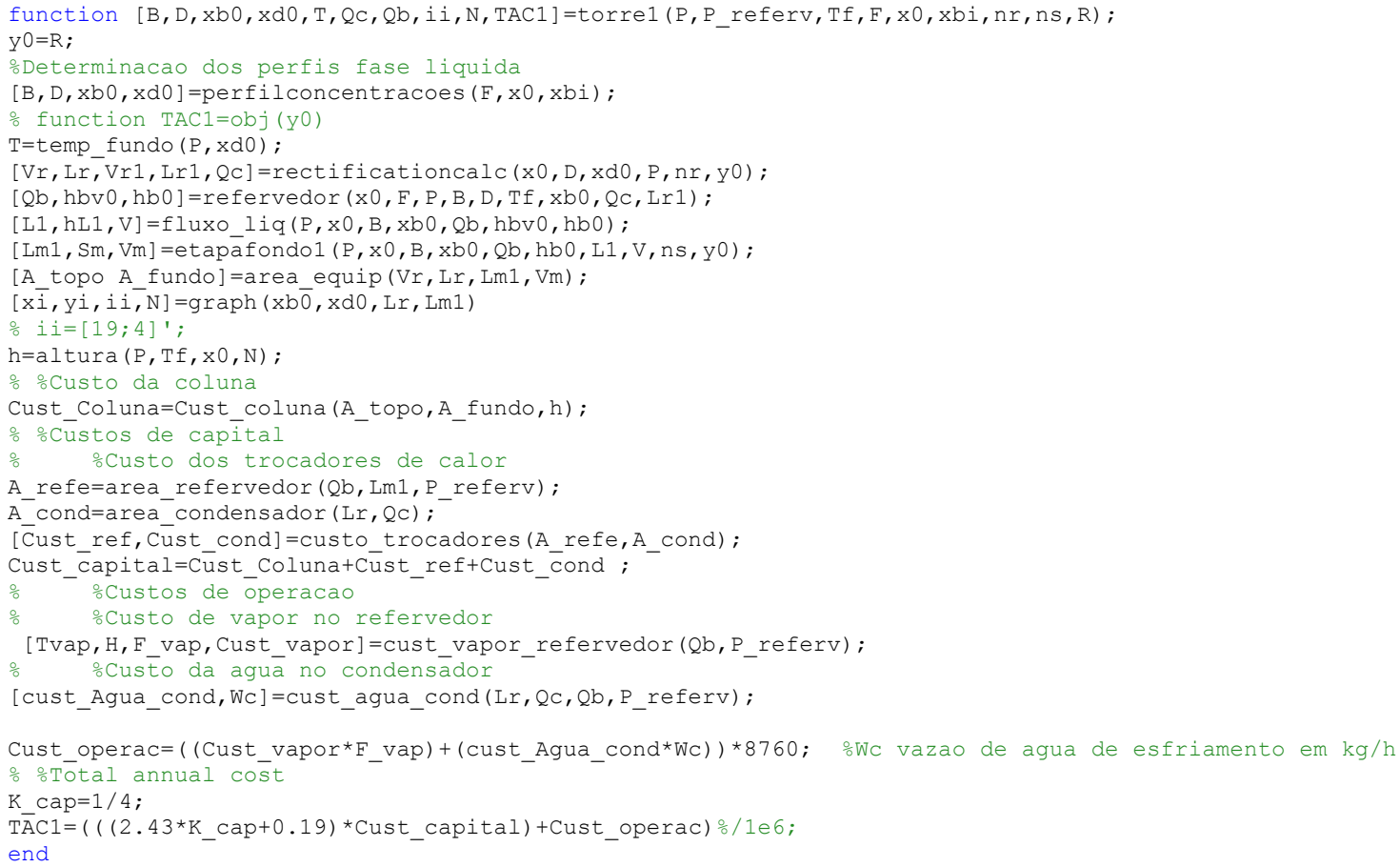




\section{Perfil de concentrações na zona de topo da coluna}

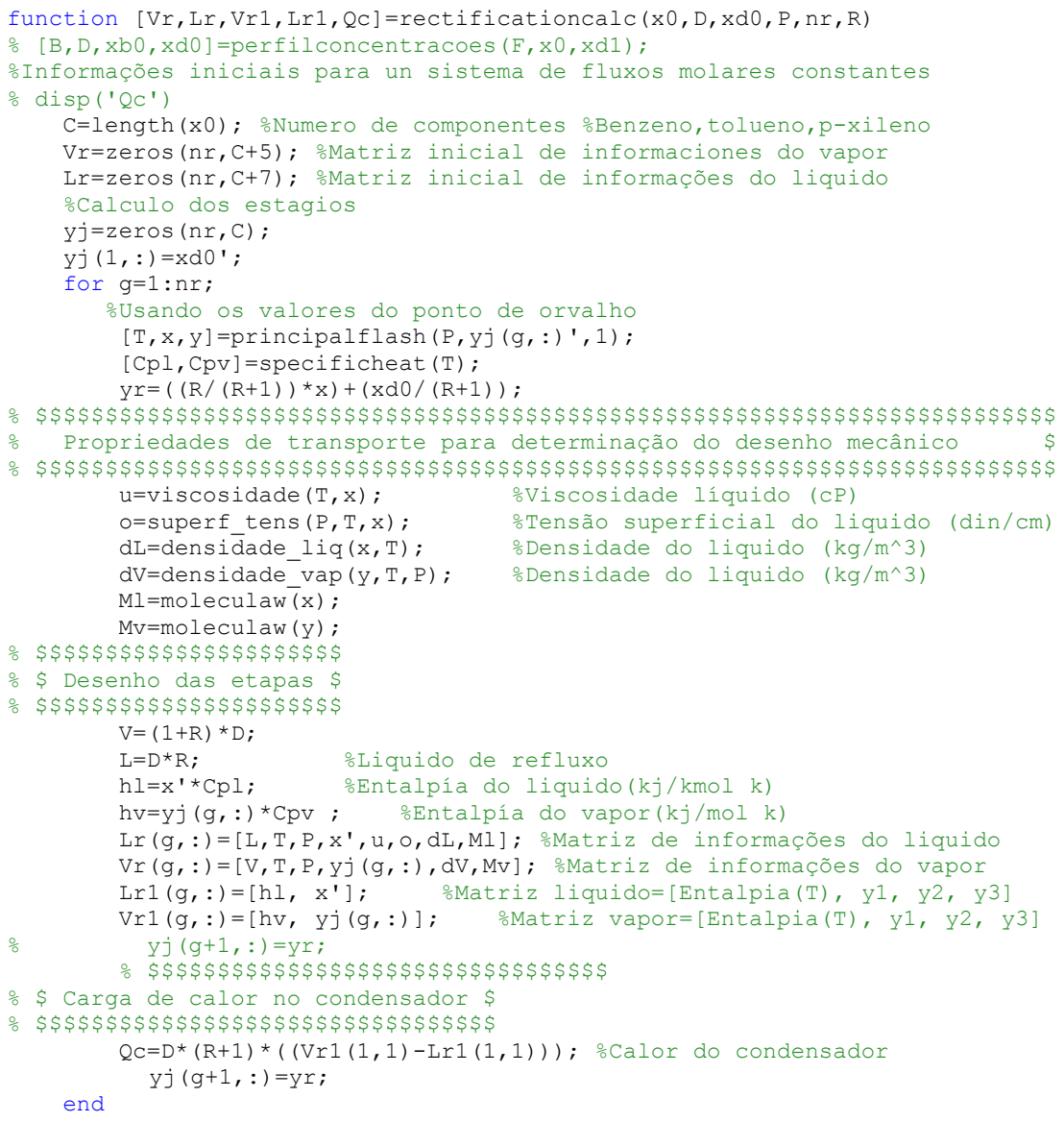

\section{Balanço no reboiler valor de fronteira}

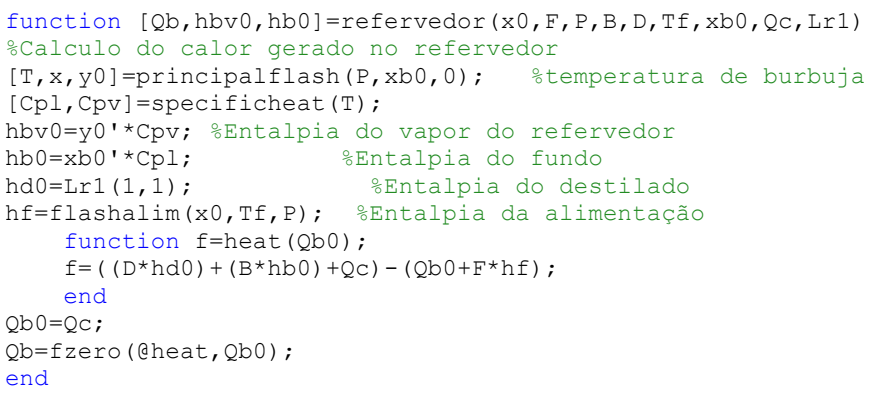

\section{Balanço de líquido no reboiler valor de fronteira}

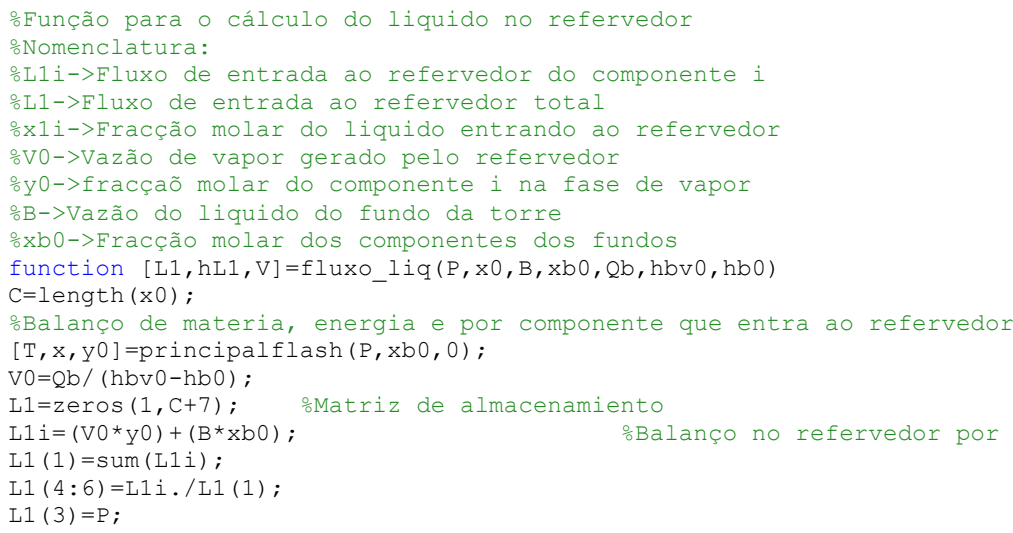


L1 (2) =principalflash (L1 (3), L1 (4:6)',0); $\mathrm{x}=\mathrm{L} 1(4: 6)$ ';

$\mathrm{L} 1(7)=\mathrm{viscosidade}(\mathrm{L} 1(2), \mathrm{x})$;

L1 (8) =superf tens $(\mathrm{L} 1(3), \mathrm{L} 1(2), \mathrm{x})$;

L1 (9) =densidāde liq $(x, L 1(2)) ; \quad$ DDensidade do liquido $\left(\mathrm{kg} / \mathrm{m}^{\wedge} 3\right)$

L1 $(10)=\operatorname{moleculaw}(x)$;

$\mathrm{Cp}=$ specificheat $(\mathrm{L} 1(2))$;

$\mathrm{hL} 1=\mathrm{L} 1(4: 6){ }^{*} \mathrm{Cp}$

function $\mathrm{ER}=$ ener $\operatorname{ref}(\mathrm{VO})$

\%Entalpia da vazão do liquido que entra ao refervedor

$\mathrm{ER}=(((\mathrm{L} 1(1) * \bar{h} \mathrm{~L} 1)-(\mathrm{B} * \mathrm{hb} 0)+\mathrm{Qb}) / \mathrm{hbv0})-\mathrm{V} 0$; \%Função objetivo para calcular a vazão de vapor gerado no refervedo end

V=fzero(@ener ref,Vo); oVapor calculado para a saída da etapa

end

\section{Perfil de concentrações na zona de fundo da coluna}

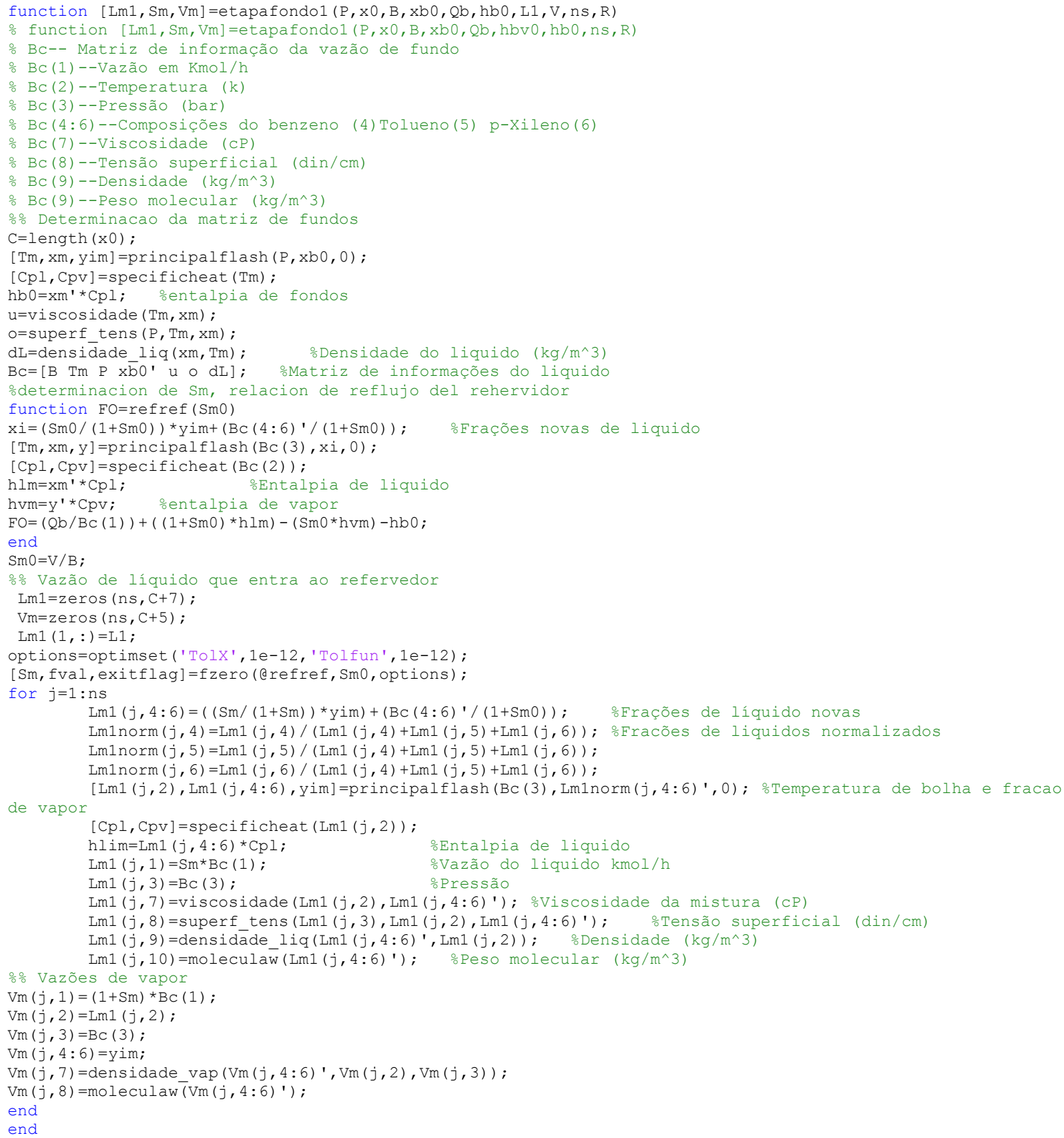




\section{APÊNDICE C. RESULTADOS PARA UMA OTIMIZAÇÃO COMBINATÓRIA EM UMA CONFIGURAÇÃO DWC.}

\begin{tabular}{|c|c|c|}
\hline $\begin{array}{l}\text { Num } \\
\text { estagios } \\
\text { prefac }\end{array}$ & $\begin{array}{l}\text { Estagio } \\
\text { alimentaç } \\
\text { ão }\end{array}$ & $\begin{array}{c}\text { Num } \\
\text { estatgios } \\
\text { col } \\
\text { principal }\end{array}$ \\
\hline 19 & 9 & 43 \\
\hline 19 & 9 & 43 \\
\hline 21 & 11 & 43 \\
\hline 21 & 10 & 43 \\
\hline 19 & 10 & 42 \\
\hline 21 & 11 & 42 \\
\hline 20 & 10 & 43 \\
\hline 19 & 10 & 43 \\
\hline 20 & 11 & 42 \\
\hline 20 & 10 & 43 \\
\hline 19 & 10 & 42 \\
\hline 21 & 11 & 42 \\
\hline 20 & 10 & 42 \\
\hline 19 & 11 & 43 \\
\hline 19 & 9 & 43 \\
\hline 21 & 11 & 43 \\
\hline 19 & 10 & 42 \\
\hline 21 & 10 & 43 \\
\hline 21 & 10 & 43 \\
\hline 19 & 11 & 43 \\
\hline 21 & 11 & 43 \\
\hline 21 & 11 & 43 \\
\hline 20 & 11 & 43 \\
\hline 21 & 10 & 43 \\
\hline 21 & 10 & 43 \\
\hline 21 & 10 & 42 \\
\hline 20 & 11 & 43 \\
\hline 19 & 9 & 42 \\
\hline 19 & 11 & 42 \\
\hline 19 & 9 & 43 \\
\hline 20 & 11 & 42 \\
\hline 21 & 10 & 42 \\
\hline 21 & 11 & 43 \\
\hline 19 & 11 & 42 \\
\hline 20 & 11 & 43 \\
\hline 19 & 9 & 43 \\
\hline 20 & 11 & 42 \\
\hline 21 & 11 & 43 \\
\hline 21 & 11 & 43 \\
\hline 19 & 9 & 43 \\
\hline 21 & 10 & 43 \\
\hline 19 & 11 & 42 \\
\hline 20 & 10 & 43 \\
\hline 19 & 10 & 43 \\
\hline 20 & 10 & 43 \\
\hline 19 & 10 & 42 \\
\hline 19 & 9 & 42 \\
\hline 19 & 10 & 43 \\
\hline 20 & 10 & 43 \\
\hline 20 & 11 & 43 \\
\hline 19 & 9 & 43 \\
\hline 21 & 11 & 42 \\
\hline 20 & 10 & 43 \\
\hline 19 & 10 & 43 \\
\hline 21 & 11 & 43 \\
\hline 20 & 10 & 43 \\
\hline 19 & 10 & 43 \\
\hline 19 & 11 & 43 \\
\hline 20 & 11 & 41 \\
\hline 20 & 11 & 41 \\
\hline 21 & 10 & 42 \\
\hline 20 & 10 & 43 \\
\hline 20 & 10 & 43 \\
\hline 19 & 11 & 43 \\
\hline 19 & 11 & 43 \\
\hline 19 & 11 & 41 \\
\hline 21 & 10 & 43 \\
\hline 21 & 10 & 42 \\
\hline 19 & 11 & 43 \\
\hline 19 & 9 & 42 \\
\hline 20 & 11 & 42 \\
\hline 21 & 11 & 42 \\
\hline 21 & 10 & 42 \\
\hline 19 & 11 & 41 \\
\hline 20 & 10 & 43 \\
\hline 20 & 11 & 43 \\
\hline 21 & 11 & 41 \\
\hline 19 & 10 & 43 \\
\hline 21 & 10 & 43 \\
\hline 21 & 10 & 43 \\
\hline 20 & 11 & 43 \\
\hline 21 & 10 & 43 \\
\hline 21 & 11 & 41 \\
\hline 19 & 10 & 42 \\
\hline 21 & 11 & 43 \\
\hline 21 & 10 & 43 \\
\hline 19 & 11 & 43 \\
\hline 20 & 10 & 43 \\
\hline 19 & 11 & 43 \\
\hline 19 & 11 & 43 \\
\hline 19 & 9 & 43 \\
\hline 20 & 11 & 42 \\
\hline 19 & 9 & 42 \\
\hline 20 & 10 & 42 \\
\hline 20 & 11 & 43 \\
\hline
\end{tabular}




\begin{tabular}{|c|c|}
\hline $\begin{array}{l}\text { Num } \\
\text { estagios } \\
\text { prefac }\end{array}$ & $\begin{array}{c}\text { Estagio } \\
\text { alimentaç } \\
\text { ão }\end{array}$ \\
\hline 21 & 10 \\
\hline 19 & 11 \\
\hline 21 & 10 \\
\hline 20 & 9 \\
\hline 20 & 9 \\
\hline 21 & 11 \\
\hline 19 & 11 \\
\hline 19 & 10 \\
\hline 19 & 11 \\
\hline 19 & 10 \\
\hline 20 & 10 \\
\hline 19 & 10 \\
\hline 20 & 11 \\
\hline 21 & 10 \\
\hline 21 & 11 \\
\hline 20 & 10 \\
\hline 20 & 11 \\
\hline 21 & 10 \\
\hline 19 & 9 \\
\hline 19 & 9 \\
\hline 19 & 10 \\
\hline 20 & 9 \\
\hline 20 & 9 \\
\hline 19 & 10 \\
\hline 19 & 11 \\
\hline 19 & 10 \\
\hline 19 & 10 \\
\hline 19 & 9 \\
\hline 21 & 11 \\
\hline 21 & 11 \\
\hline 20 & 10 \\
\hline 20 & 11 \\
\hline 21 & 11 \\
\hline 19 & 10 \\
\hline 20 & 9 \\
\hline 20 & 9 \\
\hline 21 & 10 \\
\hline 19 & 9 \\
\hline 19 & 9 \\
\hline 19 & 9 \\
\hline 21 & 11 \\
\hline 19 & 10 \\
\hline 19 & 11 \\
\hline 19 & 10 \\
\hline 20 & 10 \\
\hline 20 & 9 \\
\hline 20 & 9 \\
\hline 20 & 10 \\
\hline 21 & 10 \\
\hline 19 & 9 \\
\hline 19 & 11 \\
\hline 20 & 10 \\
\hline 19 & 10 \\
\hline 20 & 10 \\
\hline 19 & 10 \\
\hline 20 & 9 \\
\hline 20 & 9 \\
\hline 19 & 11 \\
\hline 20 & 11 \\
\hline 20 & 10 \\
\hline 19 & 9 \\
\hline 19 & 10 \\
\hline 20 & 11 \\
\hline 21 & 10 \\
\hline 20 & 9 \\
\hline 20 & 9 \\
\hline 20 & 9 \\
\hline 20 & 9 \\
\hline 19 & 9 \\
\hline 20 & 11 \\
\hline 20 & 9 \\
\hline 20 & 9 \\
\hline 21 & 10 \\
\hline 21 & 10 \\
\hline 19 & 10 \\
\hline 19 & 11 \\
\hline 20 & 10 \\
\hline 21 & 10 \\
\hline 20 & 9 \\
\hline 20 & 9 \\
\hline 20 & 9 \\
\hline 20 & 9 \\
\hline 19 & 9 \\
\hline 19 & 10 \\
\hline 19 & 11 \\
\hline 21 & 10 \\
\hline 20 & 9 \\
\hline 20 & 9 \\
\hline 21 & 10 \\
\hline 20 & 10 \\
\hline 21 & 10 \\
\hline 20 & 9 \\
\hline 20 & 9 \\
\hline 19 & 9 \\
\hline 21 & 11 \\
\hline 20 & 10 \\
\hline
\end{tabular}




\begin{tabular}{|c|c|}
\hline $\begin{array}{l}\text { Num } \\
\text { estagios } \\
\text { prefac }\end{array}$ & $\begin{array}{l}\text { Estagio } \\
\text { alimentą̧ } \\
\text { ão }\end{array}$ \\
\hline 20 & 10 \\
\hline 21 & 10 \\
\hline 19 & 10 \\
\hline 19 & 9 \\
\hline 21 & 10 \\
\hline 21 & 10 \\
\hline 20 & 9 \\
\hline 20 & 9 \\
\hline 19 & 10 \\
\hline 20 & 10 \\
\hline 19 & 9 \\
\hline 20 & 9 \\
\hline 20 & 9 \\
\hline 21 & 11 \\
\hline 20 & 9 \\
\hline 20 & 9 \\
\hline 20 & 10 \\
\hline 19 & 11 \\
\hline 21 & 10 \\
\hline 20 & 11 \\
\hline 20 & 10 \\
\hline 20 & 9 \\
\hline 20 & 9 \\
\hline 19 & 9 \\
\hline 20 & 10 \\
\hline 21 & 10 \\
\hline 21 & 11 \\
\hline 20 & 10 \\
\hline 21 & 10 \\
\hline 20 & 9 \\
\hline 20 & 9 \\
\hline 19 & 9 \\
\hline 20 & 10 \\
\hline 21 & 10 \\
\hline 21 & 11 \\
\hline 21 & 10 \\
\hline 20 & 11 \\
\hline 19 & 11 \\
\hline 20 & 9 \\
\hline 20 & 9 \\
\hline 19 & 11 \\
\hline 21 & 11 \\
\hline 19 & 11 \\
\hline 19 & 9 \\
\hline 21 & 10 \\
\hline 21 & 11 \\
\hline 21 & 11 \\
\hline 21 & 11 \\
\hline 20 & 9 \\
\hline 20 & 9 \\
\hline 20 & 11 \\
\hline 19 & 10 \\
\hline 19 & 10 \\
\hline 19 & 11 \\
\hline 20 & 10 \\
\hline 21 & 11 \\
\hline 19 & 10 \\
\hline 20 & 9 \\
\hline 20 & 9 \\
\hline 20 & 11 \\
\hline 20 & 11 \\
\hline 21 & 11 \\
\hline 19 & 9 \\
\hline 20 & 11 \\
\hline 19 & 9 \\
\hline 20 & 10 \\
\hline 21 & 10 \\
\hline 20 & 11 \\
\hline 19 & 9 \\
\hline 20 & 10 \\
\hline 19 & 9 \\
\hline 20 & 10 \\
\hline 20 & 10 \\
\hline 20 & 11 \\
\hline 19 & 9 \\
\hline 20 & 10 \\
\hline 21 & 11 \\
\hline 20 & 11 \\
\hline 19 & 10 \\
\hline 21 & 10 \\
\hline 19 & 9 \\
\hline 19 & 9 \\
\hline 20 & 10 \\
\hline 21 & 10 \\
\hline 21 & 11 \\
\hline 21 & 11 \\
\hline 19 & 10 \\
\hline 20 & 11 \\
\hline 20 & 10 \\
\hline 19 & 11 \\
\hline 21 & 10 \\
\hline 19 & 9 \\
\hline 19 & 9 \\
\hline 19 & 11 \\
\hline 20 & 9 \\
\hline 20 & 9 \\
\hline
\end{tabular}




\begin{tabular}{|c|c|}
\hline $\begin{array}{l}\text { Num } \\
\text { estagios } \\
\text { prefac }\end{array}$ & $\begin{array}{l}\text { Estagio } \\
\text { alimentą̧ } \\
\text { ão }\end{array}$ \\
\hline 19 & 9 \\
\hline 19 & 9 \\
\hline 19 & 11 \\
\hline 19 & 10 \\
\hline 19 & 11 \\
\hline 19 & 10 \\
\hline 20 & 11 \\
\hline 20 & 9 \\
\hline 20 & 9 \\
\hline 20 & 11 \\
\hline 20 & 10 \\
\hline 19 & 9 \\
\hline 20 & 10 \\
\hline 21 & 10 \\
\hline 19 & 10 \\
\hline 20 & 11 \\
\hline 20 & 9 \\
\hline 20 & 9 \\
\hline 19 & 10 \\
\hline 20 & 9 \\
\hline 20 & 9 \\
\hline 19 & 9 \\
\hline 20 & 10 \\
\hline 19 & 9 \\
\hline 20 & 11 \\
\hline 20 & 10 \\
\hline 19 & 9 \\
\hline 20 & 10 \\
\hline 21 & 11 \\
\hline 19 & 10 \\
\hline 20 & 9 \\
\hline 20 & 9 \\
\hline 19 & 9 \\
\hline 20 & 11 \\
\hline 19 & 9 \\
\hline 21 & 10 \\
\hline 19 & 10 \\
\hline 19 & 10 \\
\hline 21 & 11 \\
\hline 19 & 10 \\
\hline 21 & 10 \\
\hline 20 & 9 \\
\hline 20 & 9 \\
\hline 20 & 10 \\
\hline 19 & 10 \\
\hline 21 & 10 \\
\hline 21 & 10 \\
\hline 19 & 11 \\
\hline 19 & 9 \\
\hline 19 & 10 \\
\hline 19 & 11 \\
\hline 20 & 11 \\
\hline 20 & 9 \\
\hline 20 & 9 \\
\hline 20 & 9 \\
\hline 20 & 9 \\
\hline 19 & 9 \\
\hline 20 & 9 \\
\hline 20 & 9 \\
\hline 21 & 11 \\
\hline 20 & 11 \\
\hline 20 & 11 \\
\hline 19 & 10 \\
\hline 19 & 10 \\
\hline 21 & 10 \\
\hline 19 & 11 \\
\hline 21 & 11 \\
\hline 20 & 9 \\
\hline 20 & 9 \\
\hline 19 & 10 \\
\hline 19 & 10 \\
\hline 20 & 11 \\
\hline 19 & 10 \\
\hline 21 & 10 \\
\hline 20 & 10 \\
\hline 21 & 11 \\
\hline 19 & 9 \\
\hline 21 & 11 \\
\hline 21 & 10 \\
\hline 20 & 10 \\
\hline 21 & 11 \\
\hline 20 & 10 \\
\hline 21 & 11 \\
\hline 21 & 10 \\
\hline 20 & 10 \\
\hline 19 & 9 \\
\hline 21 & 11 \\
\hline 20 & 9 \\
\hline 20 & 9 \\
\hline 19 & 11 \\
\hline 21 & 11 \\
\hline 20 & 9 \\
\hline 20 & 9 \\
\hline 21 & 11 \\
\hline 19 & 11 \\
\hline 20 & 11 \\
\hline
\end{tabular}




\begin{tabular}{|c|c|}
\hline $\begin{array}{l}\text { Num } \\
\text { estagios } \\
\text { prefac }\end{array}$ & $\begin{array}{c}\text { Estagio } \\
\text { alimentaç } \\
\text { ão }\end{array}$ \\
\hline 21 & 11 \\
\hline 20 & 11 \\
\hline 21 & 11 \\
\hline 21 & 10 \\
\hline 19 & 11 \\
\hline 21 & 11 \\
\hline 19 & 11 \\
\hline 20 & 9 \\
\hline 20 & 9 \\
\hline 21 & 10 \\
\hline 20 & 10 \\
\hline 20 & 11 \\
\hline 20 & 9 \\
\hline 20 & 9 \\
\hline 20 & 11 \\
\hline 21 & 11 \\
\hline 20 & 9 \\
\hline 20 & 9 \\
\hline 20 & 11 \\
\hline 20 & 9 \\
\hline 20 & 9 \\
\hline 19 & 10 \\
\hline 19 & 9 \\
\hline 20 & 10 \\
\hline 20 & 9 \\
\hline 20 & 9 \\
\hline 19 & 10 \\
\hline 21 & 10 \\
\hline 20 & 10 \\
\hline 20 & 9 \\
\hline 20 & 9 \\
\hline 21 & 10 \\
\hline 20 & 10 \\
\hline 19 & 9 \\
\hline 21 & 10 \\
\hline 19 & 11 \\
\hline 21 & 11 \\
\hline 20 & 9 \\
\hline 20 & 9 \\
\hline 20 & 9 \\
\hline 20 & 9 \\
\hline 19 & 9 \\
\hline 19 & 11 \\
\hline 19 & 11 \\
\hline 19 & 11 \\
\hline 21 & 10 \\
\hline 20 & 11 \\
\hline 20 & 11 \\
\hline 20 & 11 \\
\hline 19 & 10 \\
\hline 19 & 10 \\
\hline 20 & 10 \\
\hline 20 & 9 \\
\hline 20 & 9 \\
\hline 21 & 11 \\
\hline 20 & 11 \\
\hline 19 & 11 \\
\hline 20 & 9 \\
\hline 20 & 9 \\
\hline 20 & 9 \\
\hline 20 & 9 \\
\hline 20 & 10 \\
\hline 19 & 10 \\
\hline 19 & 11 \\
\hline 19 & 11 \\
\hline 20 & 11 \\
\hline 19 & 11 \\
\hline 19 & 11 \\
\hline 19 & 9 \\
\hline 20 & 11 \\
\hline 19 & 10 \\
\hline 19 & 9 \\
\hline 19 & 9 \\
\hline 19 & 10 \\
\hline 20 & 11 \\
\hline 21 & 10 \\
\hline 20 & 9 \\
\hline 20 & 9 \\
\hline 20 & 11 \\
\hline 19 & 9 \\
\hline 20 & 9 \\
\hline 20 & 9 \\
\hline 20 & 11 \\
\hline 19 & 11 \\
\hline 21 & 11 \\
\hline 19 & 9 \\
\hline 21 & 10 \\
\hline 19 & 10 \\
\hline 20 & 9 \\
\hline 20 & 9 \\
\hline 19 & 10 \\
\hline 20 & 9 \\
\hline 20 & 9 \\
\hline 20 & 9 \\
\hline 20 & 9 \\
\hline 20 & 9 \\
\hline
\end{tabular}




\begin{tabular}{|c|c|}
\hline $\begin{array}{l}\text { Num } \\
\text { estagios } \\
\text { prefac }\end{array}$ & $\begin{array}{c}\text { Estagio } \\
\text { alimentaç } \\
\text { ão }\end{array}$ \\
\hline 20 & 9 \\
\hline 20 & 9 \\
\hline 20 & 9 \\
\hline 21 & 10 \\
\hline 19 & 11 \\
\hline 19 & 11 \\
\hline 19 & 11 \\
\hline 21 & 10 \\
\hline 20 & 11 \\
\hline 20 & 11 \\
\hline 20 & 10 \\
\hline 21 & 11 \\
\hline 19 & 11 \\
\hline 19 & 10 \\
\hline 20 & 10 \\
\hline 20 & 10 \\
\hline 19 & 9 \\
\hline 20 & 11 \\
\hline 19 & 9 \\
\hline 21 & 11 \\
\hline 21 & 11 \\
\hline 20 & 9 \\
\hline 20 & 9 \\
\hline 21 & 11 \\
\hline 20 & 11 \\
\hline 19 & 9 \\
\hline 20 & 10 \\
\hline 21 & 10 \\
\hline 19 & 11 \\
\hline 21 & 11 \\
\hline 20 & 10 \\
\hline 20 & 10 \\
\hline 19 & 11 \\
\hline 21 & 11 \\
\hline 20 & 9 \\
\hline 20 & 9 \\
\hline 19 & 10 \\
\hline 20 & 9 \\
\hline 20 & 9 \\
\hline 20 & 9 \\
\hline 20 & 9 \\
\hline 20 & 11 \\
\hline 20 & 11 \\
\hline 20 & 11 \\
\hline 19 & 11 \\
\hline 19 & 11 \\
\hline 20 & 11 \\
\hline 21 & 11 \\
\hline 19 & 10 \\
\hline 19 & 11 \\
\hline 20 & 11 \\
\hline 19 & 10 \\
\hline 19 & 9 \\
\hline 21 & 10 \\
\hline 20 & 10 \\
\hline 20 & 10 \\
\hline 20 & 11 \\
\hline 21 & 10 \\
\hline 19 & 11 \\
\hline 19 & 11 \\
\hline 21 & 11 \\
\hline 21 & 11 \\
\hline 20 & 10 \\
\hline 19 & 11 \\
\hline 21 & 11 \\
\hline 19 & 10 \\
\hline 20 & 10 \\
\hline 19 & 9 \\
\hline 19 & 9 \\
\hline 19 & 11 \\
\hline 19 & 9 \\
\hline 21 & 10 \\
\hline 20 & 9 \\
\hline 20 & 9 \\
\hline 20 & 10 \\
\hline 20 & 11 \\
\hline 19 & 10 \\
\hline 21 & 11 \\
\hline 21 & 10 \\
\hline 21 & 10 \\
\hline 19 & 11 \\
\hline 20 & 9 \\
\hline 20 & 9 \\
\hline 20 & 10 \\
\hline 21 & 11 \\
\hline 20 & 10 \\
\hline 21 & 11 \\
\hline 20 & 10 \\
\hline 19 & 11 \\
\hline 19 & 11 \\
\hline 21 & 10 \\
\hline 20 & 9 \\
\hline 20 & 9 \\
\hline 21 & 11 \\
\hline 19 & 11 \\
\hline & \\
\hline
\end{tabular}




\begin{tabular}{|c|c|c|c|c|c|c|c|c|c|c|c|c|c|c|}
\hline $\begin{array}{l}\text { Num } \\
\text { estagios } \\
\text { prefac }\end{array}$ & $\begin{array}{c}\text { Estagio } \\
\text { alimentaç } \\
\text { ão }\end{array}$ & $\begin{array}{c}\text { Num } \\
\text { estatgios } \\
\text { col } \\
\text { principal }\end{array}$ & $\begin{array}{l}\text { Estagio } \\
\text { Conexão } \\
\text { superior }\end{array}$ & $\begin{array}{l}\text { Estagio } \\
\text { Saida } \\
\text { lateral }\end{array}$ & $\begin{array}{c}\text { Estagio } \\
\text { Conexão } \\
\text { inferior }\end{array}$ & $\begin{array}{l}\text { Vazão } \\
\text { Destilado } \\
(\mathrm{kmol} / \mathrm{h})\end{array}$ & $\begin{array}{l}\text { Razão de } \\
\text { refluxo }\end{array}$ & $\begin{array}{l}\text { Vazão de } \\
\text { liquido } \\
\text { conexão } \\
\text { superior } \\
(\mathrm{kmol} / \mathrm{h}) \\
\end{array}$ & $\begin{array}{c}\text { Vazão } \\
\text { saida } \\
\text { lateral } \\
(\mathrm{kmol} / \mathrm{h})\end{array}$ & $\begin{array}{c}\text { Vazão de } \\
\text { vapor } \\
\text { conexão } \\
\text { inferior } \\
(\mathrm{kmol} / \mathrm{h}) \\
\end{array}$ & $\begin{array}{c}\text { Fração } \\
\text { molar } \\
\text { benzeno }\end{array}$ & $\begin{array}{c}\text { Fração } \\
\text { molar } \\
\text { tolueno }\end{array}$ & $\begin{array}{c}\text { Fração } \\
\text { molar P- } \\
\text { xileno }\end{array}$ & $\begin{array}{l}\text { TAC X10 } \\
\text { (US\$/ano) }\end{array}$ \\
\hline 21 & 10 & 41 & 7 & 25 & 38 & 21,25345 & 40 & 89 & 15,00011 & 101 & 0,999307 & 0,984478 & 0,991444 & 8,739862 \\
\hline 19 & 11 & 42 & 7 & 25 & 37 & 21,10569 & 40 & 89 & 15 & 101 & 0,999178 & 0,98461 & 0,995827 & 8,757674 \\
\hline 20 & 11 & 41 & 7 & 25 & 38 & 21,65594 & 39,27396 & 89 & 15,20491 & 101 & 0,999242 & 0,98 & 0,992477 & 8,765688 \\
\hline 21 & 11 & 41 & 5 & 25 & 38 & 21,44774 & 39,79734 & 89,00126 & 15 & 100,9959 & 0,995931 & 0,986551 & 0,99 & 8,789912 \\
\hline 19 & 9 & 42 & 6 & 26 & 38 & 21,83936 & 40 & 89 & 15 & 101 & 0,997958 & 0,985628 & 0,993341 & 8,925921 \\
\hline 21 & 10 & 42 & 5 & 26 & 38 & 21,79117 & 40 & 89 & 15 & 101 & 0,995309 & 0,986683 & 0,992139 & 8,963626 \\
\hline 21 & 11 & 41 & 5 & 25 & 37 & 21,8465 & 40 & 89 & 15 & 101 & 0,995147 & 0,985499 & 0,992798 & 8,966806 \\
\hline 20 & 11 & 42 & 7 & 24 & 37 & 21,71842 & 40 & 89 & 15 & 101 & 0,999116 & 0,986218 & 0,996216 & 8,986677 \\
\hline 20 & 11 & 43 & 5 & 24 & 36 & 22,10609 & 40 & 89 & 15,42959 & 101 & 0,994644 & 0,988043 & 0,996853 & 9,169502 \\
\hline 19 & 11 & 41 & 5 & 25 & 36 & 15 & 40 & 90,99919 & 15 & 99 & 0,999817 & 0,979904 & 0,990846 & 930682,3 \\
\hline 19 & 11 & 41 & 6 & 25 & 37 & 15,83081 & 31,45907 & 89,31205 & 17,32314 & 100,5712 & 0,999901 & 0,976774 & 0,990266 & 72634549 \\
\hline 20 & 11 & 41 & 6 & 26 & 38 & 18,09418 & 38,9341 & 89,05662 & 17,342 & 100,9427 & 0,996142 & 0,984425 & 0,988559 & 93551533 \\
\hline
\end{tabular}

